\title{
DISCLAIMER
}

This report was prepared as an account of work sponsored by an agency of the United States Government. Neither the United States Government nor any agency thereof, nor any of their employees, makes any warranty, express or implied, or assumes any legal liability or responsibility for the accuracy, completeness, or usefulness of any information, apparatus, product, or process disclosed, or represents that its use would not infringe privately owned rights. Reference herein to any specific commercial product, process, or service by trade name, trademark, manufacturer, or otherwise does not necessarily constitute or imply its endorsement, recommendation, or favoring by the United States Government or any agency thereof. The views and opinions of authors expressed herein do not necessarily state or reflect those of the United States Government or any agency thereof.

\section{THULIUM-170 OXIDE HEAT SOURCE EXPERIMENTAL AND ANALYTICAL RADIATION AND SHIELDING STUDY}

Prepared By

A. Tse and C.A. Nelson

Prepared For

\section{DIVISION OF ISOTOPES DEVELOPMENT}

U.S. ATOMIC ENERGY COMMISSION

CONTRACT NUMBER: AT-(40-1)-3693

MAY 1970

By

SANDERS NUCLEAR CORPORATION

Nashua, New Hampshire
SNC-3693-4

RADIOISOTOPE AND RADIATION

APPLICATIONS

TID 4500 (55TH ED.)

UC-23
SNC- $-3693-4$

DE87 008096 


\section{DISCLAIMER}

This report was prepared as an account of work sponsored by an agency of the United States Government. Neither the United States Government nor any agency Thereof, nor any of their employees, makes any warranty, express or implied, or assumes any legal liability or responsibility for the accuracy, completeness, or usefulness of any information, apparatus, product, or process disclosed, or represents that its use would not infringe privately owned rights. Reference herein to any specific commercial product, process, or service by trade name, trademark, manufacturer, or otherwise does not necessarily constitute or imply its endorsement, recommendation, or favoring by the United States Government or any agency thereof. The views and opinions of authors expressed herein do not necessarily state or reflect those of the United States Government or any agency thereof. 


\section{DISCLAIMER}

Portions of this document may be illegible in electronic image products. Images are produced from the best available original document. 
TABLE OF CONTENTS

\author{
Abstract \\ Section 1 \\ Introduction
}

Section 2

Summary

Section 3

Comparison of Experimental and Analytical Dose Rates

\section{Paragraph}

3.1

3.2

3.3

3.4

3.5

Radiation Characteristics of $\mathrm{Tm}-170$

Page

$3-1$

$3-3$

$3-4$

Experimental

$3-6$

Comparison of Results

$3-12$

\author{
Section 4 \\ References \\ Appendix A \\ Experimental Data
}

Appendix $B$

Experimental Apparatus, Procedures and Results

B. 1

Description and Calibration of Thulium Oxide Source $B-2$

B . 2

Experimental Apparatus

$\mathrm{B}-5$ 
TABLE OF CONTENTS (Cont)

Paragraph

B. 3

B. 3.1

B. 3.2

B. 3.3

B. 3.4

B. 3.5

B. 4

B. 4.1

B . 4.2

B. 5

B. 6

B. 6.1

B. 6.2

B. $6 \cdot 3$
Page

Thermoluminescent Dosimetry (TLD) System B-9

Thermoluminescent Phosphor B-9

$\begin{array}{ll}\text { TLD Readout System } & B-9\end{array}$

TLD Readout Instrument Calibration B-15

$\begin{array}{ll}\text { TLD Phosphor Calibration } & B-17\end{array}$

$\begin{array}{ll}\text { TLD Powder Dispenser Calibration } & B-17\end{array}$

$\begin{array}{ll}\text { Experimental Procedures } & B-21\end{array}$

Procedures Prior to Measurements B-23

Dose Rate Measurement Procedures B-23

Experimental Data Reduction B-26

Supplementary Measurements $B-28$

Half-Life Determination

$\mathrm{B}-28$

Ratio of Dose at $19 \mathrm{~cm}$ to $100 \mathrm{~cm}$ Separation

Distance

$B-28$

$B-31$

Dose Rate from Depleted Uranium Absorber

\section{Appendix C}

Analytical Techniques, Procedures and Results

C. 1

C. 1.1

C. 1.2

C. 1.3

C. 1.4

C. 2

C. 3

C. 3.1

C. 3.2

C. $3 \cdot 3$

C. 4

C. 5

C. 6

C. 7
$\mathrm{C}-2$

$\mathrm{C}-2$

Dose Rates and Gamma Fluxes

$\mathrm{C}-2$

Exact Equation for Computing Uncollided Flux

Approximate Equation for Computing Uncollided Flux C-6
Justification for Use of the Approximate Equation C-8

Computer Code Development

$\mathrm{C}-10$

Main Program Input Data

$\mathrm{C}-11$

Volumetric Source Strength

$\mathrm{C}-11$

Photon spectrum

$\mathrm{C}-11$

Linear Absorption Coefficients

C -11

Uncollided Dose Rates

$\mathrm{C}-17$

Build-up Factor Consideration

$\mathrm{C}-21$

Tota1 Dose Rates

C -26

Radiation Scattering from the Experimental

Environment 


\section{TABLE OF CONTENTS (Cont)}

Paragraph
C. 7.1
C. 7.2
C. 7.3
C. 7.4

Single and Multiple Scatter by Shielding

Page

Material

$\mathrm{C}-31$

Double Scatter by the Absorber

$\mathrm{C}-31$

Single Backscatter

$\mathrm{C}-32$

Double Scatter

$\mathrm{C}-35$ 


\section{LIST OF ILLUSTRATIONS}

Figure

Page

$3-1$

Decay Scheme of $\mathrm{Tm}-170$

$3-2$

$3-2$

Comparison of Computed and Experimental

Dose Rate Data for Thulium-170 using

Aluminum Absorbers

$3-3$

Comparison of Computed and Experimental

Dose Rate Data for Thulium-170 using

Stainless steel Absorbers

$3-4$

Comparison of Computed and Experimental

Dose Rate Data for Thulium-170 using

Lead Absorbers

$3-5$

Comparison of Computed and Experimental

Dose Rate Data for Thulium-170 using

Tungsten Absorbers

$3-6$

Comparison of Computed and Experimental

Dose Rate Data for Thulium-170 using

Uranium Absorbers

3-11

B-1

Representative Thulium Source and Capsule

B -3

B -2

Dose Rate Measurement Fixture

B -6

B-3

Source Shie1d Cask

B-6

B-4

Top View of a Partially Assembled Source

Shield Cask

B-6

B -5

Thermoluminescent Dosimetry (TLD) Reader

B -6

B-6

Experimental Apparatus

B -7

B-7

Dose Rate Measurements Schematic Arrangement

B- 8

$B-8$

Source Shield Enclosure Arrangement

B -10

B -9

Dosimeter Mounting Arrangement

B-11

B -10

Response of Con-Rad Lithium Fluoride TLD Dosimeters

to Radiation Energy

B -12 


\section{LIST OF ILLUSTRATIONS (Cont)}

Figure

$\mathrm{B}-11$

B- 12

B -13

$B-14$

$\mathrm{C}-1$

$\mathrm{C}-2$

$\mathrm{C}-3$

$c-4$

C -5

$\mathrm{C}-6$

C-7

$\mathrm{C}-8$

$\mathrm{C}-9$

$\mathrm{C}-10$

C -11

$\mathrm{C}-12$
Block Diagram of Readout Instrument

Page

Phosphor Dispenser Vibrator

Decay Rate for Tm-170 Sources

Experimental Ratio (D) $100 \mathrm{~cm}^{/(D)} 19 \mathrm{~cm}$

Spatial Relationships Between Source, Shield

and Dose Point

$\mathrm{C}-4$

Attenuation Distances for Self-Absorption and

Shielding Materials

$\mathrm{C}-4$

Geometry for a Truncated Right-Circular Cone

Source

$\mathrm{C}-7$

Simulation of a Cylindrical Source by a Truncated Right-Circular Cone Source

$\mathrm{C}-7$

Spatial Dimensions for the Source and Dose Point

Geometry

$\mathrm{C}-9$

Determination of Half-Value Thickness

$\mathrm{C}-20$

Dose Build-up Factor - Pb (Point Isotropic Source)

$\mathrm{C}-24$

Dose Build-up Factor - Al (Point Isotropic Source)

$\mathrm{C}-25$

Radiation Scattering from Experimental Set-up

$\mathrm{C}-32$

Radiation Scattering from Hot Cell Wall

$\mathrm{C}-33$

Spatial Dimensions Between Source and Hot Cell

Wa11

C -35

Double Scattering from Source and Hot Cell 


\section{LIST OF TABLES}

Table

Page

$3-1$

Radiation Characteristics of $\mathrm{Tm}-170$

$3-2$

$A-1$

Data Summary for Aluminum Absorbers

A-2

$A-2$

Data Summary for Stainless Steel Absorbers

A -3

A-3

Data Summary for Lead Absorbers

A-4

A-4

Data Summary for Tungsten Absorbers

$A-5$

A- 5

Data Summary for Depleted Uranium Absorbers

A-6

$B-1$

Thermal and Radiation Strengths of Thulium-170

$0 x i d e$

$\mathrm{B}-2$

$\mathrm{B}-2$

Physical Characteristics of Thulium-170 Oxide

Wafers

$\mathrm{B}-4$

Dimensions of Thulium-170 Oxide Sources (Inches)

B -4

$\mathrm{B}-3$

Measurement Precision of LiF Phosphor

$\mathrm{B}-13$

Reproducibility of TLD Phosphor Dispenser

Vibrator

B- 20

B-6

Dose Rate Measurement Matrix

B-22

B -7

Statistical Analyses of Measured Dose Rates

$B-27$

$\mathrm{B}-8$

Unshielded Dose Rates

B- 29

$\mathrm{B}-9$

Experimental Ratio

(D) $100 \mathrm{~cm}^{/(\text {(D) }} 19 \mathrm{~cm}$

B-32

B -10

Dose Rates for Depleted Uranium Absorbers

B-35

$\mathrm{C}-1$

Gamma Spectrum of $\mathrm{Tm}_{2} \mathrm{O}_{3}$ Source

$\mathrm{C}-3$

$\mathrm{C}-2$

Gamma Spectrum and Linear Absorption Coefficients

$\mathrm{C}-14$

$\mathrm{C}-3$

Linear Absorption Coefficients for Shielding

Materials

$\mathrm{C}-16$

$\mathrm{C}-4$

Typical Uncollided Dose Rates From Computer

Calculations

C -18

$\mathrm{C}-5$

Half-Value-Thickness Studies

$\mathrm{C}-19$

C-6

Dose Build-up Factor for Lead

$c-22$ 


\section{LIST OF TABLES (Cont)}

$\underline{\mathrm{Table}}$

$$
\mathrm{C}-7
$$

$\mathrm{C}-8$

C -9

C -10
Dose Build-up Factors

Calculation of Total Dose Rate at $19 \mathrm{~cm}$ for 20.7-Watt Source With $\mathrm{Pb}$ Shields of $\frac{1}{4}, \frac{1}{2}$ and

1 Inch Thicknesses

Calculated Dose Rates at $19 \mathrm{~cm}$ (Rad/hr)

$\mathrm{C}-29$

Calculated Dose Rates at $100 \mathrm{~cm}(\mathrm{Rad} / \mathrm{hr})$ 
Radiation dose rates from three thulium-170 oxide sources (20.7, 10.0 and 5.0 thermal watts) were measured through three thicknesses ( $\frac{1}{4}, \frac{1}{2}$ and 1 inch) of absorber by thermoluminescent dosimetry techniques. Absorber materials used were aluminum, stainless steel, lead, tungsten and depleted uranium. Resultant radiation doses were measured at two source - to - dose point separation distances - (19 cm and $100 \mathrm{~cm})$. Comparison of theoretical dose rates calculated by computer with measured dose rates validated the calculation technique for lead, tungsten and uranium absorbers but not for aluminum and stainless steel.

Use of infinite medium build-up factors ( $B_{\infty}$ ) was thus validated in computation of dose rates for lead, tungsten and uranium absorbers; use of $B_{\infty}$ in computation of dose rates for aluminum and stainless steel absorbers overestimated dose rates vis-a-vis experimentally determined dose rates by an approximate factor of 2 . 
Thulium-170 in the sesquioxide form is a potential isotopic heat source for thermoelectric and thermionic applications. The overall objective of this program is to establish the feasibility of application of the oxide as a heat source by assessing and analyzing the properties of the oxide; several of these properties have already been discussed in previous reports $(1,2)$. The discussion herein relates to the application of several types of shielding materials to a representative pressed, sintered and activated $\mathrm{Tm}_{2} \mathrm{O}_{3}$ source, and the development of techniques and methods of analysis that will allow calculated dose rates to predict reliably those dose rates to be experienced experimentally.

The radioactive sources were in the form of $\mathrm{Tm}_{2} \mathrm{O}_{3}$ wafers of sufficient activity to obtain dose rates through the absorbers that would yield reliable data. Three source strengths were supplied - 20.7, 10.0 and 5.0 watts (thermal), respectively.

Five absorber materials selected were aluminum, stainless steel, lead, tungsten and depleted uranium; absorbers with thickness of $\frac{1}{4}, \frac{1}{2}$ and 1 inch were used to determine the dose rates at two source-to-dose point distances; 19 and $100 \mathrm{~cm}$.

Computer programs were developed to generate the theoretical dose rate. The 19 centimeter source-to-dose point distance was selected as a theoretical dose point as it closely conformed to the finite boundary established by the absorber. A build-up factor for infinite medium $\left(B_{\infty}\right)$ was used throughout the calculations 
to determine the scattered flux component. A more rigorous treatment of the build-up factor is necessarily highly complex and was beyond the scope of this work.

Doses were measured using lithium fluoride powder as a phosphor and subsequent1y reading the absorbed dose with a thermoluminescent phosphor readout system.

A comparison of experimental results with theoretical values is presented in section 3 .

All of the experimental data, development of mathematical relationships, calculation procedures including discussion where appropriate, and error analyses are found in the Appendices. 


\section{SECTION 2}

\section{SUMMARY}

Dose rates from 5,10 and 20.7 -watt $\operatorname{Tm}_{2} \mathrm{O}_{3}$ sources at two different source-to-dose point distances (19 and $100 \mathrm{~cm}$ ) were experimentally determined using thermoluminescent dosimetry techniques. Five different absorber materials (aluminum, stainless steel, lead, tungsten and depleted uranium) of three different thickness ( $\frac{1}{4}, \frac{1}{2}$ and 1 inch) were used. The overall uncertainty (experimental error) in the measured dose rate was $\pm 9 \%$.

A computer code (FORTRAN) was developed to generate theoretical dose rates for the uncollided flux; a buildup factor for infinite medium was used to obtain the total flux.

$$
\text { Predicted-to-measured dose rate ratios of } 0.58 \text { to } 1.85
$$
characterized results for the three most dense absorbers; ratios of 0.84 to 3.0 characterized aluminum and stainless steel. Deviations of these ratios from 1 are primarily attributable to the assumption of an infinite medium for the buildup factor in generating the theoretical dose rates. Departure of dose rates at $100 \mathrm{~cm}$ from the inverse square $1 \mathrm{aw}$ is also attributable to the build-up factor used in the analytical predictions.

The applicability to kilowatt sources of the dose rate computational method used in this study was analyzed. It was concluded that an infinite medium build-up factor should be used and a 22 energy group computation made; dose rates accurate to 10 to $20 \%$ will result. Of equal importance to system design, required shield thicknesses ( $P b, W$ or $U$ ) will be overestimated by only 2 to $3 \%$. 
SECTION 3

COMPARISON OF EXPERIMENTAL AND ANALYTICAL DOSE RATES

\subsection{RADIATION CHARACTERISTICS OF Tm-170}

The radiation characteristics of $\mathrm{Tm}-170$ have been measured and reported in the literature. The most current data are to be found in the Table of Isotopes ${ }^{(6)}$ and the NBS Nuclear Data sheets The decay scheme of $\mathrm{Tm}-170$ is presented in Figure 3-1. Table 3-1 identifies the radiations emitted by radioactive decay of Tm-170.

In addition to the beta, gamma and X-radiation, bremsstrahlung is produced as the beta particles slow down within the source medium (a more detailed discussion can be found in references 35,37 and 38 ). This bremsstrahlung radiation, combined with gama and x-rays, constitutes the entire electromagnetic radiation spectrum of the source. Bremsstrahlung production for $\mathrm{Tm}-170$ source has been calculated by Arnold (8). The number of bremsstrahlung photons, within $50 \mathrm{Kev}$ energy intervals, per $0.968 \mathrm{Mev}$ and $0.884 \mathrm{Mev}$ beta particles are tabulated in Appendix C. The total bremsstrahlung production for $\mathrm{Tm}-170$ is the sum of that for each beta group weighted by the abundance of each group. All photons in each energy interval are assumed to have energy at the midpoint of that interval.

Another important radiation property is the ratio of activity in curies to power in watts. This factor for Tm-170 has recently been reported by Cornman $(9)$ as $445 \pm 22$ curies per watt. This value is used throughout this report. 
- andane nuclear

componation

$0.968 \mathrm{Mev} \beta$

$(78 \%)$

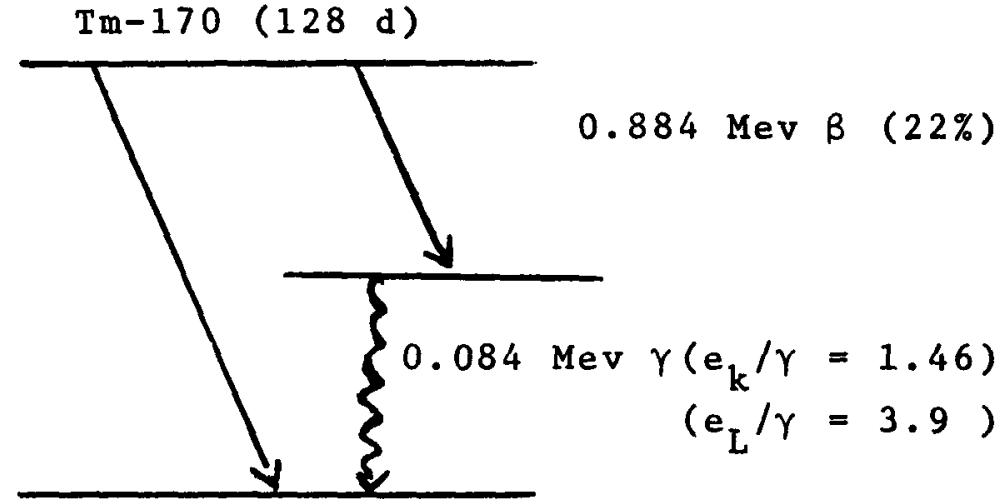

$Y b-170$ (stable)

TABLE $3-1$

RADIATION CHARACTERISTICS OF Tm-170

Radiation

Emitted

Beta

Beta

Gamma

$x-r a y$

$x-$ ray
Energy

(Mev)

0.968

0.884

0.084

0.052

0.009
Abundance

(\%)

78

22

3.46

5.05

13.49 


\subsection{CALCULATED DOSE RATES}

Equations for the uncollided flux were developed for $\mathrm{Tm}_{2} \mathrm{O}_{3}$ sources that allowed an approximate solution to be used rather than a more complex exact solution. Analysis indicates that the deviation from the true flux using this approximate solution is negligible.

A computer code was developed using the equations of the approximate solution. $19 \mathrm{~cm}$ was selected for the calculated sourceto-dose point distance. FORTRAN was used to develop the code and a total of 22 photon energy groups were used to calculate the doses. The main program input data are given in the appendices.

Several factors were considered for inclusion in the computation:

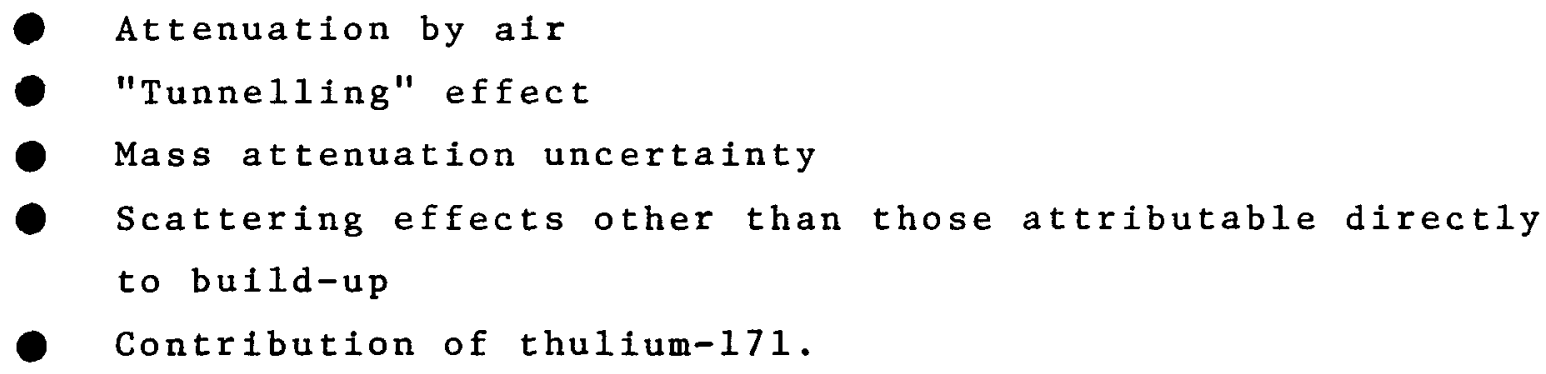

The attenuation by air is very small compared to that of the encapsulation material and could be excluded from the computation. The "tunnelling effect" was also evaluated for this computation and found to be insignificant. The uncertainty for mass attenuation coefficients is taken as $5 \%$ (see appendices).

Other scattering effects are possible and are discussed in Appendix C, paragraph C.7. For these calculations, analysis shows the scattering to be either insignificant or to have been eliminated by the experimental design.

The contribution of thulium-171 to the dose rate is negligible because of the small percentage of the total activity that it represents and its low energy radiation compared to that of thulium-170. From mass analysis measurements made on $10 \mathrm{Ju} 1 \mathrm{y} 1968$, the isotope distribution for $\mathrm{Tm}-170$ and $\mathrm{Tm}-171$ were 17.7 and $5.5 \%$, 
respectively. However, the activity of $\mathrm{Tm}-171$ was only $5.7 \%$ that of the Tm-170 activity because Tm-171 has much longer half-11fe ( 1.9 years), compared to that of $\mathrm{Tm}-170$ (128 days). The maximum beta energy of $\mathrm{Tm}-171$ ( $0.1 \mathrm{Mev}$ ) is considerably lower than that of Tm-170 ( $0.9 \mathrm{Mev);} \mathrm{therefore,} \mathrm{the} \mathrm{attenuation} \mathrm{through} \mathrm{the} \mathrm{encap-}$ sulation material and absorbers will virtually eliminate any contribution to the dose rate due to Tm-171 atoms. For these reasons, the radiation from thulium-171 was not considered to be contributory to the dose rate and was excluded in the analytical dose rate computations.

Verification of the computer results was accomplished by comparing theoretical half-value thicknesses $(0.693 / \mu)$ with those generated by the computer program (HVT). (See Appendix C, paragraph C.4).

The total dose is obtained by adjusting the uncollided flux for the scatter component, the build-up factor. In these calculations we have assumed a build-up factor for an infinite homogeneous medium because the analyses of Compton scattering for a finite medium is very complex and beyond the scope of this program.

This assumption is reasonably sound for lead, tungsten and uranium, but would be expected to introduce a larger error for aluminum and stainless steel (See Appendix C, paragraph C.5).

To extend the uncollided dose rates to $100 \mathrm{~cm}$, the second dose to source point, the dose rates for $19 \mathrm{~cm}$ were used. Using the $1 / \mathrm{r}^{2}$ relationship, each dose at $19 \mathrm{~cm}$ was multiplied by $\frac{(19)^{2}}{(100)^{2}}=3.61 \times 10^{-2}$ and the corresponding dose at $100 \mathrm{~cm}$ determined.

The calculated dose rates are presented in Appendix A.

\subsection{EXPERIMENTAL}

A detailed description of the experimental apparatus and experiments is presented in Appendix $B$ and the results in Appendix A. Tables A-1 through A-5 present the ratio of calculated to measured dose 
rates for the various source strengths, absorber materials, etc.

Five separate TLD dosimeters were used to absorb the integrated dose in each experimental exposure (11). Subsequently, each of the dosimeter LiF powder charges was loaded onto three heating elements so that a total of 15 readings of integrated dose was obtained. These data were then averaged and statistically analyzed. A sample case is given in Appendix B, paragraph B.5 to show how the measured data is averaged and analyzed.

After average measured doses and probable errors were obtained, the background doses were subtracted. The net dose rates (rad/hr) were then determined by dividing the net doses (rad) by the exposure time in hours. These values are the net dose rates at the time of measurement. Correction for decay must be made to obtain the dose rate at initial activity. All dose rates were normalized to August 2, 1968 (date of assay by calorimetric techniques) by the following equation:

$$
\mathrm{D}=\mathrm{D}_{\mathrm{m}} / \mathrm{e}^{-\lambda t}
$$

where $D=$ normalized dose rate (August 2, 1968)

$$
\begin{aligned}
D_{m}= & \text { dose rate at the time of measurement } \\
t= & \text { number of days between August } 2,1968 \text { and the time } \\
& \text { of measurement } \\
\lambda= & \text { decay constant }=0.693 / \mathrm{T}_{\frac{1}{2}} \\
\mathrm{~T}_{\frac{1}{2}}= & \text { half-1ife of } 170_{\mathrm{Tm}}=128 \text { days }
\end{aligned}
$$

A decay curve was plotted ( $e^{-\lambda t}$ vs. $t$ ) and the decay correction factors were obtained from the curve. The normalized dose rates were then determined by dividing the net dose rates at the time of measurement by this decay correction factor.

For the uranium absorber, another correction is required because uranium is itself radioactive. Experiments were performed (as shown in Appendix B, paragraph B.6) with three uranium absorbers to obtain 
the uranium dose rates. These results were then subtracted from the normalized dose rates.

The overall uncertainty for the measured data is approximately $\pm 9 \%$

\subsection{COMPARISON OF RESULTS}

Figures 3-2 through 3-6 show the comparison between analytical and experimental dose rates. The experimental results differ from the analytical predictions in two ways. One, the theoretical dose rates are generally greater for a given source-to-dose point distance than the actual dose rates and two, the measured dose rates at $100 \mathrm{~cm}$ are not those expected if the inverse square law were operating.

In the first case, the differences are generally outside the experimental error $( \pm 9 \%)$ and are largely due to the use of $B_{\infty}$ in the analytical predictions. The error results, because the uncertainty in the calculated values is very high and for the following reasons:

- A build-up factor for an infinite medium has been assumed.

- No data were available to assess $B_{\infty}$ for energies less than $0.5 \mathrm{Mev}$.

- No data are available for a $\mu t<1$.

Although the last source of error might be small, the curves of Figures $c-7$ and $C-8$ clearly show the difficulty in extrapolating from the 0.5 Mev point back to zero and the resulting large uncertainty that exists, especially for an energy grouping that would be the most contributory. This uncertainty is also clearly greater for aluminum and stainless steel than for the high $Z$ materials.

Further, the assumption of a build-up factor for an infinite medium will overestimate the dose rate to an extent that depends on the photon energy, absorbing medium and the geometry. As discussed in in Appendix C, paragraph C.5, the dose rates for aluminum and stainless steel might be overestimated by as much as $50 \%$ whereas that of the heavy materials only 10 to $20 \%$.

The second difference is the departure from the inverse square law. Tha doses from an unshielded source followed well the $1 / \mathrm{r}^{2} \mathrm{re}-$ 


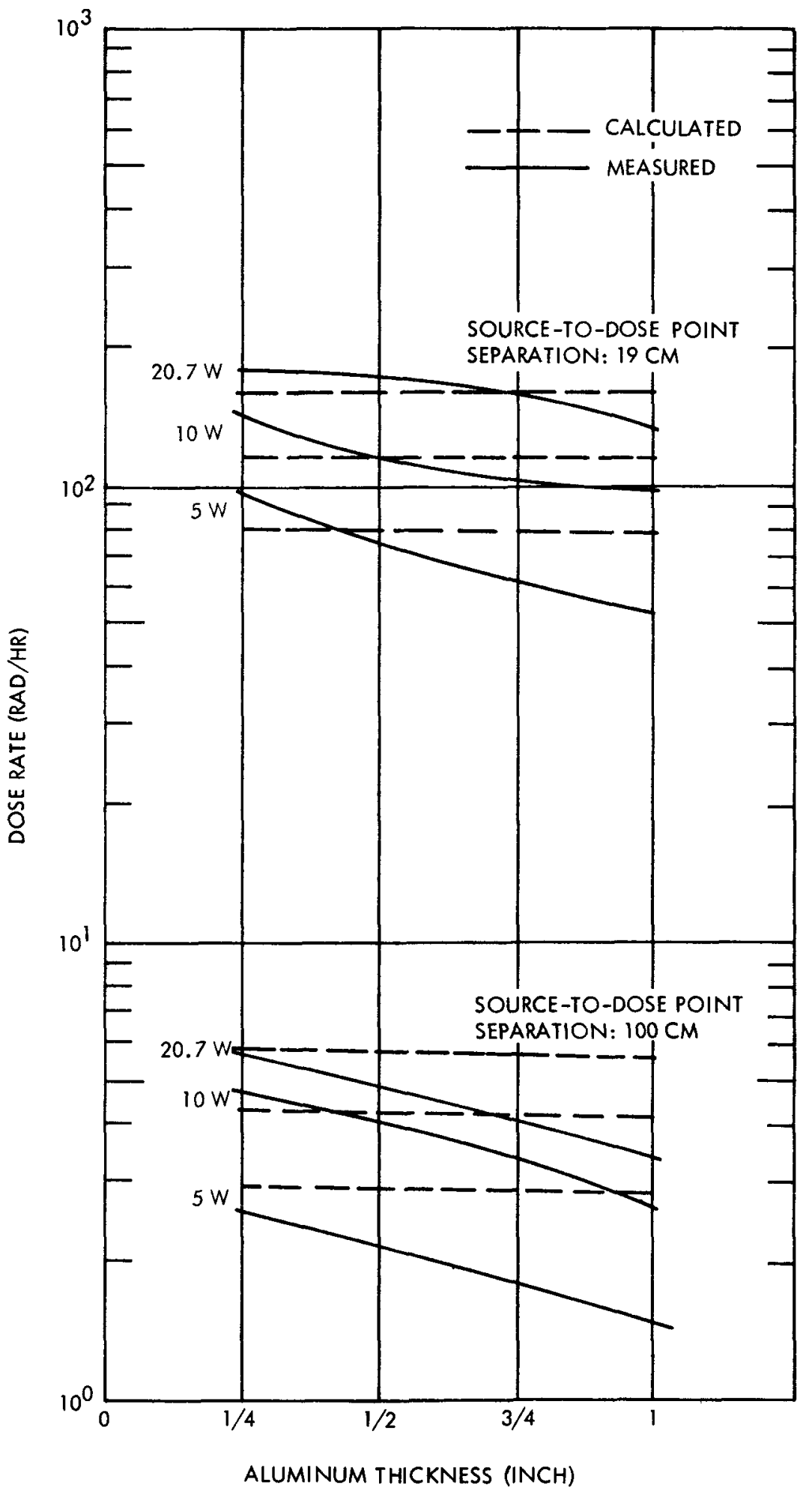

Figure 3-2. Comparison of Computed and Experimental Dose Rate Data for Thulium -170 using Aluminum Absorbers 


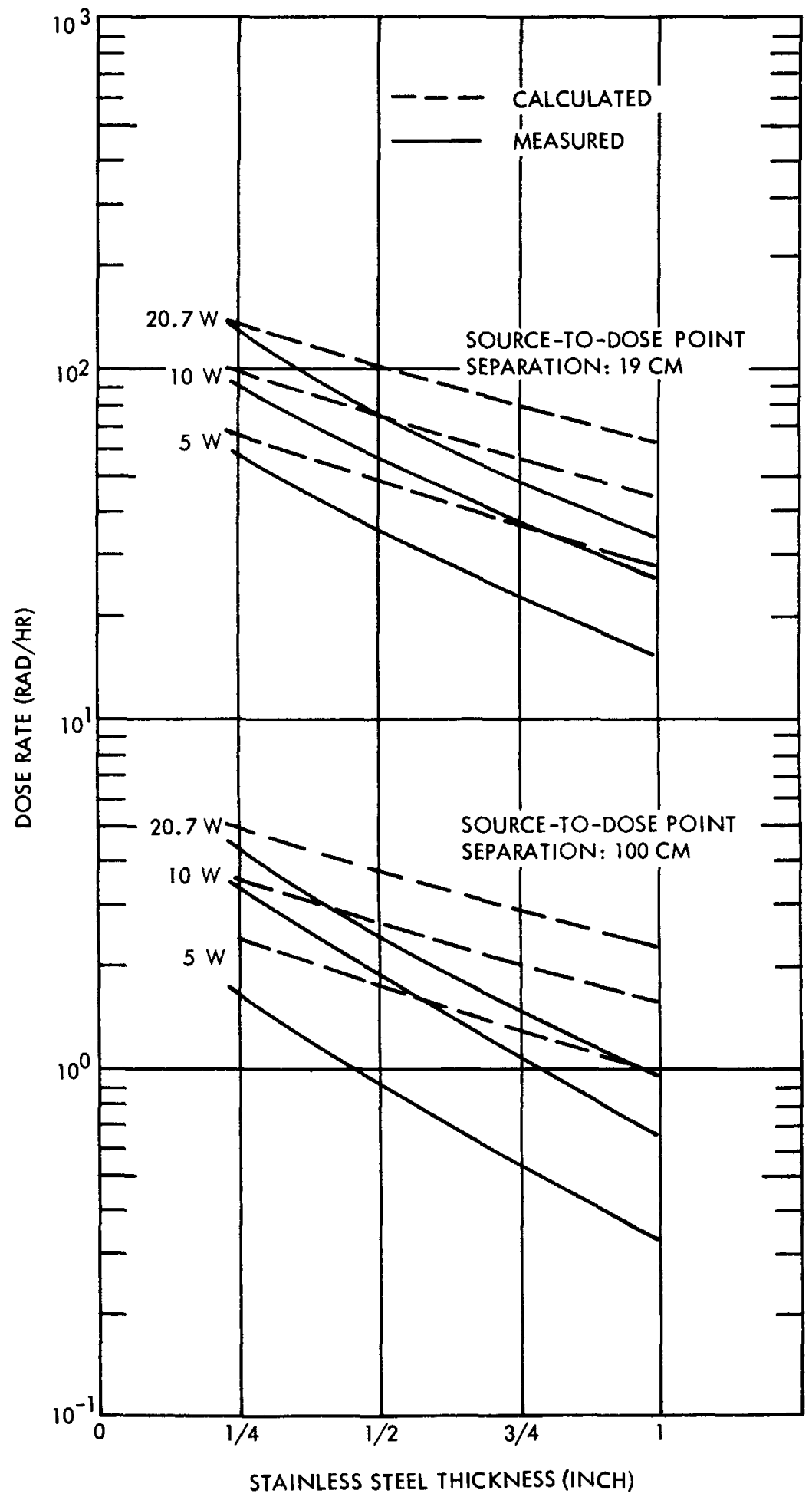

Figure 3-3. Comparison of Computed and Experimental Dose Rate Data for Thulium-170 using stainless Steel Absorbers 


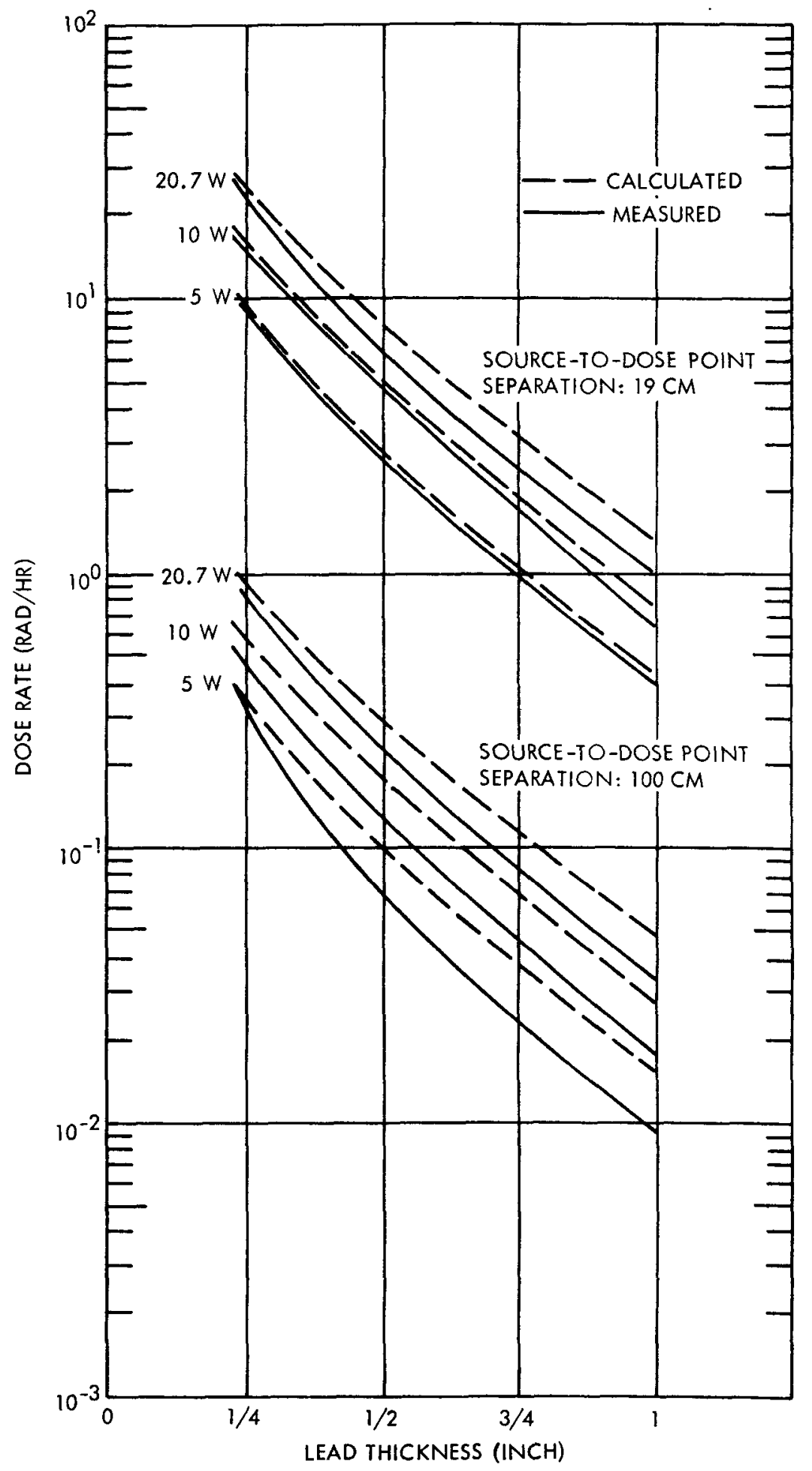

Figure 3-4. Comparison of Computed and Experimental Dose Rate Data for Thulium-170 using Lead Absorbers 


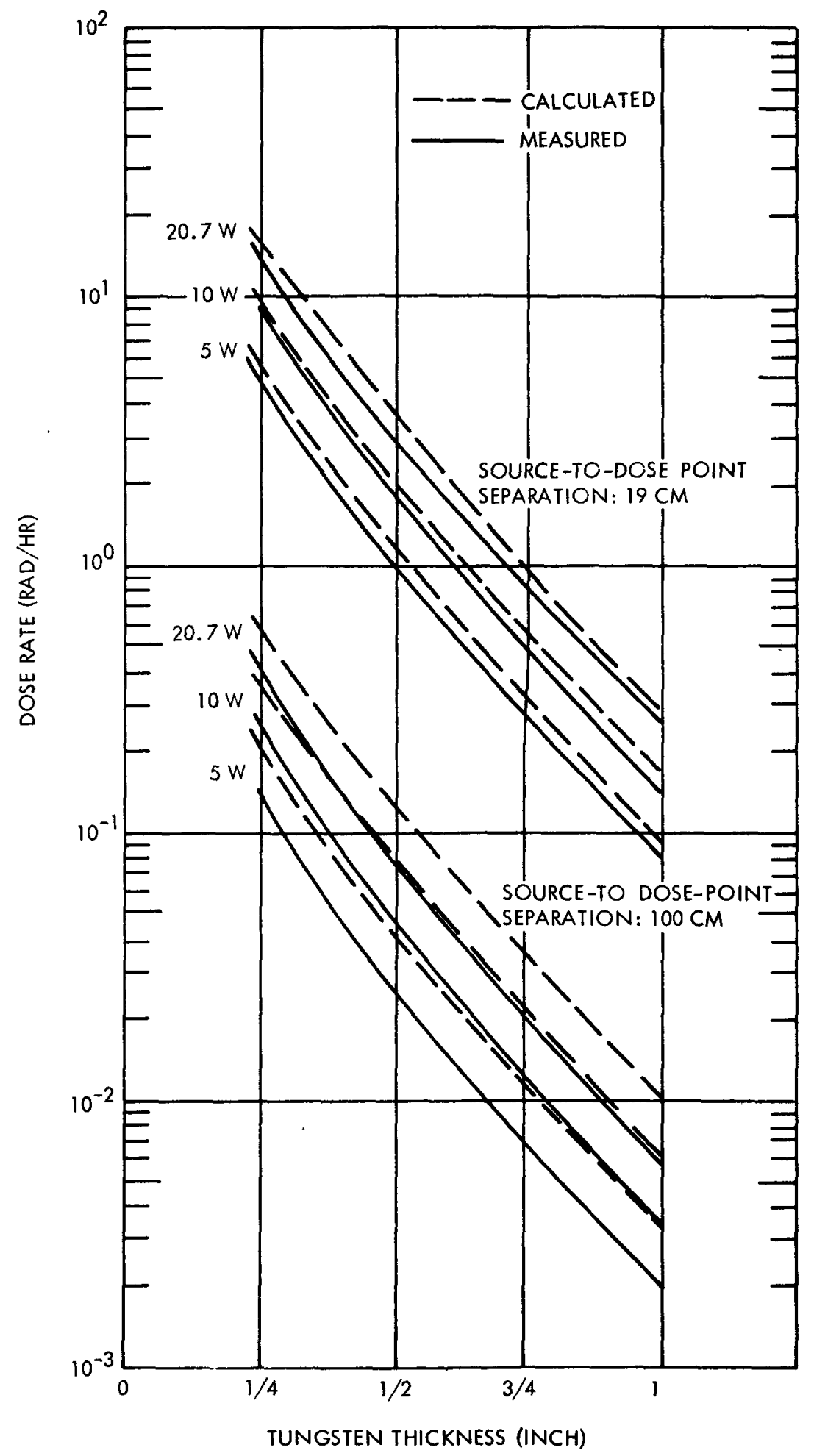

Figurt 3-5. Comparison of Computed and Experimental Dose Rate Data for Thulium-170 using Tungsten Absorbers 


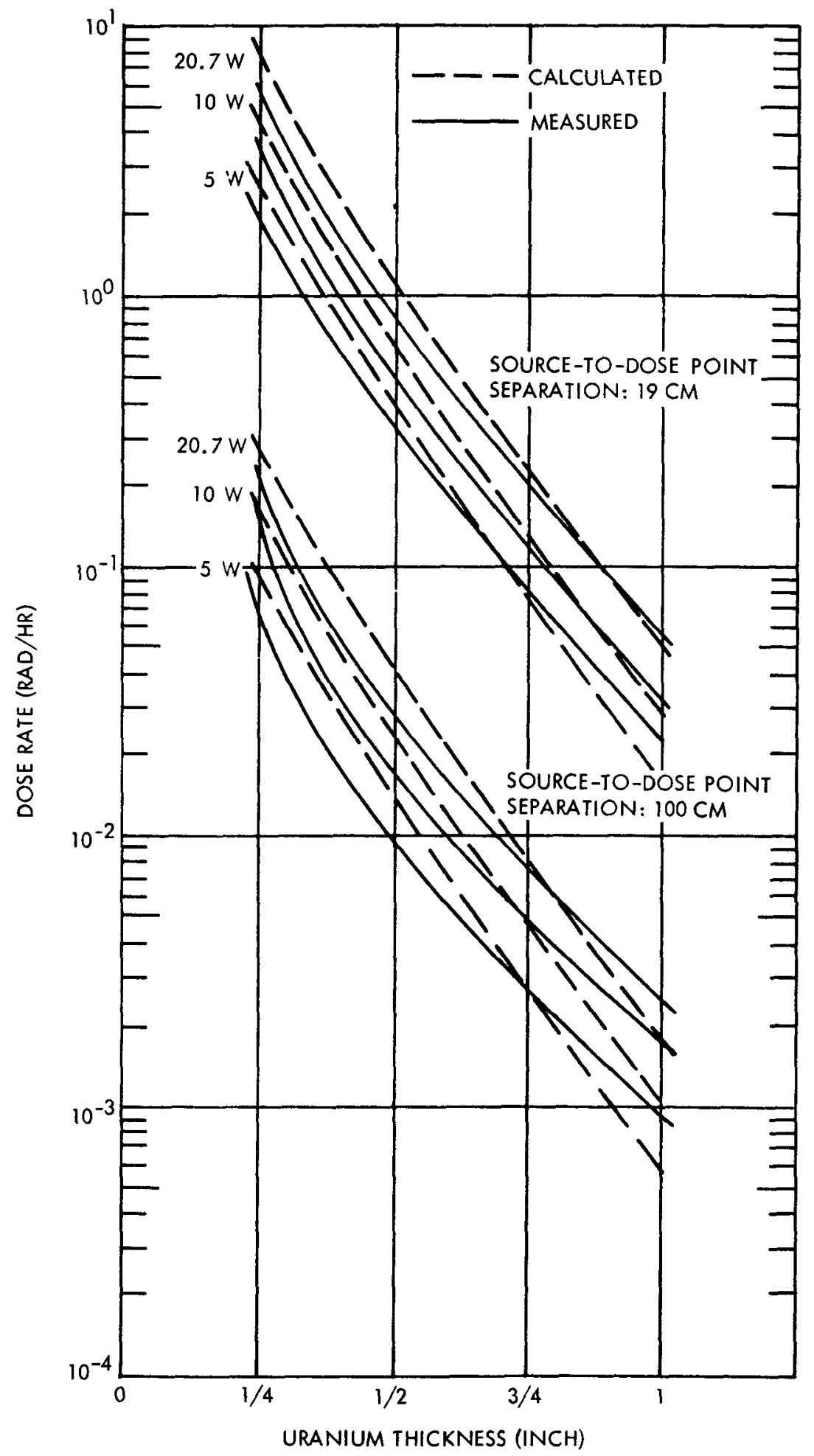

Figure 3-6. Comparison of Computed and Experimental Dose Rate Data for Thulium-170 using Uranium Absorbers 
lationship and therefore, the difference must lie with the absorber.

The reason for the deviation can be seen by again considering the scattered component of the dose rate. In the calculation of total duse rate, build-up factor for infinite medium ( $B_{\infty}$ ) has been used. This $B_{\infty}$ is obtained by assuming both the radiation source and the dose point are imbedded in an infinite homogeneous medium. For $19 \mathrm{~cm}$ geometry, the dose point is very close to the shield surface $(\sim 2$ to $3 \mathrm{~cm})$, while for $100 \mathrm{~cm}$ geometry, the separation distance between the shield surface and the dose point is approximately $80 \mathrm{~cm}$. The solid angle subtended by the detector is nearly $2 \pi$ for $19 \mathrm{~cm}$ geometry while it is much smaller for $100 \mathrm{~cm}$ geometry. Therefore, compared to the $100 \mathrm{~cm}$ geometry, the $19 \mathrm{~cm}$ geometry more closely approximates the infinite medium case. Consequently, $B_{\infty}$ is more applicable to dose point located close to the shield surface. If $B_{\infty}$ is applied to dose point far away from shield surface, it overestimates the total dose. The degree of overestimation depends on the shielding material and its thickness, or more specifically that scattering for $100 \mathrm{~cm}$ is a different case than scattering for $19 \mathrm{~cm}$. Because of the complexity of the problem, it is very difficult to evaluate analytically. Therefore, to extend the total dose rate correctly from $19 \mathrm{~cm}$ to $100 \mathrm{~cm}$, experimental ratios $\left(D_{100} / D_{19}\right)$ have to be used. These ratios are listed in Table $B-9$. (see Appendix B, paragraph B.6.2). For practical shielding design, this overestimation increases the margin of safety.

\subsection{EXTENSION TO LARGE SCALE APPLICATIONS}

The sources used in this study had a maximum power of 20 watts. In actuality, sources in the kilowatt range would be more the rule. We will extend the results then to larger thulium-170 sources and will discuss on 1 y lead, tungsten and uranium shield materials as aluminum and stainless steel only attenuate radiation in a relatively minor way.

A change in source strength only means an increase in volumetric source strength. Equations show that the dose rates are 


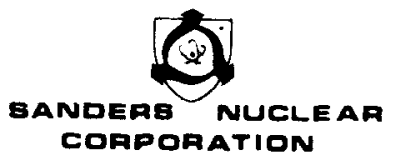

increased proportionally with the volumetric source strength. However, a change of this nature without change in source dimension and source geometry is unlikely and these changes may result in considerable difference in resultant dose rates.

Since the gamma spectrum for thulium-170 consists of mainly low energy photons, the self-absorption becomes important. Calculations must be made to re-evaluate the dose rates. The methods have been described in Appendix $C$ and the reader is cautioned against using less than 22 energy groups in the analysis as dose rates can be increased by as much as a factor of 2 if only four groups are used.

$B_{\infty}$ should be used to obtain the dose rates. This will overestimate the dose rates by 10 to $20 \%$ but will result in only a 2 to $3 \%$ overestimation in shielding thickness (based on a 1 kilowatt thulium-170 source). This conservative margin is desirable because an uncertainty of 3 to $5 \%$ is involved in the absorption coefficients.

Axial dose rates were used throughout this study. The readers are directed to the work of Arnold (8) for radial dose rate information. 


\section{SECTION 4}

\section{REFERENCES}

1. Anderson, R. W., "Compatibility Study of Containment Materials for Thulium Oxide," SNC-3693-1, Sanders Nuclear Corporation, December 1969 .

2. Nelson, C. A., R. W. Anderson and W. J. Fretague, "Phase Diagram Determination of the $\mathrm{Tm}_{2} \mathrm{O}_{3}-\mathrm{Yb}_{2} \mathrm{O}_{3}$ system," SNC-3693-2, Sanders Nuclear Corporation, May 1970.

3. Grodstein, G. W., "X-Ray Attenuation Coefficients From 10 Kev to $100 \mathrm{Mev}, "$ NBS Circular 583, National Bureau of Standards (1957).

4. Storm, E., E. Gilbert, I. Harvey, "Gamma Ray Absorption Coefficients for Elements 1 through 100," LA-2237, Los Alamos Scientific Laboratory, Los Alamos, New Mexico (1958).

5. Hubbe1, J. H. and M. J. Beyer, "Photon Attenuation and Energy Absorption Coefficients," NBS Report 8681, Nationa1 Bureau of Standards (1966).

6. Lederer, C. M., J. M. Hollander, I. Perlman, Table of Isotopes, 6th Edition, John Wiley and Sons, Inc., New York (1967).

7. "Nuclear Data Sheets," Academic Press, New York (1966).

8. Arnold, E. D., "Handbood of shielding Requirements and Radiation Characteristics of Isotopic Power Sources for Terrestrial, Marine, and Space Applications," USAEC Report ORNL-3576, Oak Ridge National Laboratory, Oak Ridge, Tennessee (1964). 
9. Cornman, W. R., "Production of Tm-170," USAEC Report DP-1052, E. I. duPont de Nemours and Co., Savannah River Laboratory, Aiken, S. C. (secret) (1967).

10. Poggenburg, J. K., private communication (1968).

11. Pinkerton, A., et al, "Direct Intercomparison of Absorbed Dose by Thermoluminescent Dosimetry," Proceedings: International Conference of Luminescence Dosimetry, Stanford University, Stanford California. (June 1965).

12. Rockwel1, T., III., Reactor Shielding Design Manual, D. Van Nostrand Co., Inc. New York (1959).

13. "Physical Aspects of Irradiation," NBS Handbook 85, National Bureau of Standards (1964).

14. Goldstein, Herbert and J. Ernest Wilkins, Jr., "Calculations of the Penetration of Gamma Rays," NDA 15C-41; Nuclear Development Associates, Inc., Whiteplains, N. Y. (June 1954).

15. Kirn, F. S., R. J. Kennedy, and H. O. Wyckoff, "Oblique Attenuation of Gamma Rays from Cobalt-60 and Cesium-137 in Polyethylene, Concrete and Lead," NBS Report 2125 (December 1952 ).

16. Price, B. T., C. C. Horton, and K. T. Spinney, Radiation Shielding, Pergamon Press, New York (1957).

17. Posey, J. C., T. A. Butler, and P. S. Baker, "Hot Cell Calorimetry for Routine Determination of Thermal Power Generated by Kilocurie Sources," 10th Hot Lab Proceedings, ANS, (November, 1962).

18. Posey, J. C., "Calorimetry for Measuring Radioactivity," Isotopes and Radiation Technology 1 (1): 92-6(Fal1 1963).

19. Bjarngard, B. E., et al, "Lithium Fluoride - Teflon Thermoluminescence Dosimeter," Proceedings: International Conference of Luminescence Dosimetry. Stanford University, Stanford, California (June, 1965). 


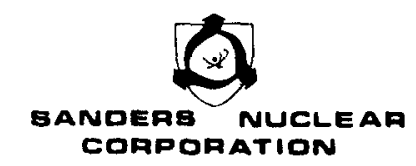

20. Bjarngard, B. and D. Jones, "The Technical Characteristics and Applications for Phosphor-Teflon Thermoluminescent Dosimeter," Paper presented at NATO Summer School on Dosimetry, Brussels, Belgium, (September, 1967).

21. Attix, F. H., ed., "Luminescence Dosimetry," United States Atomic Energy Commission Conference Report No. CONF-650637, Proceedings International Conference of Luminescence Dosimetry, Stanford, California (1965).

22. Friedlander, G., J. W. Kennedy, and J. M. Miller, Nuclear and Radiochemistry, 2nd Edition, John Wiley and Sons, Inc., New York (1967).

23. Gardner, R. P. and R. L. Ely, Jr., Radioisotope Measurement Applications in Engineering, Reinhold Publishing Co., New York (1967).

24. Vo1k, W., App1ied Statistics for Engineers, McGraw-Hill Book Co., New York (1958).

25. Price, W. J., Nuclear Radiation Detection, McGraw-Hill Book Co., New York (1964).

26. Arkin, H., and R. R. Colton, Table for statisticians, Barnes and Noble Co., New York (1950).

27. Hodgman, C. D. (ed), Standard Mathematical Tables, $12 t h$ Edition, Chemical Rubber Publishing Co., Cleveland, Ohio (1959).

28. IBM System/360 Scientific Subroutine Package.

29. Handbook of Mathematical Functions, NBS Applied Mathematics Series 55, National Bureau of Standards (1964).

30. Metals Handbook, Volume 1, 8 th edition, American Society for Meta1s (1961).

31. Allen, S. J., Phys. Rev., 28907 (1926).

32. Victoreen, J. J.,App1. Phys. 20, 1141 (1949). 
33. Spencer, L. V., and V. Fano, Phys. Rev. 81, 464 (1951).

34. Spencer, L. V., and V. Fano, Research NBS 46, 446 (1951).

35. Fitzgerald, J. J., G. L. Brownell, and F. J. Mahoney, Mathematical Theory of Radiation Dosimetry, Gordon and Breach, New York (1967).

36. Nelson, C. A., R. W. Anderson, M. Talbot and W. Bierds, "Thulium Oxide Fuel Characterization Study, Part III - Procedures," USAEC Report, SNC-3693-5, Sanders Nuclear Corporation, Nashua, N.H. (1970).

37. Evans, R. D., The Atomic Nucleus, McGraw-Hill Book Co., Inc., New York (1955).

38. Kaplan, I., Nuclear Physics, Addison-Wesley Publishing Co., Inc., Reading, Massachusetts (1956). 
Q corporation

APPENDIX A

EXPERIMENTAL DATA

$A-1$ 
TABLE A-1

DATA SUMMARY FOR ALUMINUM ABSORBERS

\begin{tabular}{|c|c|c|c|c|c|c|c|c|}
\hline $\begin{array}{l}\text { Inttial } \\
\text { soncee } \\
\text { strength } \\
\text { (rette) } \\
\end{array}$ & $\begin{array}{c}\text { Absorber } \\
\text { Thickness } \\
\text { (1nches) }\end{array}$ & $\begin{array}{l}\text { Exposure } \\
\text { T1me } \\
\text { (hours) }\end{array}$ & $\begin{array}{c}\text { Menaured } \\
\text { Dose } \\
\text { (rads) }\end{array}$ & $\begin{array}{c}\text { Net } \\
\text { Dose } \\
\text { (rads) }\end{array}$ & $\begin{array}{c}\text { Net Dose } \\
\text { Rate } \\
(r a d s / h r) \\
\end{array}$ & $\begin{array}{c}\text { Measured" } \\
\text { Dose Rate } \\
\text { (rade/hr) } \\
\end{array}$ & $\begin{array}{l}\text { Calculated } \\
\text { Doae Rate } \\
\text { (rade/hr) }\end{array}$ & $\begin{array}{l}\text { Matio } \\
\text { Calculated } \\
\text { to Measured }\end{array}$ \\
\hline $\begin{array}{l}1.19 \mathrm{~cm} \\
20.7\end{array}$ & $\begin{array}{l}\frac{1}{4} \\
\frac{1}{2} \\
1\end{array}$ & $\begin{array}{l}0.25 \\
0.25 \\
0.25 \\
\end{array}$ & $\begin{array}{l}21.7 \pm .3 \\
20.9 \pm .2 \\
16.2 \pm .2\end{array}$ & $\begin{array}{l}21.7 \\
20.9 \\
16.2\end{array}$ & $\begin{array}{l}86.8 \\
83.6 \\
64.7\end{array}$ & 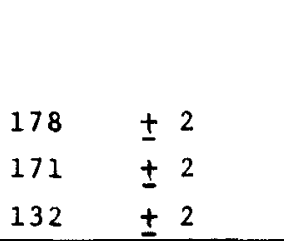 & $\begin{array}{l}161 \\
160 \\
156\end{array}$ & $\begin{array}{l}0.90 \\
0.94 \\
1.18\end{array}$ \\
\hline 5 & $\begin{array}{l}\frac{3}{4} \\
\frac{1}{2} \\
1\end{array}$ & $\begin{array}{l}0.25 \\
0.25 \\
0.25\end{array}$ & $\begin{aligned} 11.7 & \pm .1 \\
9.10 & \pm .03 \\
6.50 & \pm .04\end{aligned}$ & $\begin{array}{l}11.7 \\
9.06 \\
6.46\end{array}$ & $\begin{array}{l}46.8 \\
36.2 \\
25.8\end{array}$ & $\begin{array}{l}94.7 \pm 1 \\
73.2 \pm .3 \\
52.2 \pm .3\end{array}$ & $\begin{array}{l}81.6 \\
81.1 \\
79.0\end{array}$ & $\begin{array}{l}0.86 \\
1.11 \\
1.51\end{array}$ \\
\hline 10 & $\begin{array}{l}\frac{1}{4} \\
\frac{1}{2} \\
1\end{array}$ & $\begin{array}{l}0.5 \\
0.5 \\
0.5\end{array}$ & $\begin{array}{l}1.22 \pm .01 \\
1.06 \pm .01 \\
.697 \pm .003\end{array}$ & $\begin{array}{l}1.19 \\
1.03 \\
.668\end{array}$ & $\begin{array}{l}2.37 \\
2.05 \\
1.34\end{array}$ & $\begin{array}{l}4.70 \pm .03 \\
4.06 \pm .01 \\
2.64 \pm .01\end{array}$ & $\begin{array}{l}4.30 \\
4.30 \\
4.20 \\
\end{array}$ & $\begin{array}{l}0.92 \\
1.06 \\
1.59\end{array}$ \\
\hline 5 & $\begin{array}{l}\frac{1}{4} \\
\frac{1}{2} \\
1\end{array}$ & $\begin{array}{l}1 \\
1 \\
4\end{array}$ & $\begin{array}{l}2.17 \pm .01 \\
1.81 \pm .01 \\
4.77 \pm .02\end{array}$ & $\begin{array}{l}2.05 \\
1.69 \\
4.65\end{array}$ & $\begin{array}{l}2.05 \\
1.69 \\
1.16\end{array}$ & $\begin{array}{l}2.58 \pm .01 \\
2.13 \pm .01 \\
1.47 \pm .01\end{array}$ & $\begin{array}{l}2.96 \\
2.92 \\
2.85\end{array}$ & $\begin{array}{l}1.15 \\
1.37 \\
1.94\end{array}$ \\
\hline
\end{tabular}

*Dose rate $1 \mathrm{~s}$ normalized to correspond to the fnitial source strength. 
TABLE A-2

DATA SUMMARY FOR STAINLESS STEEL ABSORBERS

\begin{tabular}{|c|c|c|c|c|c|c|c|c|}
\hline $\begin{array}{l}\text { Inftial } \\
\text { Source } \\
\text { Strength } \\
\text { (wats) }\end{array}$ & $\begin{array}{l}\text { Absorber } \\
\text { Thickness } \\
\text { (Inches) }\end{array}$ & $\begin{array}{l}\text { Exposure } \\
\text { Time } \\
\text { (hours) }\end{array}$ & $\begin{array}{l}\text { Measured } \\
\text { Dose } \\
(\text { rads) }\end{array}$ & $\begin{array}{c}\text { Net } \\
\text { Dose } \\
(\operatorname{rads})\end{array}$ & $\begin{array}{c}\text { Net Dose } \\
\text { Rate } \\
(\operatorname{rads} / \mathrm{hr})\end{array}$ & $\begin{array}{l}\text { Measured* } \\
\text { Dose Rate } \\
\text { (rads/hr) }\end{array}$ & $\begin{array}{l}\text { Calculated } \\
\text { Doge Rate } \\
\text { (rado/hr) }\end{array}$ & $\begin{array}{l}\text { Ratio } \\
\text { Calculated } \\
\text { to Measured }\end{array}$ \\
\hline 20.7 & $\begin{array}{l}\frac{1}{4} \\
\frac{1}{2} \\
1\end{array}$ & $\begin{array}{l}.25 \\
.25 \\
.25\end{array}$ & $\begin{aligned} 16.1 & \pm .2 \\
9.01 & \pm .05 \\
3.95 & \pm .03\end{aligned}$ & $\begin{array}{r}16.1 \\
8.99 \\
3.94\end{array}$ & $\begin{array}{l}64.2 \\
36.0 \\
15.7\end{array}$ & $\begin{aligned} 131 & \pm 2 \\
73.6 & \pm .4 \\
32.2 & \pm .2\end{aligned}$ & $\begin{array}{r}132 \\
102 \\
59\end{array}$ & $\begin{array}{l}1.01 \\
1.38 \\
1.83\end{array}$ \\
\hline 10 & $\begin{array}{l}\frac{1}{4} \\
1 \\
1\end{array}$ & $\begin{array}{l}.25 \\
.25 \\
.25\end{array}$ & $\begin{array}{r}10.80 \pm .05 \\
6.81 \pm .05 \\
3.08 \pm .04\end{array}$ & $\begin{array}{l}10.7 \\
6.80 \\
3.07\end{array}$ & $\begin{array}{l}43 \\
27.2 \\
12\end{array}$ & $\begin{array}{l}87.6 \pm .4 \\
55.4 \pm .4 \\
24.4 \pm .3\end{array}$ & $\begin{array}{l}95.4 \\
73.4 \\
41.2\end{array}$ & $\begin{array}{l}1.09 \\
1.32 \\
1.68\end{array}$ \\
\hline 5 & $\begin{array}{l}\frac{1}{4} \\
\frac{1}{2} \\
1\end{array}$ & $\begin{array}{l}.25 \\
.25 \\
.25\end{array}$ & $\begin{array}{l}7.15 \pm .05 \\
4.35 \pm .04 \\
1.90 \pm .02\end{array}$ & $\begin{array}{l}7.11 \\
4.32 \\
1.86\end{array}$ & $\begin{array}{r}28.4 \\
17.3 \\
7.45\end{array}$ & $\begin{array}{l}57.2 \pm .4 \\
34.8 \pm .3 \\
15.0 \pm .2\end{array}$ & $\begin{array}{l}63.6 \\
48.1 \\
26.3\end{array}$ & $\begin{array}{l}1.11 \\
1.38 \\
1.75\end{array}$ \\
\hline 2. $100 \mathrm{c}$ & $\frac{1}{4}$ & $\begin{array}{l}.5 \\
.5 \\
.5\end{array}$ & $\begin{array}{r}1.66 \pm .01 \\
.996 \pm .003 \\
.460 \pm .001\end{array}$ & $\begin{array}{r}1.53 \\
.869 \\
.333\end{array}$ & $\begin{array}{l}3.06 \\
1.74 \\
.666\end{array}$ & $\begin{array}{l}4.20 \pm .02 \\
2.38 \pm .01 \\
.211 \pm .004\end{array}$ & $\begin{array}{l}4.77 \\
3.72 \\
2.13\end{array}$ & $\begin{array}{l}1.13 \\
1.56 \\
2.34\end{array}$ \\
\hline 10 & $\begin{array}{l}\frac{1}{4} \\
1 \\
1\end{array}$ & $\begin{array}{l}.75 \\
.75 \\
1.5\end{array}$ & $\begin{array}{r}1.26 \pm .01 \\
.717 \pm .002 \\
.492 \pm .002\end{array}$ & $\begin{array}{r}1.24 \\
.689 \\
.464\end{array}$ & $\begin{array}{l}1.65 \\
.918 \\
.31\end{array}$ & $\begin{array}{l}3.25 \pm .01 \\
2.81 \pm .01 \\
.610 \pm .002\end{array}$ & $\begin{array}{l}3.43 \\
2.64 \\
1.48\end{array}$ & $\begin{array}{l}1.05 \\
1.46 \\
2.42\end{array}$ \\
\hline 5 & $\begin{array}{l}\frac{1}{4} \\
\frac{1}{2} \\
1\end{array}$ & $\begin{array}{l}1.5 \\
1.5 \\
1.5\end{array}$ & $\begin{array}{l}2.01 \pm .01 \\
1.16 \pm .01 \\
.482 \pm .003\end{array}$ & $\begin{array}{r}1.89 \\
1.04 \\
.366\end{array}$ & $\begin{array}{r}1.26 \\
.625 \\
.244\end{array}$ & $\begin{array}{r}1.62 \pm .01 \\
.862 \pm .005 \\
.313 \pm .002\end{array}$ & $\begin{array}{l}2.30 \\
1.73 \\
0.24\end{array}$ & $\begin{array}{l}1.42 \\
1.94 \\
3.00\end{array}$ \\
\hline
\end{tabular}

wope rate 1. normelized to correspond to the inftial cource etrength.

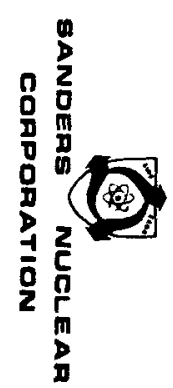


TABLE A-3

DATA SUMMARY FOR LEAD ABSORBERS

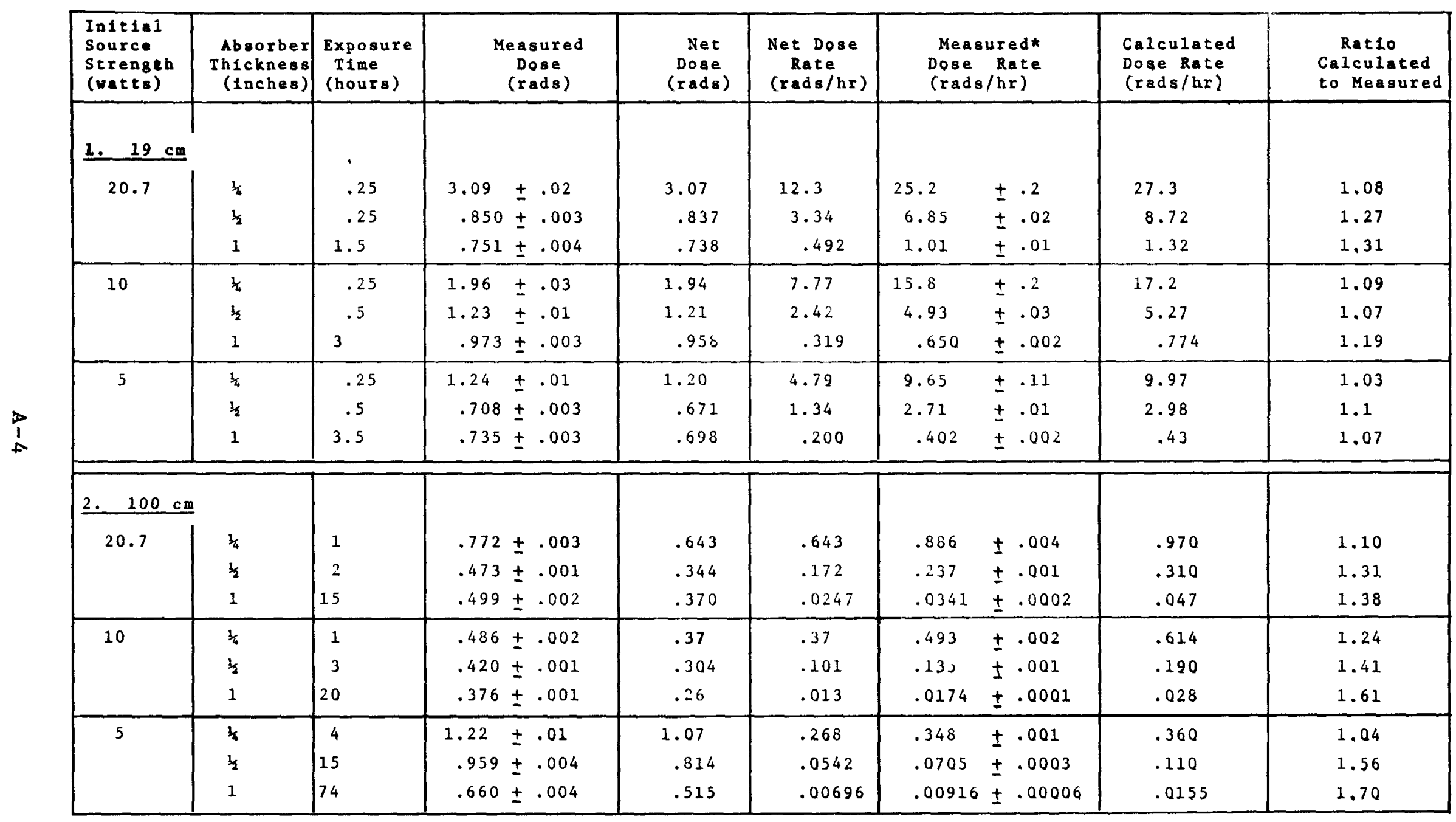

*Dose rate is normalized to correspond to the Inftial source strength. 
TABLE A-4

DATA SUMMARY FOR TUNGSTEN ABSORBERS

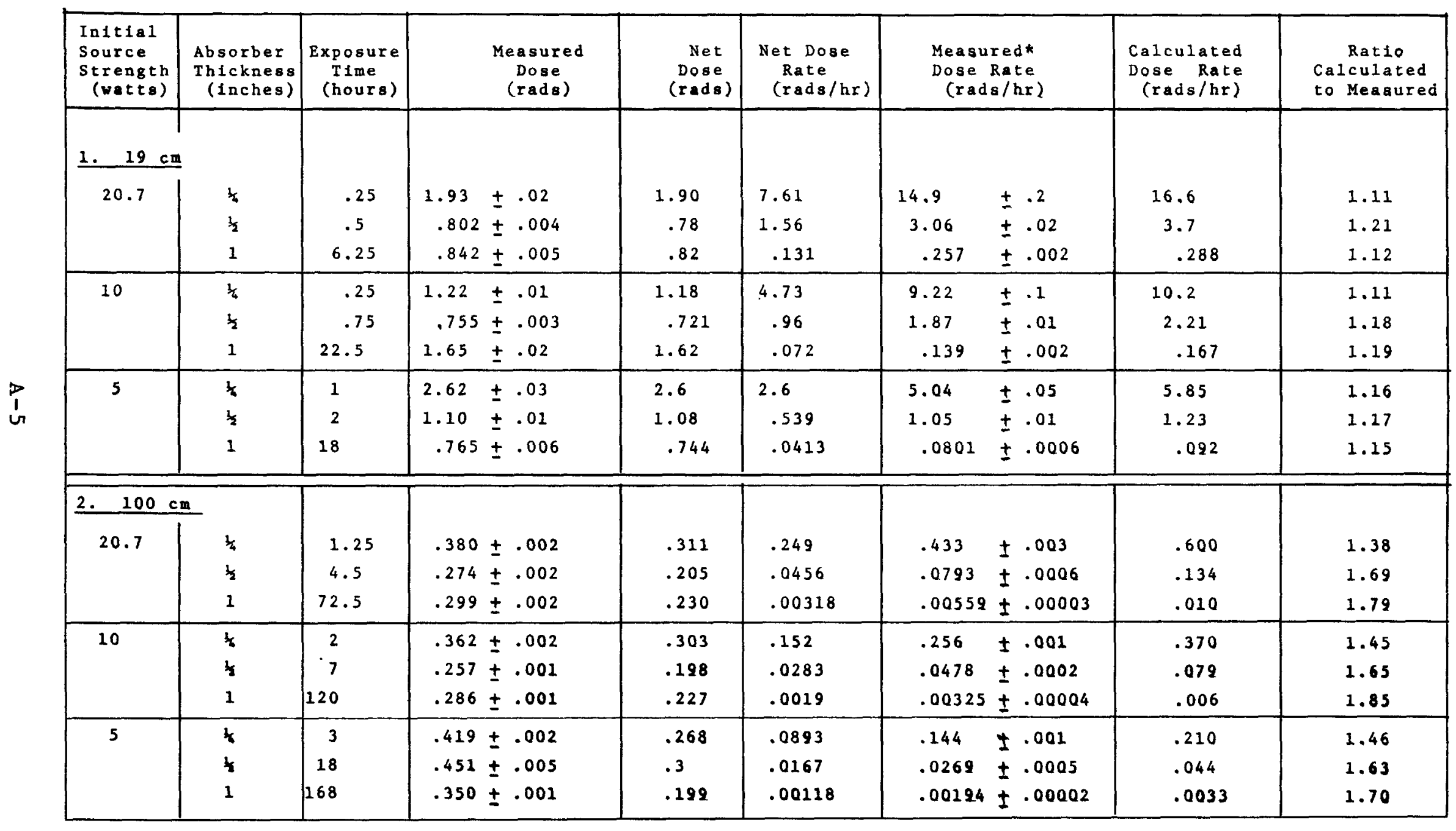

Aose rate 1 e normalized to correspond to the Inftial cource etrength. 
TABLE $A-5$

DATA SUMMARY FOR DEPLETED URANIUM ABSORBERS

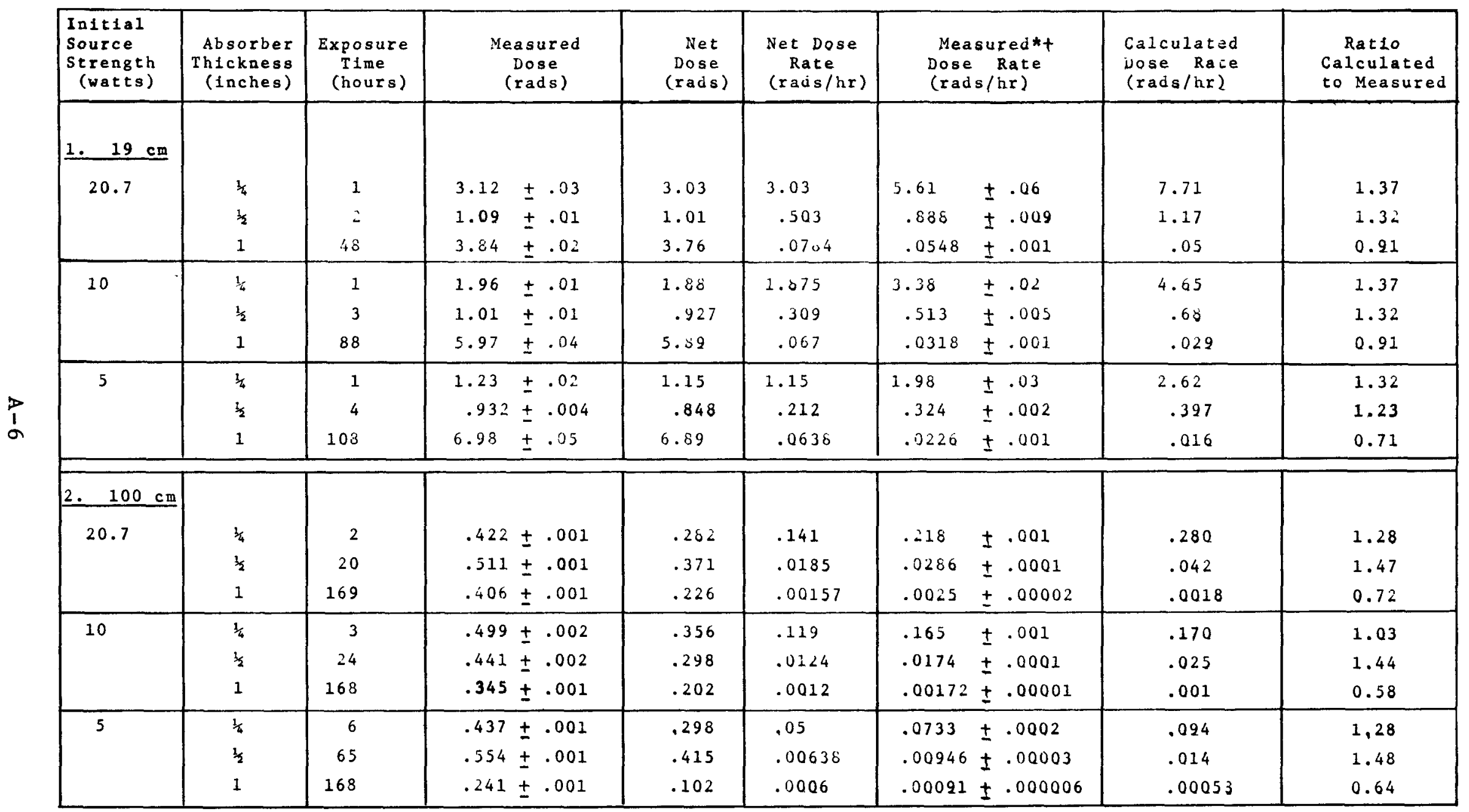

* Dose rate is normalized to correspond to the intial source strength.

+Uranium background is subtracted. 
gANDEAB NUCLEAR COAPOAATION

\section{APPENDIX B}

EXPERIMENTAL APPARATUS, PROCEDURES AND RESULTS

$\mathrm{B}-1$ 


\section{B. 1 DESCRIPTION AND CALIBRATION OF THULIUM OXIDE SOURCE}

The individual radiation sources used in these measurements consisted of doubly encapsulated stacks of thulium-170 oxide wafers as depicted in Figure B-1. Both the exterior capsule and liner were $\mathrm{Ha}=$ te 110 y $\mathrm{C}$.

The thermal and radiation strengths of the sources are given in Table $B-1$. These thermal strengths were determined calorimetrical1y on 2 August 1968 by ORNL (10). The calorimeter and the procedures used are described in references 17 and 18 . The calorimeter was calibrated in a standard cell just prior to use. The calibration was made using a precision heater and a calibrated wattmeter and recording the thermocouple potentiometer reading as a function of power input to the heater. The same potentiometer and standard cell were then used to measure the heat output of the radiation sources. Since the calorimeter used was a less refined model than the type described in the references, the accuracy is estimated at $2 \%$ at the $95 \%$ confidence leve 1 .

One irradiated wafer from these sources was dissolved by ORNL for analysis and assumed to be representative of the batch. A mass spectrographic analysis made on $10 \mathrm{July} 1968$ gave the following thulium isotopic distribution: $\operatorname{Tm}-169$ (76.8\%), $\operatorname{Tm}-170$ (17.7\%), Tm-171 (5.5\%). A chemical analysis of the solution performed on 25 June 1968 determined the ytterbium content to be $17 \%$ by weight.

TABLE B-1

THERMAL AND RADIATION STRENGTHS OF THULIUM-170 OXIDE

\section{$\underline{\text { Source }}$}

No. 1

No. 2

No. 3
Thermal Strength (watts)

$$
\begin{array}{r}
5.0 \pm 0.1 \\
10.0 \pm 0.1 \\
20.7 \pm 0.1
\end{array}
$$

Radiation Strength* (curles)

$$
\begin{aligned}
& 2225 \pm 119 \\
& 4450 \pm 225 \\
& 9211 \pm 455
\end{aligned}
$$

*Conversion factor $=445 \pm 22$ curies/watt ${ }^{(9)}$ 


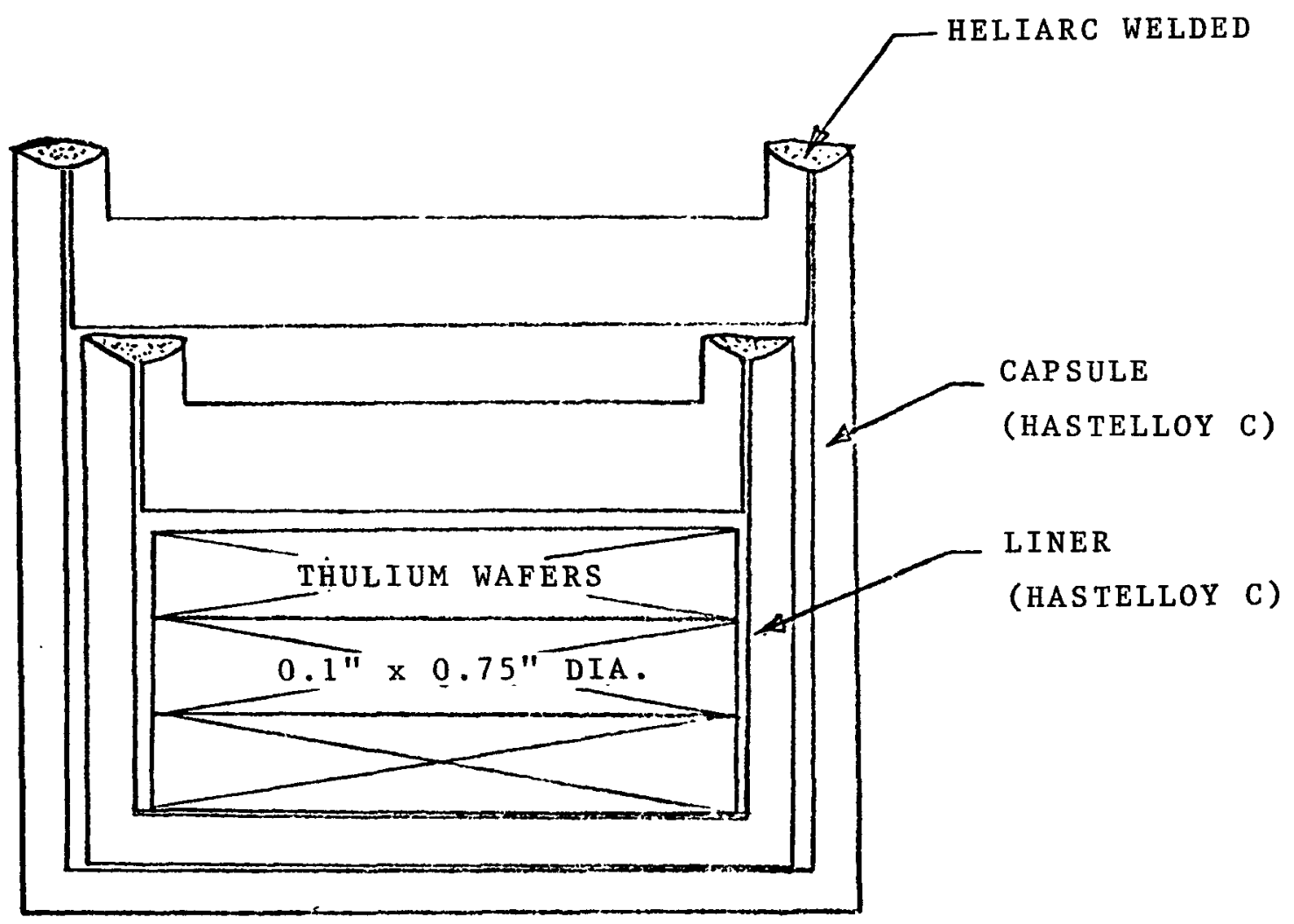

Figure B-1. Representative Thulium Source and Capsule 
The physical characteristics of individual $\mathrm{Tm}_{2} \mathrm{O}_{3}$ wafers used in the sources are described in Table B-2. The distribution of these wafers in the sources was as follows: Source No. 1 (Wafer No. 6), Source No. 2 (Wafers No. 5, 8), and Source No. 3 (Wafers No. 1, 2, 3, 7). Table B-3 gives the precise dimensions (in inches) of the exterior capsules and their liners.

TABLE B-2

PHYSICAL CHARACTERISTICS OF THULIUM-170 OXIDE WAFERS

\begin{tabular}{ccccc}
$\begin{array}{c}\text { Wafer } \\
\text { No. }\end{array}$ & $\begin{array}{c}\text { Weight } \\
(\text { gms })\end{array}$ & $\begin{array}{c}\text { Diameter } \\
\text { (inches) }\end{array}$ & $\begin{array}{c}\text { Thickness } \\
\text { (mils) }\end{array}$ & $\begin{array}{r}\text { Theoretical Density } \\
(\%)\end{array}$ \\
\cline { 1 - 2 } 1 & 4.8768 & 0.736 & 98.5 & 80.0 \\
2 & 4.8500 & 0.730 & 100.1 & 79.6 \\
3 & 5.0450 & 0.732 & 99.9 & 83.7 \\
5 & 4.5846 & 0.742 & 95.5 & 76.2 \\
6 & 4.8380 & 0.735 & 99.4 & 78.7 \\
7 & 4.9690 & 0.738 & 100.0 & 79.9 \\
8 & 4.9243 & 0.734 & 99.5 & 79.7
\end{tabular}

TABLE B-3

DIMENSIONS OF THULIUM-170 OXIDE SOURCES (INCHES)

\begin{tabular}{|c|c|c|c|c|c|}
\hline $\begin{array}{c}\text { Capsule } \\
\text { No. } \\
\end{array}$ & $\begin{array}{l}\text { Bottom } \\
\text { Thickness } \\
\end{array}$ & $\begin{array}{c}\text { Wall } \\
\text { Thickness } \\
\end{array}$ & $\begin{array}{c}\text { Capsule } \\
\text { OD }\end{array}$ & $\begin{array}{c}\text { Capsule } \\
\text { ID } \\
\end{array}$ & $\begin{array}{l}\text { Capsule } \\
\text { He1ght }\end{array}$ \\
\hline xteriol & Capsule & & & & \\
\hline 1 & $0.0513-0.0518$ & $0.0330-0.0352$ & 0.9210 & 0.8520 & 0.9600 \\
\hline 2 & $0.0511-0.0514$ & $0.0327-0.0340$ & 0.9200 & 0.8530 & 0.9600 \\
\hline 3 & $0.0512-0.0515$ & $0.0326-0.0335$ & 0.9190 & 0.8525 & 0.9590 \\
\hline
\end{tabular}

\section{Capsule Liners}

$\begin{array}{llllll}1 & 0.0495-0.0503 & 0.0388-0.0405 & 0.842 & 0.760 & 0.6715 \\ 2 & 0.0495-0.0505 & 0.0365-0.0380 & 0.844 & 0.7674 & 0.6700 \\ 3 & 0.0495-0.0505 & 0.0385-0.0405 & 0.842 & 0.761 & 0.6684\end{array}$




\section{B. 2 EXPERIMENTAL APPARATUS}

The equipment used in this experiment to perform thulium-170 dose rate measurements is shown in Figures B-2 through B-5. They are also schematically depicted in Figure B-6. Figure B-2 is an axial photograph of the measurement fixture showing the source shield cask with the beam tunnel shutter open and the one-quarter inch lead absorber in the absorber holder. Also shown is the radiation scatter shield (see Appendix C, paragraph C.7) and the radiation dosimeters in their holder at the one meter irradiation position. Figure $B-3$ is a disassembled view of the source shield cask and the absorber holder showing the shield cask plug and the aluminum source holder. Also shown is a model fuel capsule. Figure B-4 is a top view of the partially assembled source shield cask and absorber holder showing the source holder in position inside the cask. Figure B-5 shows the thermoluminescent dosimetry (TLD) reader (Con-Rad Mode1 5100B) used in the experiment to evaluate the dosimeters. Included is a dosimeter holder loaded with five black polyethylene dosimeter capsules and the vibratory instrument (see paragraph B.3 for a detailed discussion) which dispenses precise quantities of TLD phosphor powder ( $L i F$ ) into them.

The measurement fixture consisted of a rectangular base platform with the following mounted upon it: (1) a shielded enclosure for the radiation sources, (2) a fixed holder for the various absorber specimens and (3) a second fixed holder for the thermoluminescent dosimeters. This fixture is schematically depicted in Figure B-7. The shield enclosure incorporated lead walls of such thickness (approximately 3 inches) that with the strongest anticipated thulium-170 source contained within it, the dose rate at one meter from the enclosure was no greater than $10 \mathrm{mr} / \mathrm{hr}$. In addition, the enclosure had a removeable lead cover over the source cavity of likewise appropriate thickness. The cavity itself was so constructed and aligned with a radiation beam "tunnel" that with the thulium capsule in place, only the axial radiation emission was allowed to exit through the tunnel and be incident upon the absorber 


\section{\$ \\ BANDEAS NUCLEAR COAPORATION}

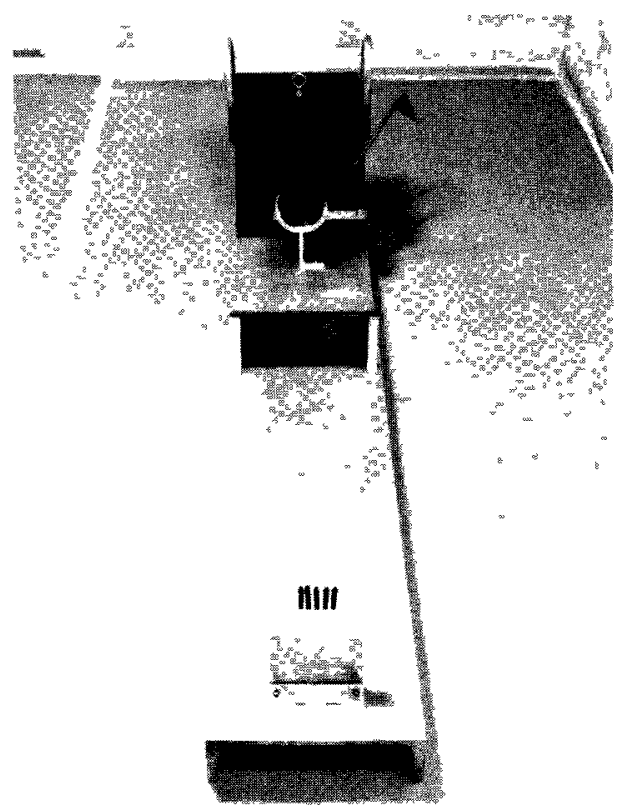

$68-1198-5$

Figure B-2. Dose Rate Measurement Fixture

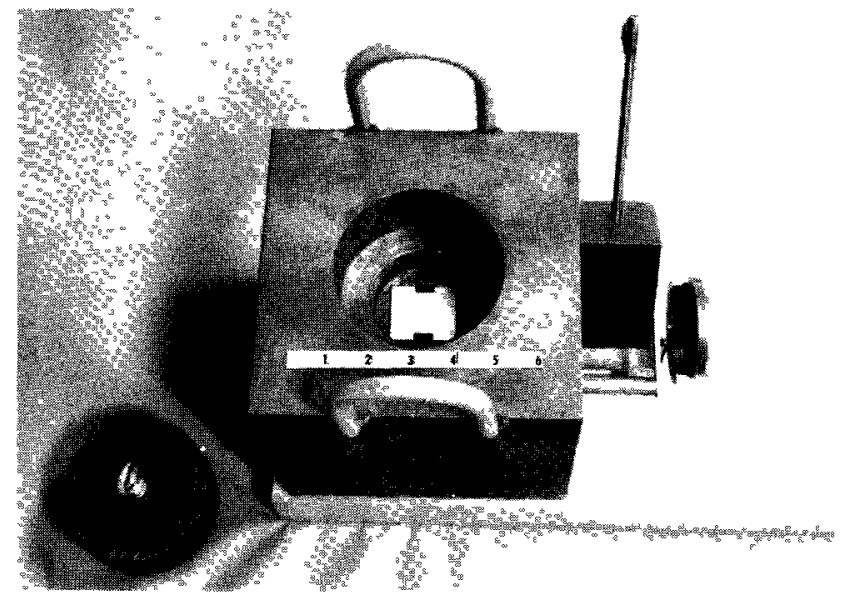

$$
\text { 68-1198-3 }
$$

Figure $B-4$. Top View of a Partial1y Assembled Source Shield Cask

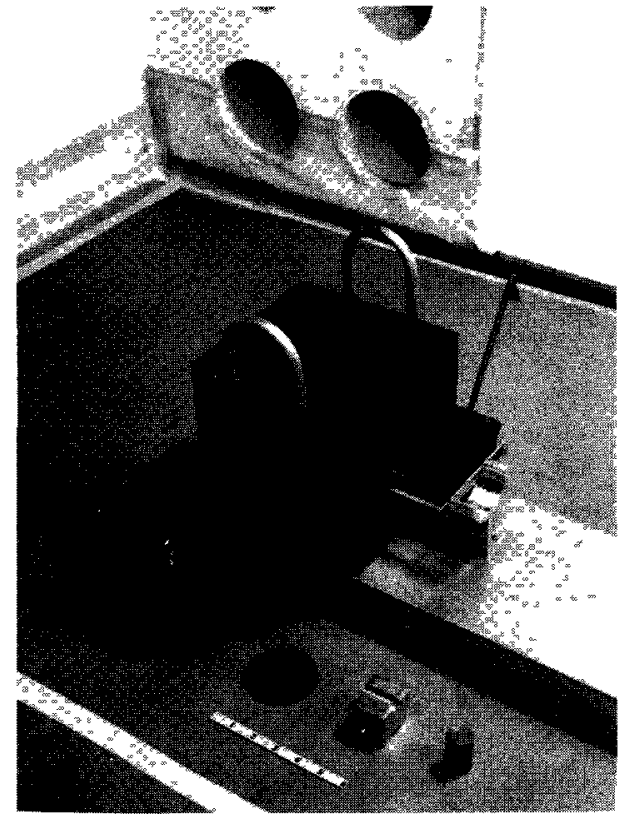

68-1198-4

Figure B-3. Source Shield Cask
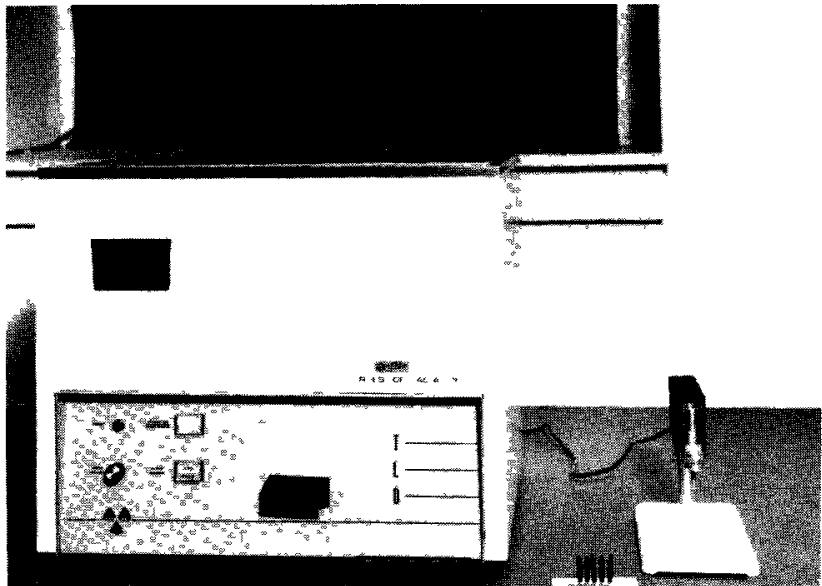

68-1198-2

Figure B-5. Thermoluminescent Dosimetry (TLD) Reader 


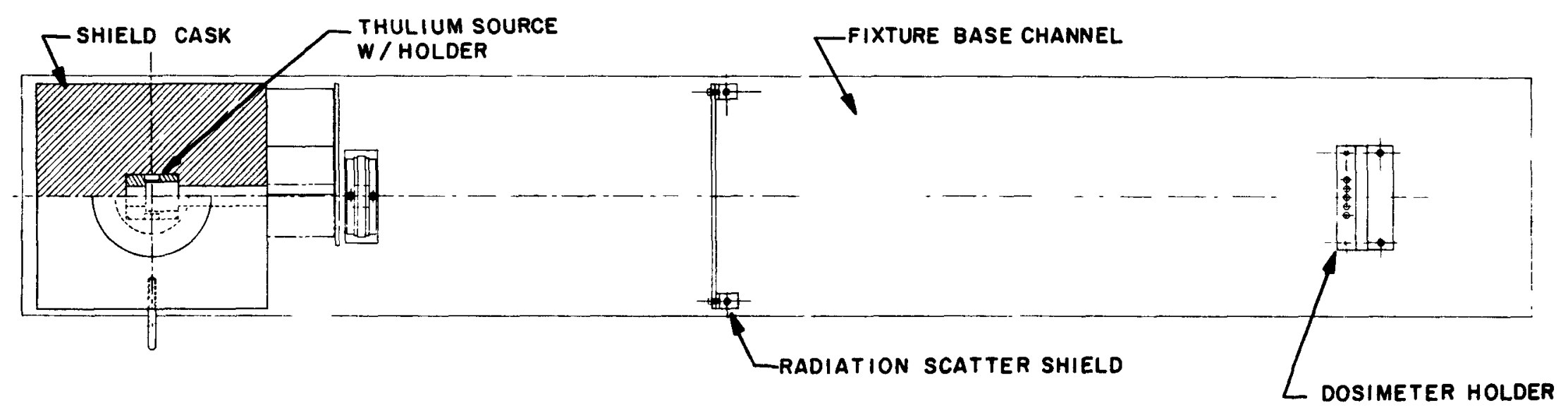

1
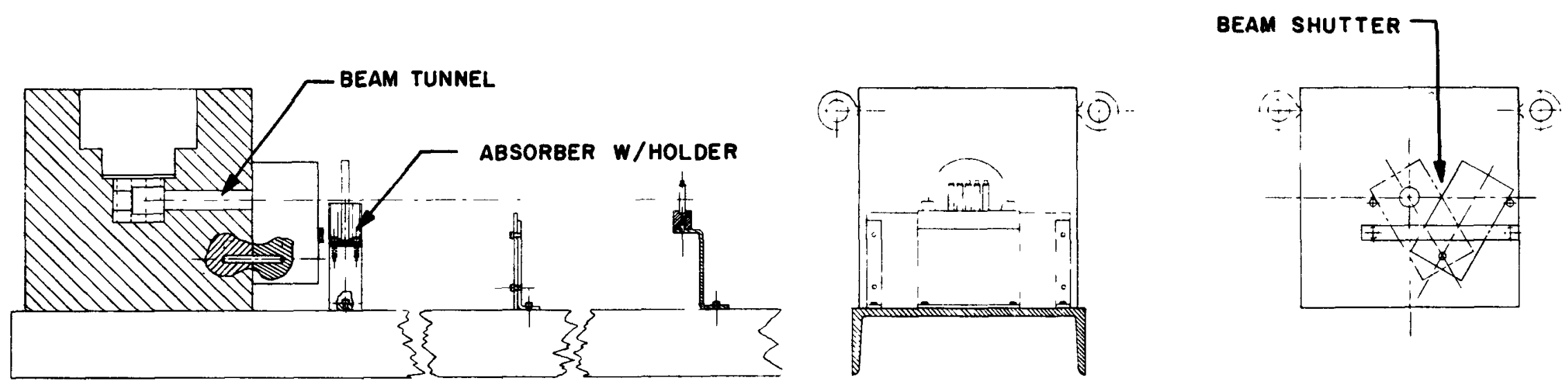

Figure B-6. Experimental Apparatus

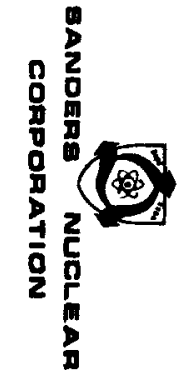




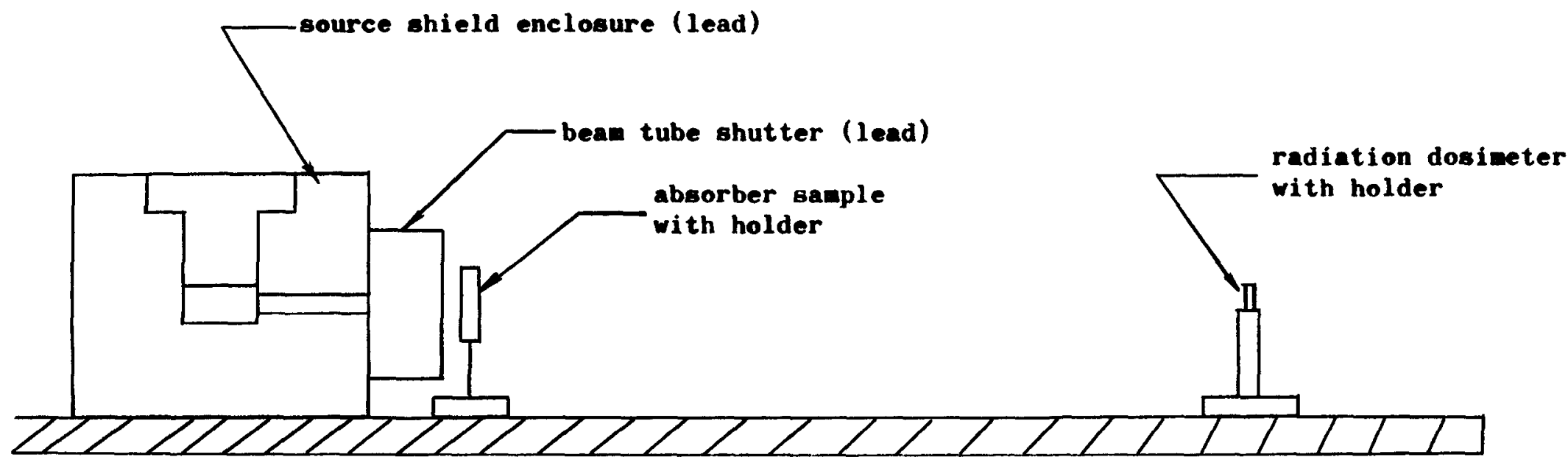


specimen. The source shield enclosure and the absorber holder are depicted in Figure B-8. Both the absorber and dosimeter holders were axially aligned with the source capsule and beam tunnel center1ine. In addition, the dosimeter holder (shown in Figure B-9) was located so that the dosimeters could be positioned at various distances from the vertical source centerline.

\section{B. 3 THERMOLUMINESCENT DOSIMETRY (TLD) SYSTEM}

B.3.1 THERMOLUMINESCENT PHOSPHOR

The thermoluminescent phosphor, TLD-700, is lithium fluoride (LiF) powder which has been refined so that it is essentially free of the Lithium-6 isotope (i.e., it consists almost entirely of Lithium-7). The range of radiation dosage measurable with this phosphor extends from $10 \mathrm{mrad}$ to $100,000 \mathrm{rad}$ for gamma, $x-r a y$, beta and electron radiation. The radiation dose measurement precision attainable with this phosphor as a function of dose is given in Table $\mathrm{B}-4^{(19)}$. The overall accuracy of dose measurement depends not only upon dosimeter precision, but also upon the accuracy of calibration of the readout instrument and dosimeter system. The expected overall accuracy was determined to be $\pm 9 \%$ for this experiment, based on large dose measurement $(>1 \mathrm{rad})$, as discussed in paragraph B.3.3.

The response of LiF phosphor vs photon energy is shown in Figure $B-10$. For all practical purposes, the response is independent of incident photon energy down to about $100 \mathrm{keV}$.

\section{B.3.2 TLD READOUT SYSTEM}

The thermoluminescence dosimetry system used in obtaining the radiation dose rates in this experiment consisted of the following:

- Con-Rad Mode1 5100 B Readout Instrument.

- Con-Rad Model PDAV Vibratory Phosphor Dispenser.

- Thermoluminescent Dosimetry Powder Type TLD-700 (LiF-7). In the operation of the readout instrument, the phosphor 


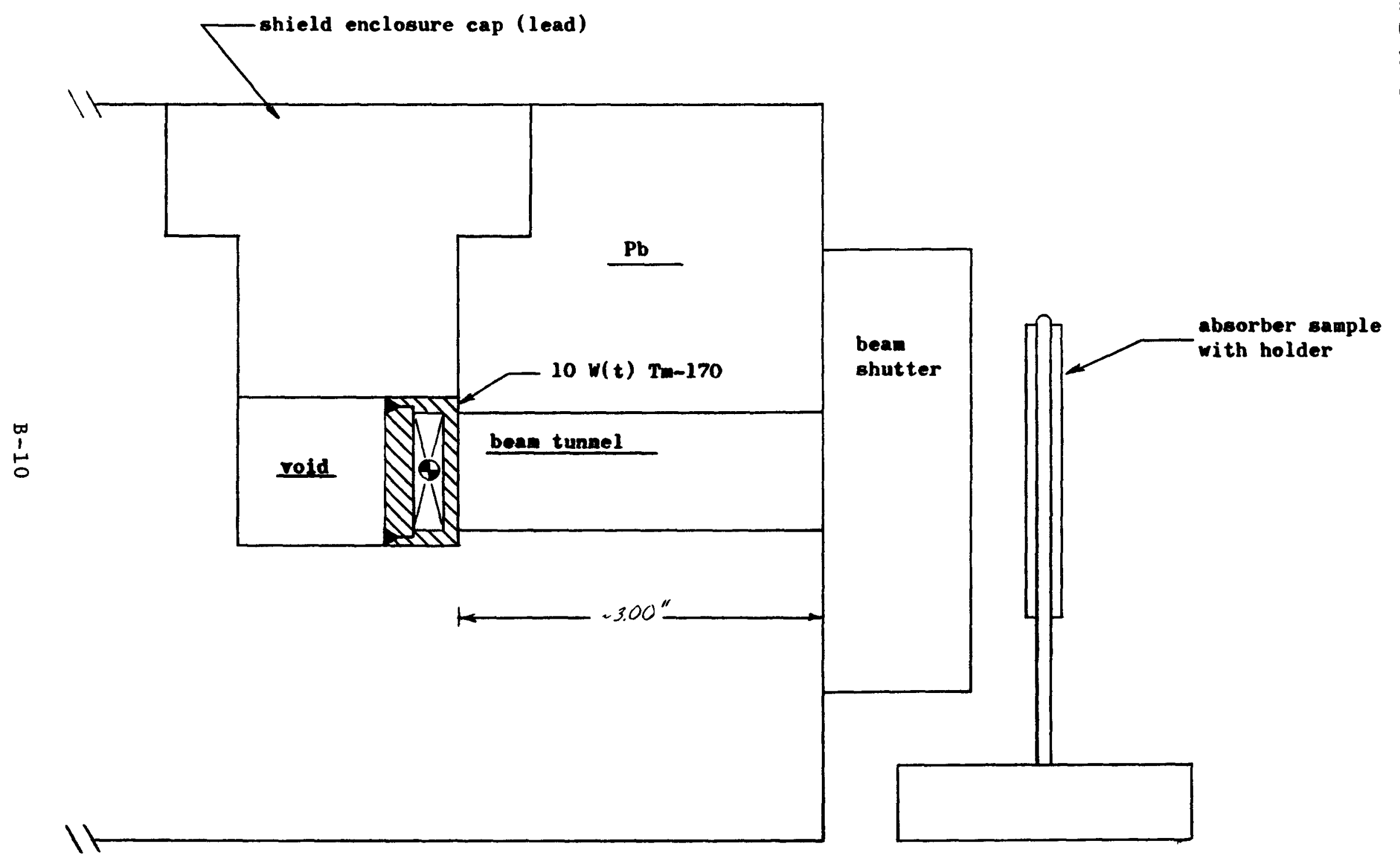

Figure B-8. Source Shield Enclosure Arrangement 


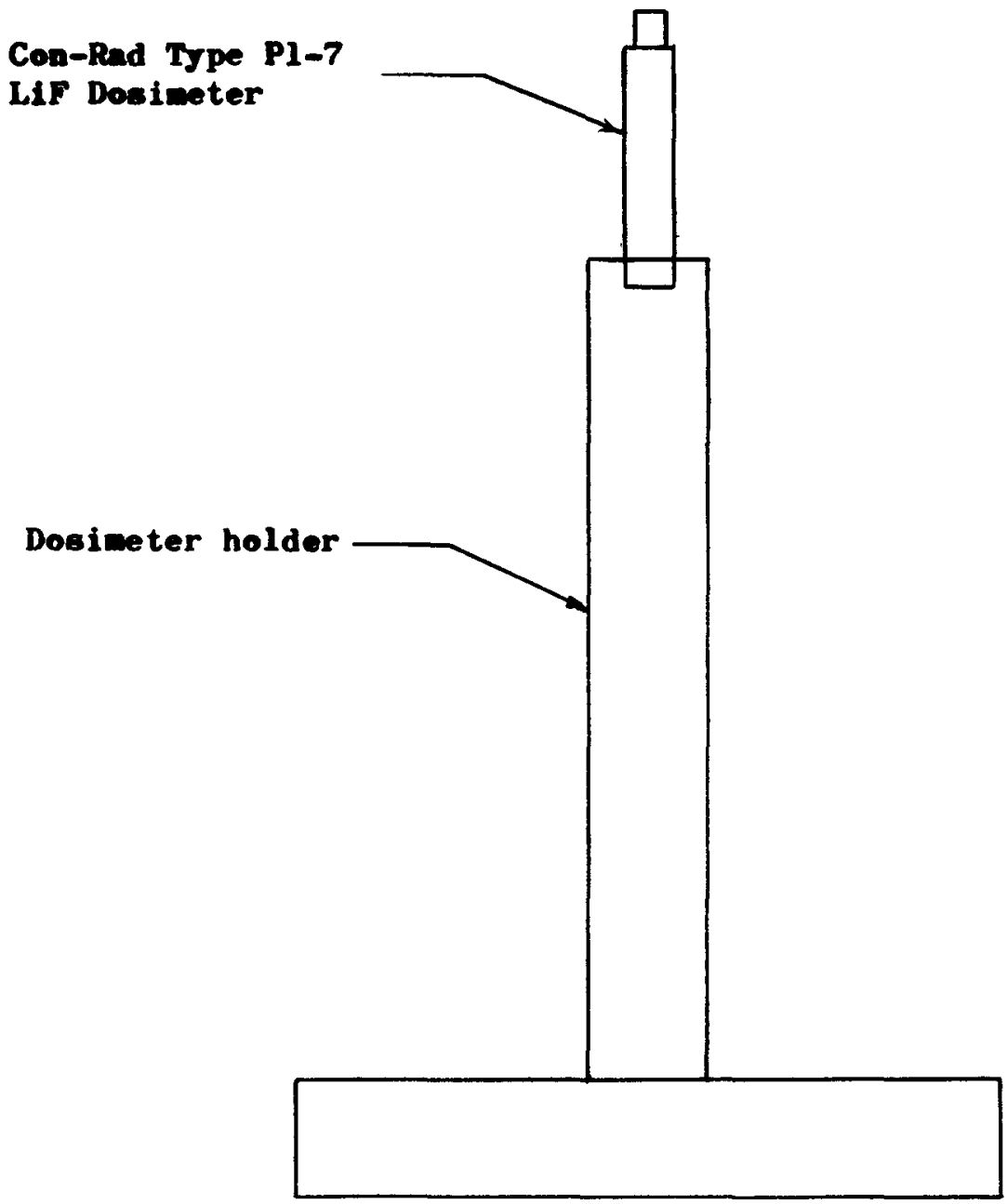

Figure B-9. Dosimeter Mounting Arrangement

$$
\text { B }-11
$$




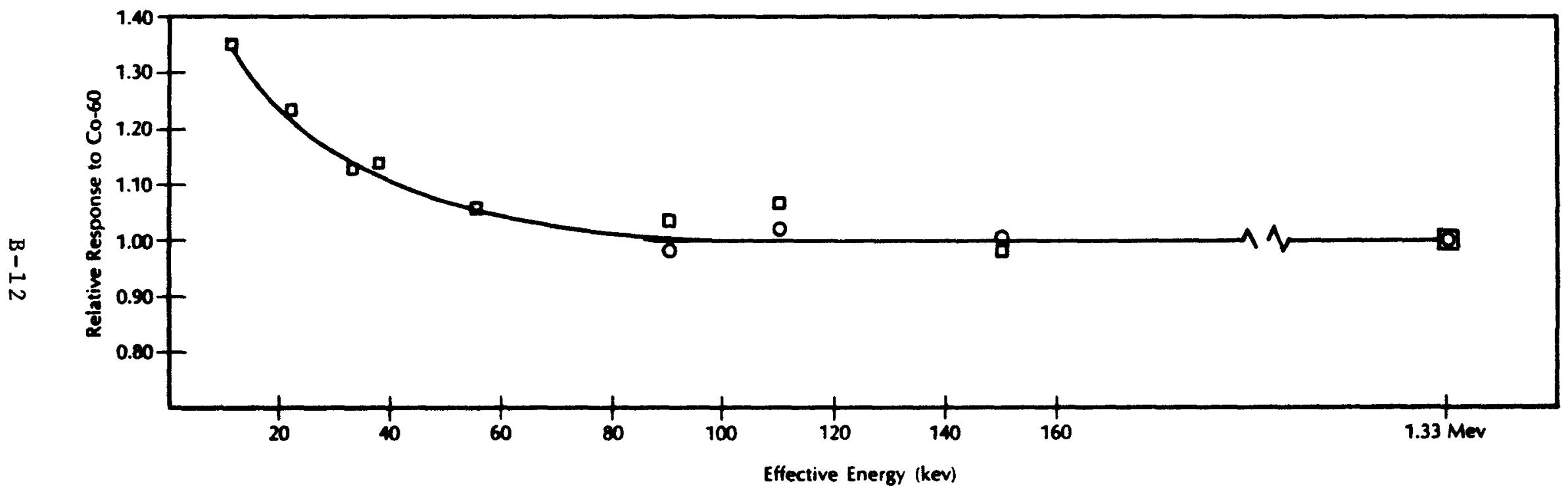

Figure B-10. Response of Con-Rad Lithium Fluoride TLD Dosimeters to Radiation Energy 
TABLE B -4

\section{MEASUREMENT PRECISION OF LIF PHOSPHOR}

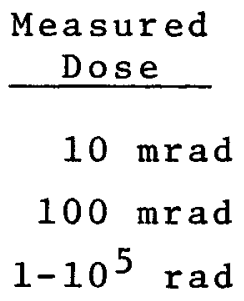

$$
\begin{aligned}
& \begin{array}{c}
\text { Measurement } \\
\text { Precision }
\end{array} \\
& \hline \pm 20 \% \text { S.D. } \\
& \pm \quad 5 \% \text { S.D. } \\
& \pm 2 \% \text { S.D. }
\end{aligned}
$$

sample or dosimeter is heated and the amount of light emitted within a fixed time period is integrated and is presented digitally. The instrument can be adjusted in such a manner that the dose can be read directly in dose units over a broad dose range. The concept of the instrument is indicated in block diagram as shown in Figure B -11 .

The system employs reusable and exchangeable heating elements. When measuring loose powder dosimeters, high-resistivity heating elements are used onto which the powder is poured. These heating elements are inserted by a slide into the instrument where the edges becomes gripped by copper-beryllium alloy contacts during heating. The Constant Current Heater Control module provides a constant current through the heating element and ensures a reproducible heating process.

A photomultiplier tube selected for a low dark current, a large range of measurable light fluxes, and a high stability is the first stage in the measuring system. A Teflon tube socket effectively prevents leakage currents. The High Voltage Power Supply provides the photomultiplier with voltage. It is continuously adjustable, and the setting can be controlled to \pm 0.3 volts, which simplifies exact adjustment of the overall light sensitivity of the instrument.

The anode current of the photomultiplier is integrated on a polystyrene capacitor in the integrator subunit. The voltage on this capacitor can be divided by successive factors of 10 by pressing a scale factor switch-button. An electrometer circuit, also placed in 


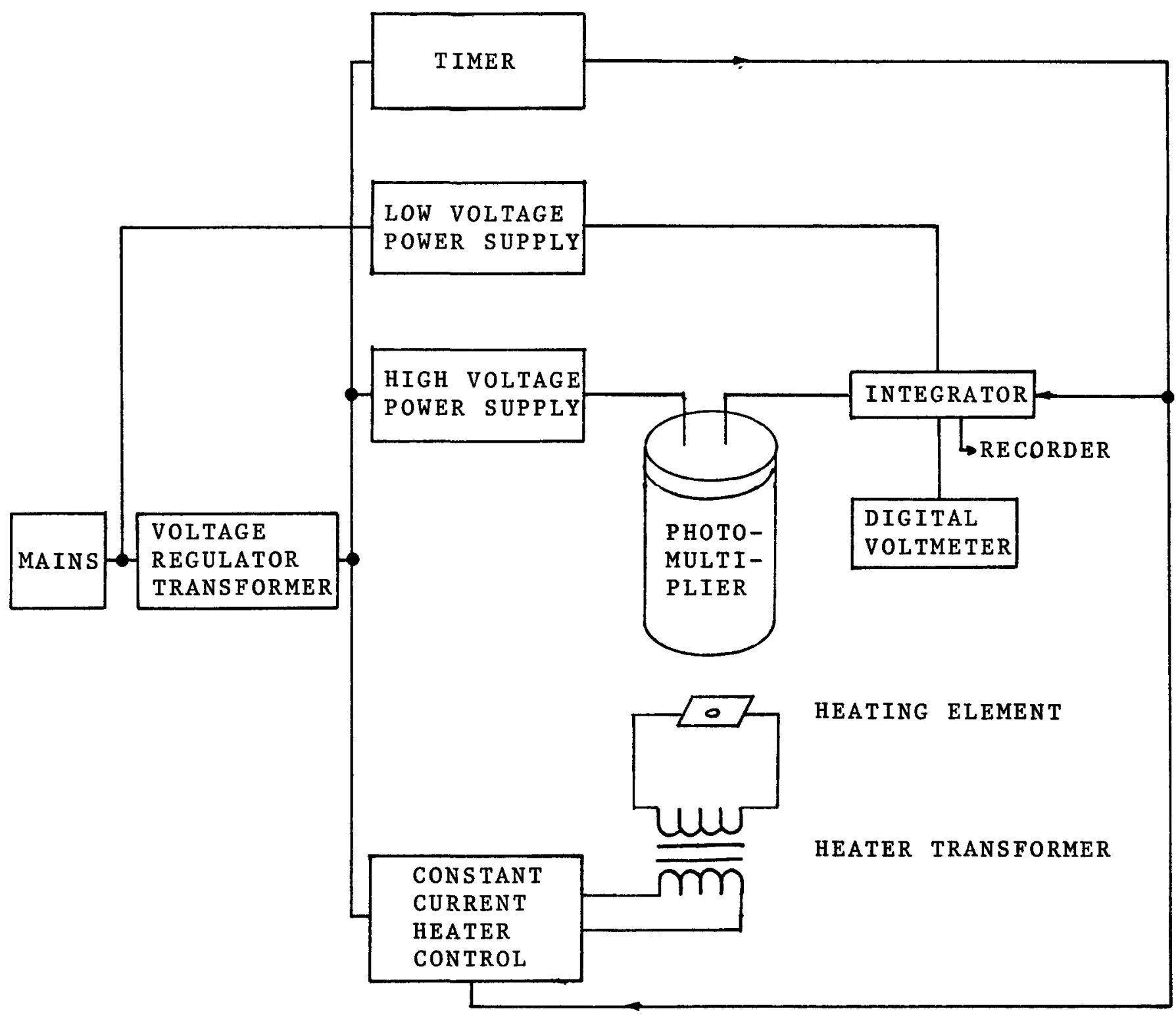

Figure B-11 Block Diagram of Readout Instrument

$$
\text { B }-14
$$


the integrator, is used as an intermediate stage when the voltage on the capacitor is measured, to provide the instrument with a long time constant in the retention of the signal. A Low Voltage Power Supply provides this part of the circuitry with the necessary voltages.

The final measurement of the collected charge from the photomultiplier and the display of the result is made with a Digital Voltmeter.

The readout cycle is controlled by a synchronous motor drive Cam Timer, which is programmed to operate a series of relays once the "Start Bar" is actuated. This feature makes routine operation simple and reliable.

A Regulating Transformer compensates effects of primary voltage fluctuations on all components of the apparatus. Among other things, it assists in keeping the heating current constant.

For measurement of small doses, the instrument is equipped with a gas inlet so that the readout chamber can be filled with appropriate gas, normally prepurified nitrogen. The use of this feature makes it possible to measure with LiF down to $10 \mathrm{mRad}$ with a standard error of less than $\pm 20 \%$. Among the accessory equipment is a recorder for glow curve registration, which can be attached without disturbance on the normal integration procedure.

\section{B. 3.3 TLD READOUT INSTRUMENT CALIBRATION}

Field calibration of Con-Rad TLD Readout Instruments was performed by means of two light sources provided with the instrument. These sources were used to set the instrument sensitivity for dosimetry phosphor obtained from Con-Rad. They were fabricated to emit the same light intensity within $\pm 2 \%$ of their corresponding standards at the Con-Rad Laboratory. The TLD phosphor obtained for the dose rate measurements along with the instrument was accompanied by an Instrument Calibration Form which provided the recommended light source readings to permit calibration of the instrument so that readout sensitivities of $0.001,0.10$ and 10 Rad per digit could be obtained with the phosphor. The initial calibration procedure employed upon receipt of the instrument is given below. 
The instrument was energized and permitted to warm up for two hours to achieve stability. Then, light source A was inserted into the readout chamber and output readings taken for photomultiplier high voltages of $400,600,800$ and 1000 volts. These readings were found to be in excellent agreement with corresponding curves provided by the manufacturer for the instrument. Similarly, 11ght source B was next inserted and readout values obtained at 1000, 1200, 1400, 1600 and 1800 volts. Again, the agreement with the specification curves was very good. Also, as part of these readings, stability of the zero point of the digital voltmeter, as well as the light source readout values, was confirmed, thereby indicating instrument stability. Finally, the instrument was calibrated to obtain readout sensitivity of 0.001 Rad per digit by reinsertion of light source $B$ and adjustment of the photomultiplier high voltage to obtain digital readout of 185, as specified on the Instrument Calibration Form. Subsequently, 10 additional readings were performed and the average value confirmed to be the required value. In addition, the standard deviation of these readouts was calculated and confirmed as not exceeding $\pm 1 \%$, thereby assuring reproducibility of the measurements.

Although this light source technique of readout instrument calibration is simple and effective, the measurement accuracy obtained thereby is limited by the following factors:

- The light source readings for the desired sensitivity are valid only for the particular batch of phosphor with which they are supplied.

The readings are valid only for dosimeter phosphor which has not been annealed (for annealed powder, see paragraph B.3.4)

- The calibration is based upon exposures to cobalt-60 gamma radiation. For photon energies less than about 100 keV, corrections should be applied for phosphor energy dependence.

- The fundamental accuracy of this calibration techniques is determined by: 
a. The accuracy of calibration by Con-Rad of batches of dosimetry phosphor which is about $\pm 4 \%$.

b. The accuracy of the light source used compared with that of the light source standard maintained at Con-Rad Laboratories to establish dosimeter sensitivities which is $\pm 2 \%$.

c. Inaccuracies created by the influence of ambient temperature on photomultiplier spectral sensitivity, variations in positioning of light source and in setting of heater current in both Con-Rad Laboratory and field instruments which should contribute less than $\pm 3 \%$

As a result of these sources of error, an overall accuracy of about $\pm 9 \%$ or better was expected for the thulium-170 dose rate measurements subsequently performed.

\section{B. 3.4 TLD PHOSPHOR CALIBRATION}

As mentioned previously, the accuracy of the TLD system calibration is partially limited by the fact that after the phosphor has been used and subsequently annealed, its sensitivity to radiation changes. Consequently, repeated exposures of a given quantity of phosphor to identical irradiation configurations would yield varying dose indications. Accordingly, since it was anticipated that it would be necessary to conduct several annealing operations during the course of these dose rate measurements, a small quantity of unirradiated phosphor was initially set aside as a control. After each annealing operation, the zero dose reading of a small sample of "clean" phosphor was compared with that of the freshly annealed stock. This assured that annealing had been complete.

\section{B. 3.5 TLD POWDER DISPENSER CALIBRATION}

An investigation was conducted regarding the reproducibility of 
measurement of thermoluminescent dosimetry (TLD) phosphor powder into the dosimeter capsules being used in the dose rate measurement exposures. The instrument being used to measure calibrated quantities of TLD phosphor (LIF-7) into the capsules is the Con-Rad Phosphor Dispenser - Vibrator (Model PDAV-1). (See Figure B-12). This instrument is claimed to measure 43.7 milligrams of phosphor with a reproducibility of \pm 0.1 percent standard deviation. The dispenser consists of a horizontal cylindrical plunger with a small vertical hole, i.e., a metering volume, normal to its axis. This plunger is closely fitted into a hole in a block of dissimilar metal which forms the dispenser body. The top of the body is machined to provide a reservoir for the powder incorporating a conical bottom with a small outlet hole which is aligned with the plunger metering volume. When the plunger is pushed, the metered volume is moved under the reservoir. A simultaneously actuated vibrator assures thorough packing of a calibrated quantity of phosphor into the cavity. After a certain vibratory packing interval, the vibrator ceases and the plunger is then pulled out against its stop whereupon the metering volume is aligned with the dispenser tube under which is placed the receptacle for the powder. Again, the vibrator is actuated during the dispensing cycle ensuring thorough removal of the calibrated phosphor quantity.

To check the reproducibility of this instrument under actual conditions, a series of 30 measurements were taken of the weights : of clean, dry phosphor powder dispensed each time. These measurements were made with an Ainsworth analytical balance (Mode1 $21 \mathrm{~N}$ ). Table B-5 presents the measured data along with associated statistical evaluation calculations. The net result of these measurements is that the average weight of phosphor dispensed by the instrument is:

$$
\text { average weight }=43.89 \pm 0.22 \% \mathrm{~S} . \mathrm{D} . \mathrm{mg} \text {. }
$$

This value appeared in good agreement with the manufacturer's claimed reproducibility of phosphor measurement, and was therefore assumed to be satisfactory. Subsequent examination of the 1iterature $(20,21)$ also revealed that owing to this comparatively large nominal phosphor 


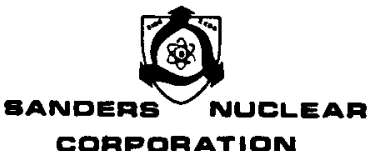

CORPORATION

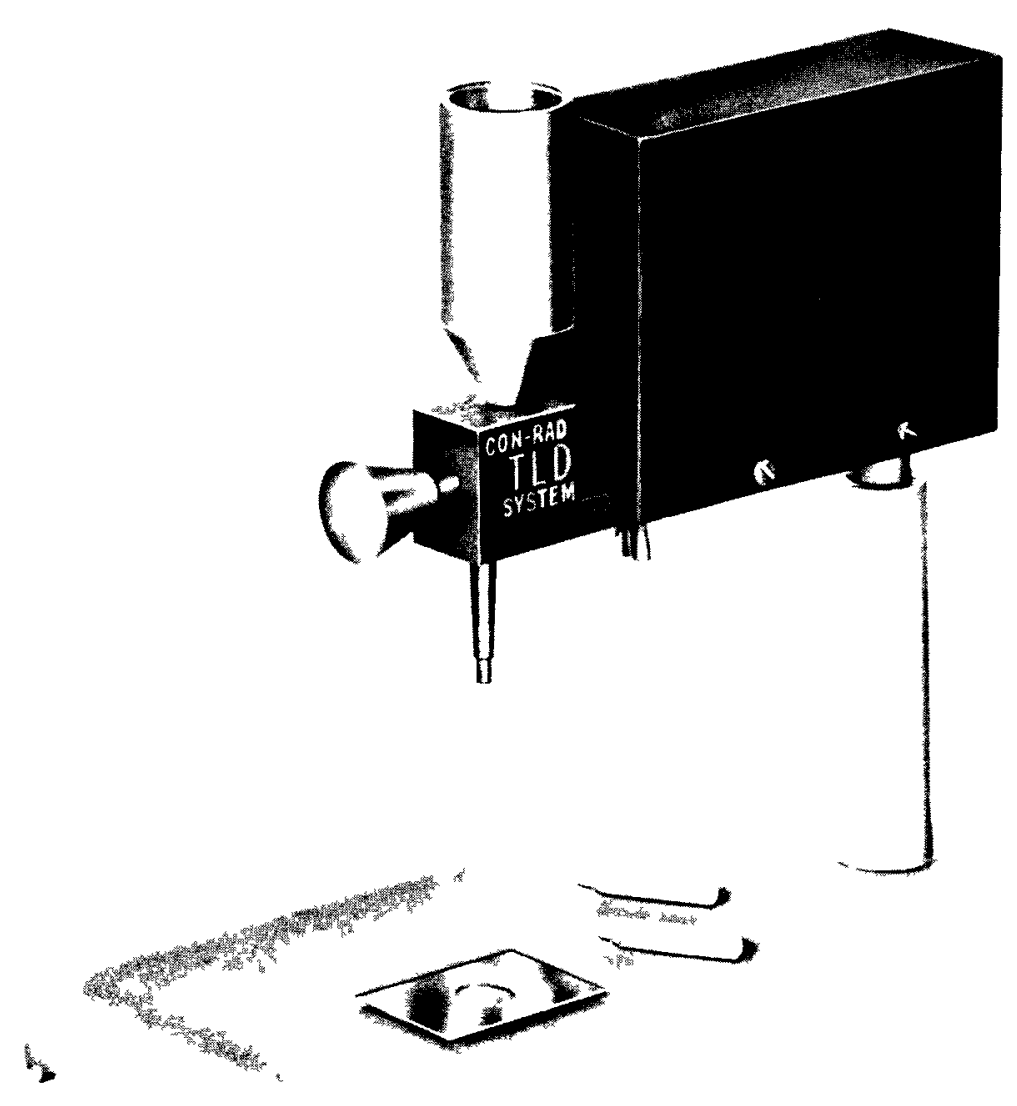

)

Figure B-12. Phosphor Dispenser Vibrator 
TABLE $\quad B-5$

REPRODUCIBILITY OF TLD PHOSPHOR DISPENSER VIBRATOR

Experimenta1 Data

Test No. Sample Weight (mg) Test No. SampleWeight (mg)

$\begin{array}{rrrr}1 & 43.9 & 16 & 43.9 \\ 2 & 44.0 & 17 & 44.1 \\ 3 & 44.0 & 18 & 43.8 \\ 4 & 43.9 & 19 & 43.9 \\ 5 & 43.9 & 20 & 43.9 \\ 6 & 44.0 & 21 & 43.8 \\ 7 & 43.9 & 22 & 43.7 \\ 8 & 43.9 & 23 & 43.8 \\ 9 & 43.8 & 24 & 43.7 \\ 10 & 43.8 & 25 & 43.9 \\ 11 & 43.8 & 26 & 43.9 \\ 12 & 47.0 & 27 & 43.9 \\ 13 & 44.0 & 28 & 43.8 \\ 14 & 44.1 & 29 & 43.9 \\ 15 & 43.9 & 30 & 43.9\end{array}$

Statistical Analysis of Data

$$
\begin{aligned}
& \bar{x}=43.89 \\
& \Sigma(x-\bar{x})^{2}=0.279 \\
& \sigma=\sqrt{\frac{1}{N-1} \sum(x-\bar{x})^{2}}=0.098 \\
& \text { or } \quad \sigma= \pm \frac{0.098}{43.89} \times 100= \pm 0.22 \%
\end{aligned}
$$


weight per dosimeter (i.e., $43.7 \mathrm{mg}$ ) the slightly higher experimental value obtained herein represented only a few additional grains of phosphor per dosimeter and any radiation dose measurement error introduced thereby is insignificant.

\section{B. 4 EXPER IMENTAL PROCEDURES*}

The radiation dose rates from thulium-170 sources through lead, stainless steel, tungsten, aluminum and depleted uranium absorbers were determined by measurement of the luminescence of lithium fluoride phosphors in a TLD readout instrument. The energy imparted to this material as a result of interactions with incident radiation is released as luminescence at elevated temperatures. The particular dosimeter used for these measurements consisted of precise quantities of LiF powder metered into special holders. Three thulium-170 sources in strengths of 5,10 and 20.7 thermal watts were utilized. Three different thicknesses ( $\frac{1}{4}, \frac{1}{2}$ and 1 inch) of each shield material (lead, tungsten, stainless steel, aluminum and depleted uranium) were used. The dose rate measurements were made at 19 and $100 \mathrm{~cm}$ from the source. Each measurement utilized five separate dosimeters in accordance with the matrix outlined in Table B-6. The use of five separate TLD dosimeters for each measurement assured high reliability of test results.

After exposure, the thermoluminescent dosimeters were read by placing them in a specially designed heating device which raised them to a specified temperature at which light is emitted proportional to the amount of radiation absorbed by the dosimeter. This light emission is detected by a photomultiplier tube, the integrated output

\footnotetext{
*A complete test procedure: (SNP100017) may be found in SNC-3693-5, Part III "Test Procedures for $\mathrm{Tm}_{2} \mathrm{O}_{3}$ Material Properties Study"(36)
} 
TABLE B-6

DOSE RATE MEASUREMENT MATRIX

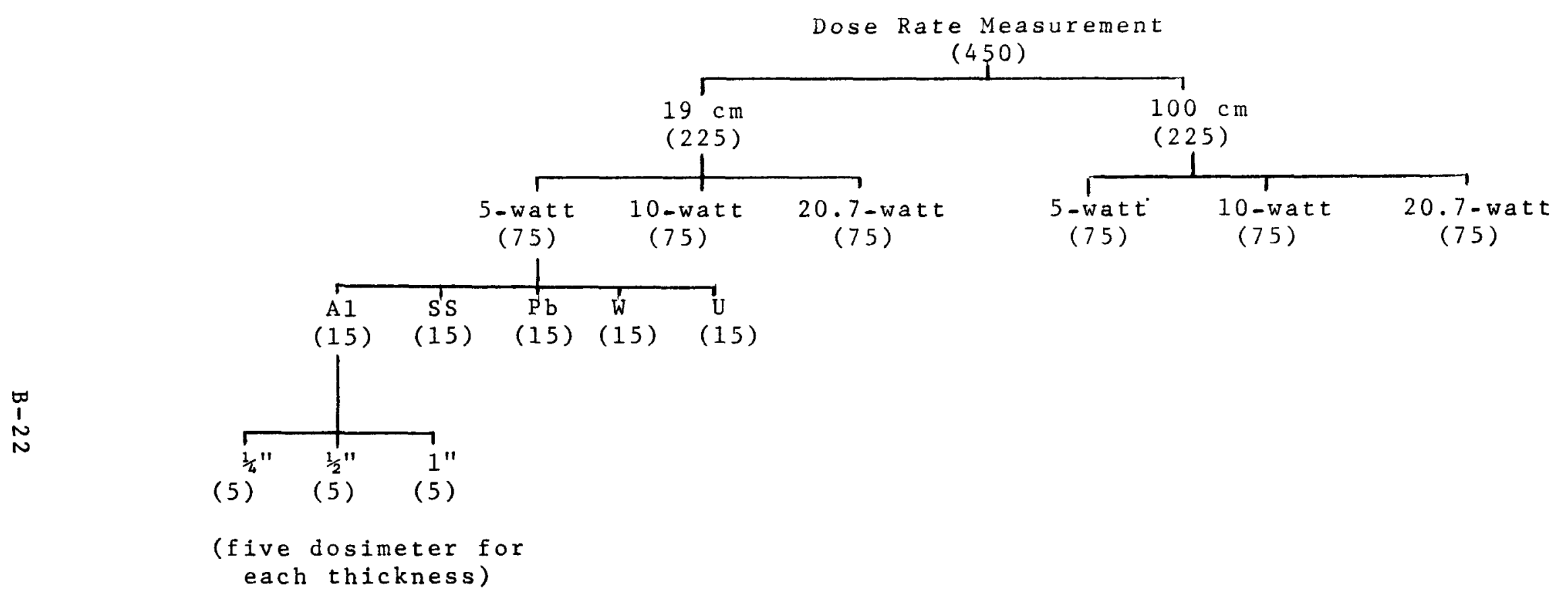




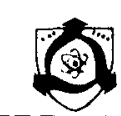

current of which is electronically converted into a dose reading. B.4.1 PROCEDURES PRIOR TO MEASUREMENTS

Each of the various absorbers to be used in the measurements was visually inspected for cleanliness, freedom from surface defects and blemishes. These absorbers were then arranged in special trays (equipped with hinged covers capable of being opened and closed with the hot cell remote manipulators) which were placed next to the measurement fixture inside the hot cell.

Each dosimeter to be used in the measurement experiment was visually inspected for.cleanliness, freedom from surface defects and blemishes. These dosimeters were also arranged in special trays (equipped with opaque covers) in groups of eight dosimeters per tray. Three of these trays (24 dosimeters, total) were placed within easy reach of the remote manipulators for each dosimeter exposure sequence with a particular absorber material. In addition, the dosimeters were located as far as practicable from the stored radiation sources and were protected by sufficient auxiliary radiation shielding that they received minimal spurious radiation exposure during source transfer operations and during purposeful source exposure procedures.

The TLD dosimeter reader was calibrated against a vendorsupplied standard. This calibration was repeated at appropriate intervals throughout the performance of measurements.

B.4.2 DOSE RATE MEASUREMENT PROCEDURES

a. The first radiation source to be measured was removed from its storage cask and transferred into the uncovered shield enclosure, the beam-hole shutter of which was closed. The shield enclosure cover was then replaced.

b. The particular thickness of absorber to be utilized was removed from its storage tray and positioned in its special holder in front of the beam-hole shutter. 
c. The first tray of dosimeters to be exposed was opened and each dosimeter was individually subjected to the following procedures:

- each dosimeter was placed in position in the dosimeter holder, the dosimeter holder was then positioned in the configuration being measured.

- the shutter in front of the radiation beam-hole was opened for a predetermined length of time.

- the shutter was closed and the dosimeters were removed from their holder; the dosimeters were replaced into their original positions in the tray. (At a11 times the tray was positioned and shielded such as to minimize nonintentional exposure of dosimeters).

d. Succeeding trays of dosimeters were opened and the sequence repeated for the successive absorber thickness until the transmitted radiation had been monitored with five dosimeters at each thickness for a total of 15 exposure readings.

e. The radiation source was replaced into storage and the exposed dosimeters were removed from the hot cell. Additional dosimeters required for the next exposure were brought in.

f. The source was returned to the shield enclosure and the first thickness of the next absorber material placed into the special holder. The complete exposure sequence of steps $c$. and d. was repeated for a total of 15 exposures, after which the procedure of step e. was repeated.

g. The sequence described in step $f$. was repeated for the remaining abosrber materials, resulting in a total of 75 exposures for the five absorber materials.

h. Steps c. through f. were repeated for the remaining two sources for a total of 225 exposures. 


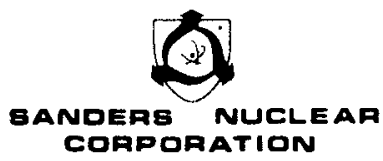

i. Having completed the procedures of steps c. through h. for each of the three thulium oxide sources and for all absorber specimens, these procedures were then repeated for each of the remaining geometrical configurations for a total of 450 exposures.

j. The exposed dosimeters were inserted into the TLD reader and their absorbed doses measured. Three readings were made for each exposed dosimeter. The resulting data were recorded on data sheets.

k. These dosimeters were annealed after reading to eliminate any thermoluminescence remaining after the irradiation and readout process. For loose LiF powder, this consists of heating it to $400^{\circ} \mathrm{C}$ for one hour, followed by exposure at $80^{\circ} \mathrm{C}$ for 24 hours. 


\section{B. 5 EXPERIMENTAL DATA REDUCTION}

The data obtained by experiment were statistically analyzed $(22-25)$ to yield a single representative value of absorbed dose from readings of each dosimeter. Comparison of this value of integrated dose with the exposure time in each case will yield the dose rate at a given separation distance due to a known strength of thulium-170 with a known thickness of absorber material.

To illustrate the procedures of experimental data analyses, the following example is presented:

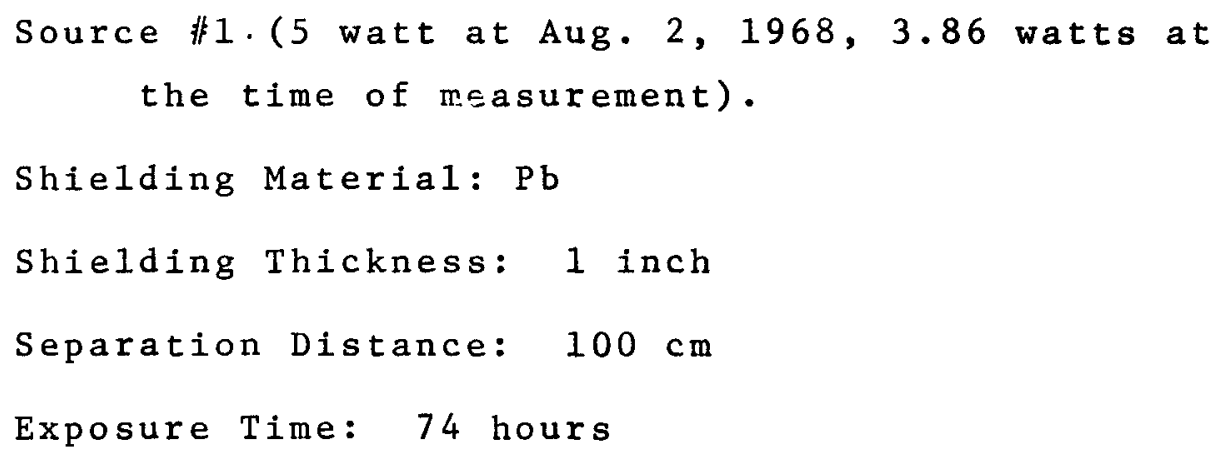

The dose measurements obtained for the above case and the statistical analyses of these data are shown in Table B-7.

The total dose is $9901 \mathrm{mRad}$ (sum of $\mathrm{X}$ observed dose, 1-15).

The arithematical average is: $\bar{x}=\frac{9901}{15}=660.06$

The sum of the square of the deviations is 6237.68. Therefore, one standard deviation is $\sigma=\sqrt{\frac{6237.68}{15-1}}=21.11$.

From the standard deviation, the standard error can be obtained as follows:

$$
\sigma_{\overline{\mathrm{x}}}=\frac{21.11}{\sqrt{15}}=5.45
$$

The probable error then, is

$$
r_{\bar{X}}=0.6745 \times 5.45=3.67
$$

Applying the Chi-square test:

$$
x^{2}=\frac{6237.68}{660.06}=9.45
$$


TABLE B-7

STATISTICAL ANALYSES OF MEASURED DOSE RATES

Observation

Number

$$
1
$$$$
2
$$

3

4

5

6

7

8

9

10

11

12

13

14

15

TOTAL

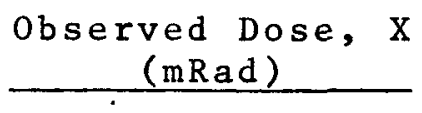

632

628

645

634

640

638

686

676

667

688

666

665

690

672

674

9901 $\underline{x-\bar{x}}$

28.06

32.06

15.06

16.06

20.06

22.06

25.94

15.94

6.94

27.94

5.94

4.94

29.94

11.94

13.94

$$
\begin{array}{r}
(x-\bar{x})^{2} \\
787.36 \\
1027.84 \\
226.80 \\
257.92 \\
402.40 \\
486.64 \\
672.88 \\
254.08 \\
48.16 \\
780.64 \\
35.28 \\
24.40 \\
896.40 \\
142.56 \\
194.32 \\
\hline
\end{array}
$$

6237.68 


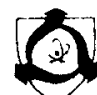

BANDERB NUCLEAR

CORPORATION

The number of degrees of freedom is:

$$
F=15-1=14
$$

Therefore, the probability $P$ from the tables $(26-27)$ is:

$$
P=0.8
$$

With this probability value, we conclude that the distribution follows Poisson distribution.

The analyzed results are as follows:

$\begin{array}{lll}\text { Measured dose } & = & 660.06 \pm 3.67 \mathrm{mRad} / 74 \mathrm{hours} \\ \text { Background } & = & 145.0 \pm 0.7 \mathrm{mRad} / 74 \text { hours } \\ \text { Net Dose } & = & 515.06 \pm 3.71 \mathrm{mRad} / 74 \mathrm{hours} \\ \text { Dose rate } & = & 6.96 \pm 0.05 \mathrm{mRad} / \mathrm{hr} \text { (at } \mathrm{time} \\ & & 0 \mathrm{measurement)} \\ \text { Normalized dose rate } & 9.16 \pm 0.06 \mathrm{mRad} / \mathrm{hr} \text { (August 2, } \\ & = & 1968) .\end{array}$

\section{B. 6 SUPPLEMENTARY MEASUREMENTS}

\section{B.6.1 HALF-LIFE DETERMINATION}

A half-life determination was made to show that the measurement system works properly by comparing the measured decay rate to the expected decay rate. The half-life of $\mathrm{Tm}-170$ is reported as 128 days. Any significant deviation from this expected decay rate would indicate some possible faults in the measurement technique.

Unshielded dose rates at $19 \mathrm{~cm}$ were taken at different time intervals. The results are shown in Table B-8. Note that the two decay rates are in good agreement within the experimental error $(\sim 10 \%)$. Figure $B-13$ shows the observed and expected decay rates for all three $\mathrm{Tm}-170$ sources.

\section{B.6.2 RATIO OF DOSE AT $19 \mathrm{CM}$ TO $100 \mathrm{CM}$ SEPARATION DISTANCES}

As discussed in Appendix C, paragraph C.4, the inverse square relationship used to extend doses at $19 \mathrm{~cm}$ separation distance to $100 \mathrm{~cm}$ only holds for the unshielded case. For the shielded case the deviation from inverse square depends on the shielding material 
TABLE B-8

UNSHIELDED DOSE RATES

$\frac{\text { Unshielded dose rates }(\mathrm{rad} / \mathrm{hr}) \text { at } 100 \mathrm{~cm}}{\text { Dec. 5, }}$

Power (watts) 20.7

10

5

measured
expected*
ratio

measured
2318

$-$

$-$

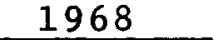

5115

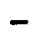

$-$

3677
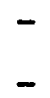

\section{8}

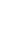

1968

3670

3459

1.06

2640

2434

1.08

1665

1566

1.06

61 days

0.7185

0.6585

3365

3063

1.1

2420

2148

1.12

1525

1448

1.05
1968

Time from September 27, 1968 -

decay correction factor

\begin{abstract}
77 days
\end{abstract}
0.7185

*Expected dose rate $=\frac{\text { measure dose rate at September 27, } 1968}{\text { decay correction factor }}$ 


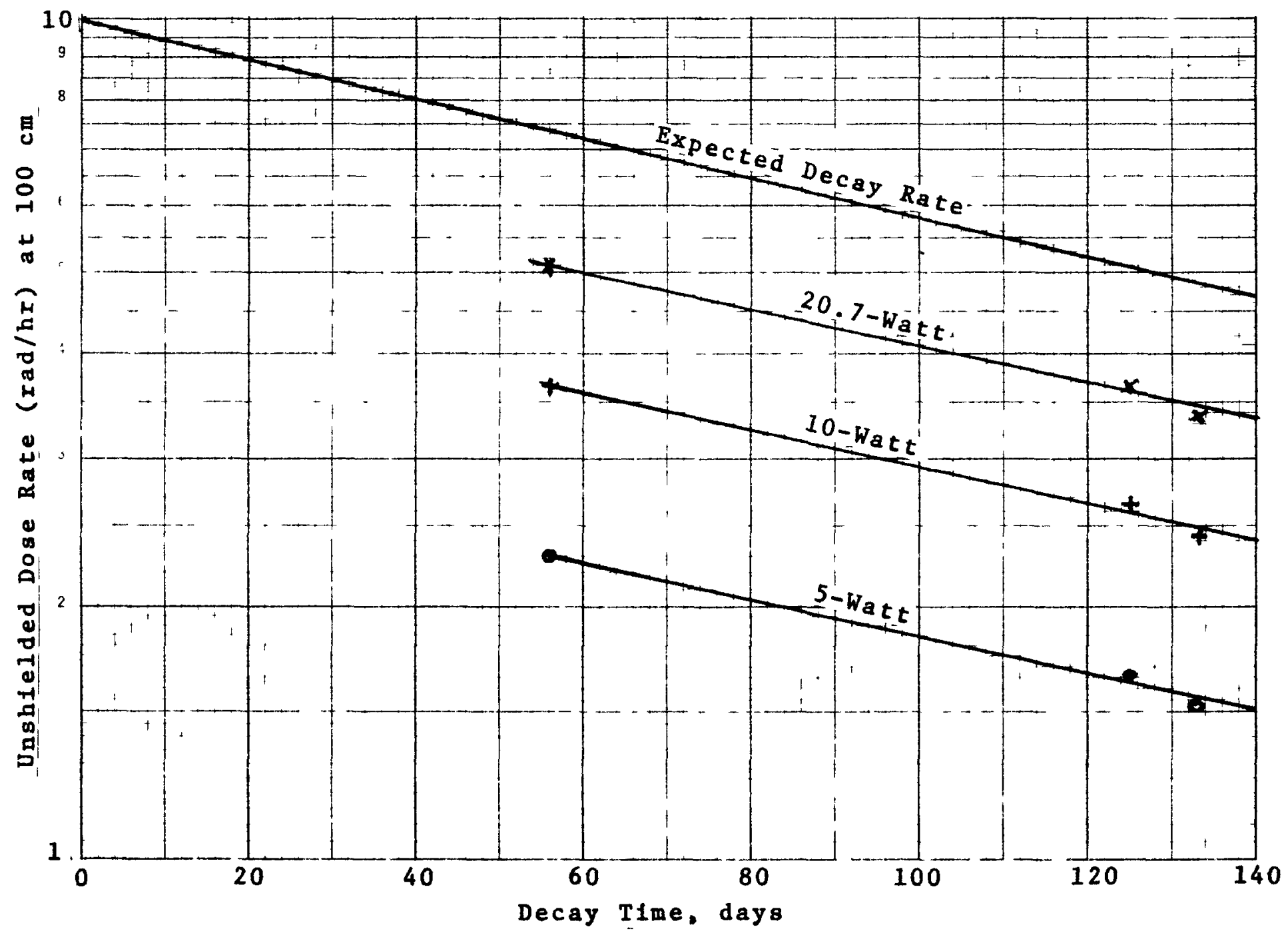


and its thickness. To extend the results from $19 \mathrm{~cm}$ separation distance to $100 \mathrm{~cm}$ experimental ratios must be used.

To obtain the experimental ratio, another dosimeter capsule holder was fabricated to permit simultaneous exposures at both $19 \mathrm{~cm}$ and $100 \mathrm{~cm}$ dose points, the 20.7-watt source (initial strength) was used as the radiation source.

Table B-9 shows the experimental ratios obtained for various materials at different thickness. These results were also plotted in Figure $B-14$. Note that for 1 inch absorbers of $W$ and $U$, the ratios were obtained from Figure B-14 by extrapolation.

\section{B.6.3 DOSE RATE FROM DEPLETED URANIUM ABSORBER}

Uranium - 238 is a naturally occuring alpha emitter. It is the first member of uranium series decay chain. This decay series is shown below:

${ }^{238} \mathrm{U} \underset{4.5 \times 10^{9} \mathrm{yr}}{\longrightarrow}{ }^{234} \mathrm{Th} \frac{\beta}{24 \mathrm{day}}>{ }^{234} \mathrm{~Pa} \frac{\beta}{2 \mathrm{~min}}^{234 \mathrm{U}}$

$\underset{2.5 \times 10^{5} \mathrm{yr}}{\longrightarrow}{ }^{230} \mathrm{Th} \underset{\frac{\alpha}{8 \times 10^{4} \mathrm{yr}}}{\longrightarrow} 10$ more decays to stable ${ }^{206} \mathrm{~Pb}$.

Therefore, ${ }^{234} \mathrm{~Pa}$ and ${ }^{234} \mathrm{Th}$ are in equilibrium with ${ }^{238} \mathrm{U}$, that is, the activity of ${ }^{234} \mathrm{~Pa}$ and ${ }^{234} \mathrm{Th}$ are approximately the same as the activity of ${ }^{238} \mathrm{U}$. The maximum beta energy of ${ }^{234} \mathrm{~Pa}$ and ${ }^{234} \mathrm{Th}$ are $2.29 \mathrm{Mev}$ and $0.191 \mathrm{Mev}$, respectively. Alphas and weak gammas are also present.

When a thermoluminescent dosimeter is placed near a uranium absorber in ${ }^{170} \mathrm{Tm}$ dose measurement, in addition to the dose received from ${ }^{170} \mathrm{Tm}$, it also records the dose from uranium absorber. To obtain true dose from ${ }^{170} \mathrm{Tm}$ source, this additional dose contributed by uranium absorber must be subtracted from the total dose.

Measurements were performed to determine the uranium dose rates. Survey meter was used to measure both gamma and beta dose rates at 1 inch from the surface of the uranium absorbers ( $\frac{1}{4}$, $\frac{1}{2}$ and 
TABLE $\quad B-9$

EXPERIMENTAL RATIO - (D) $100 \mathrm{CM}^{/(D)} 19 \mathrm{CM}$

A1

S S

$\mathrm{Pb}$

W

U

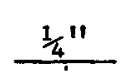

$3.44 \times 10^{-2}$

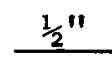

$3.35 \times 10^{-2}$

$3.17 \times 10^{-2}$

$3.02 \times 10^{-2}$

$3.12 \times 10^{-2}$

$2.88 \times 10^{-2}$

$2.9 \times 10^{-2}$

$2.66 \times 10^{-2}$

$2.72 \times 10^{-2}$
$3 \times 10^{-2}$

$2.74 \times 10^{-2}$

$2.6 \times 10^{-2}$

$2.37 \times 10^{-2}$

$2.25 \times 10^{-2}$ 


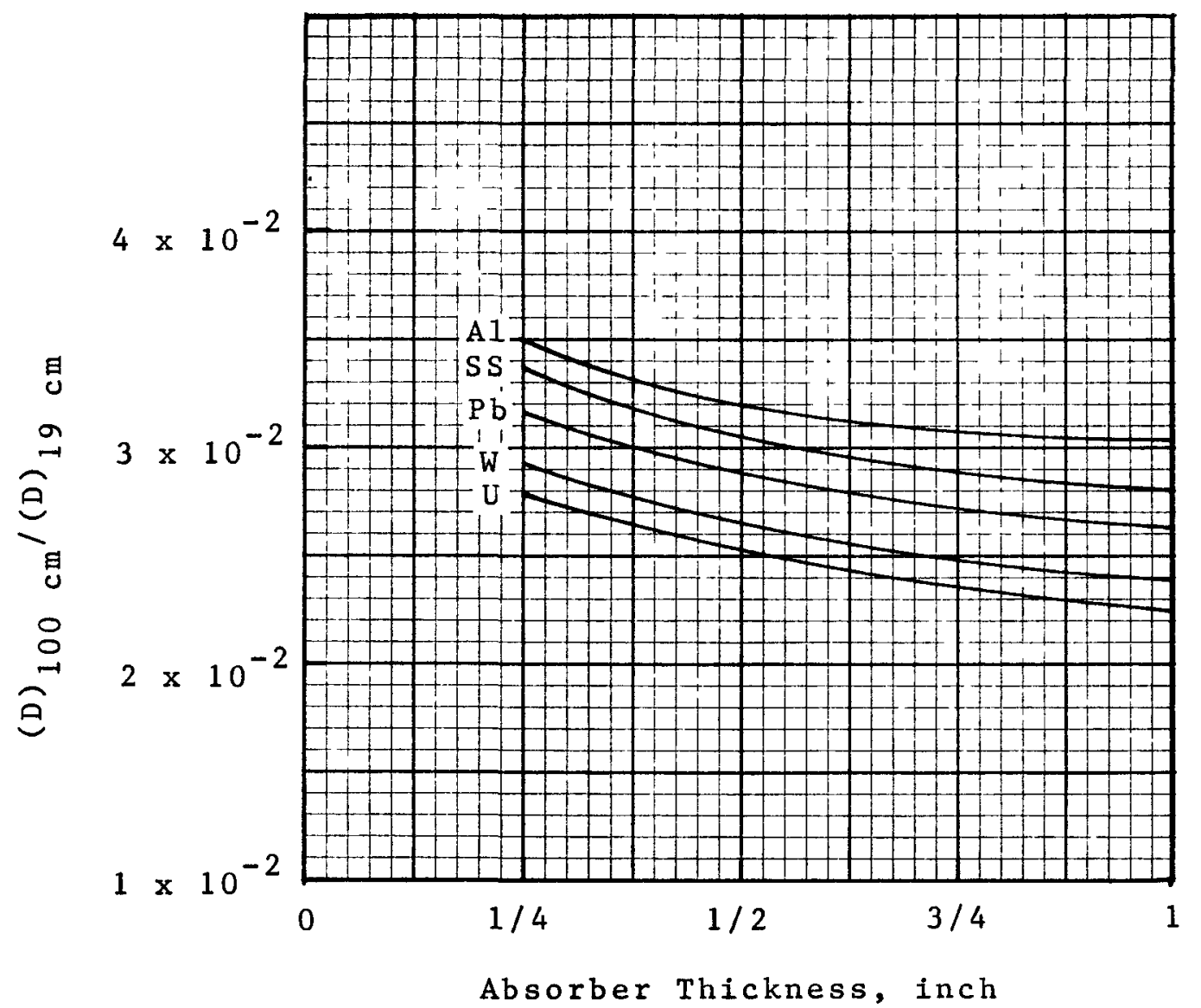

Figure B-14. Experimental Ratio (D) $100 \mathrm{CM}^{/(D)} 19 \mathrm{cM}$ 
1 inch). All three measurements gave the same dose rates $-45 \mathrm{mrad} / \mathrm{hr}$ at 1 inch. This is expected because almost all of the dose was delivered by beta radiation. The maximum range of 1 Mev beta is approximately $0.25 \mathrm{~mm}$ in uranium. Thus, al1 of the dose was produced iy the betas at the surface of the uranium absorber, i.e., the dose rates are independent of the thickness of the absorber.

Table B-10 shows the calculation of uranium dose rates corresponding to the geometry of Tm-170 experiment. The summary data tabulations for depleted uranium (as presented in Appendix A) have been corrected using these results. Note that the corrections are only made for $19 \mathrm{~cm}$ geometry. The uranium background for $100 \mathrm{~cm}$ geometry is so small that a correction is not necessary. 
TABLE $B-10$

DOSE RATES FOR DEPLETED URANIUM ABSORBERS
Thickness of $\mathrm{U}$ Absorber (inches)

$\frac{1}{4}$

$\frac{1}{2}$

1
Distance Between Surface of $U$ to Dosimeter (inches)

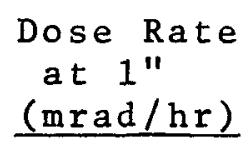

Dose Rate at $1^{\prime \prime}$

(mrad/hr)

45

45

45
1. 075
0.95
0.7

Dose Rate at Dosimeter $(\mathrm{mrad} / \mathrm{hr})$

39

50

92 
gANDERS NUCLEAR -operation

APPENDIX C

ANALYTICAL TECHNIQUES, PROCEDURES AND RESULTS

$c-1$ 


\section{1 UNCOLLIDED DOSE RATE EQUATIONS}

C.1.1 DOSE RATES AND GAMMA FLUXES

The gamma dose rate in tissue can be determined if one knows the gamma flux at the point of interest. For a shielded radiation source, the gamma flux consists of two components: uncollided and scattered. The first component can be readily evaluated by using the exponential attenuation through source medium and shield material. The attenuation through source medium is called selfattenuation. The scattered component requires sophisticated and lengthy computations. In this section, only the uncollided portion is treated. The scattered portion is discussed in paragraph C.5.

For a multigroup gamma spectrum, dose rates are calculated for each gamma energy group and then summed over all the energy groups to obtain the total gamma dose rate. Since 22 energy groups have been used for $\mathrm{Tm}-170$ (see Table C-1), 22 separate dose rate calculations are required.

The uncollided dose rate in tissue from gamma rays of initial energy $E_{0}$ can be calculated from uncollided gamma flux by the following equation ${ }^{(8)}$ :

$$
D_{\text {unc. }}\left(\mathrm{E}_{\mathrm{o}}\right)=5.767 \times 10^{-2}(\mu \mathrm{a} / \rho)_{\text {tissue }} \mathrm{E}_{\mathrm{o}} \emptyset\left(\mathrm{E}_{\mathrm{o}}\right)
$$

where $D_{\text {unc. }}\left(E_{0}\right)=$ uncollided dose rate, mrads/hr

$$
\begin{aligned}
& \left(\mu_{a} / \rho\right)_{\text {tissue }}=\text { energy absorption mass attenuation } \\
& \text { coefficient for tissue, } \mathrm{cm}^{2} / \mathrm{gm} \\
& E_{0}=\text { initial photon energy, Mev } \\
& \emptyset^{0}\left(E_{0}\right)=\text { uncollided gamma flux, photons } / \mathrm{cm}^{2}-\mathrm{sec} \text {. }
\end{aligned}
$$

\section{C.1.2 EXACT EQUATION FOR COMPUTING UNCOLLIDED FLUX}

The configuration of source and the relationship between source, shield, and dose point are shown in Figure $C-1$. The source is assumed to be a right circular cylinder with diameter $R$ and height $h$. The dose point, $c$, is located on the axis of the cylinder at a distance, a, away from the surface of the source. The thickness 
TABLE $\quad \mathrm{C}-1$

GAMMA SPECTRUM OF $\operatorname{Tm}_{2} \mathrm{O}_{3}$ SOURCE

Types of

Radiation

Gamma

$x-r a y$

$x-r a y$

Bremsstrah1ung
Photon Energy

(Mev)

0.084

0.052

0.009

0.05

0.1

0.015

0.2

0.25

0.3

0.35

0.4

0.45

0.5

0.55

0.6

0.65

0.7

0.75

0.8

0.85

0.9

0.95
Photons per

Disintegration

$3.459 \times 10^{-2}$

$5.050 \times 10^{-2}$

$1.349 \times 10^{-1}$

$5.574 \times 10^{-2}$

$2.014 \times 10^{-2}$

$9.857 \times 10^{-3}$

$5.430 \times 10^{-3}$

$3.169 \times 10^{-3}$

$1.903 \times 10^{-3}$

$1.155 \times 10^{-3}$

$6.992 \times 10^{-4}$

$4.180 \times 10^{-4}$

$2.441 \times 10^{-4}$

$1.377 \times 10^{-4}$

$7.386 \times 10^{-5}$

$3.700 \times 10^{-5}$

$1.683 \times 10^{-5}$

$6.669 \times 10^{-6}$

$2.136 \times 10^{-6}$

$4.778 \times 10^{-7}$

$4.897 \times 10^{-8}$

$1.713 \times 10^{-10}$ 


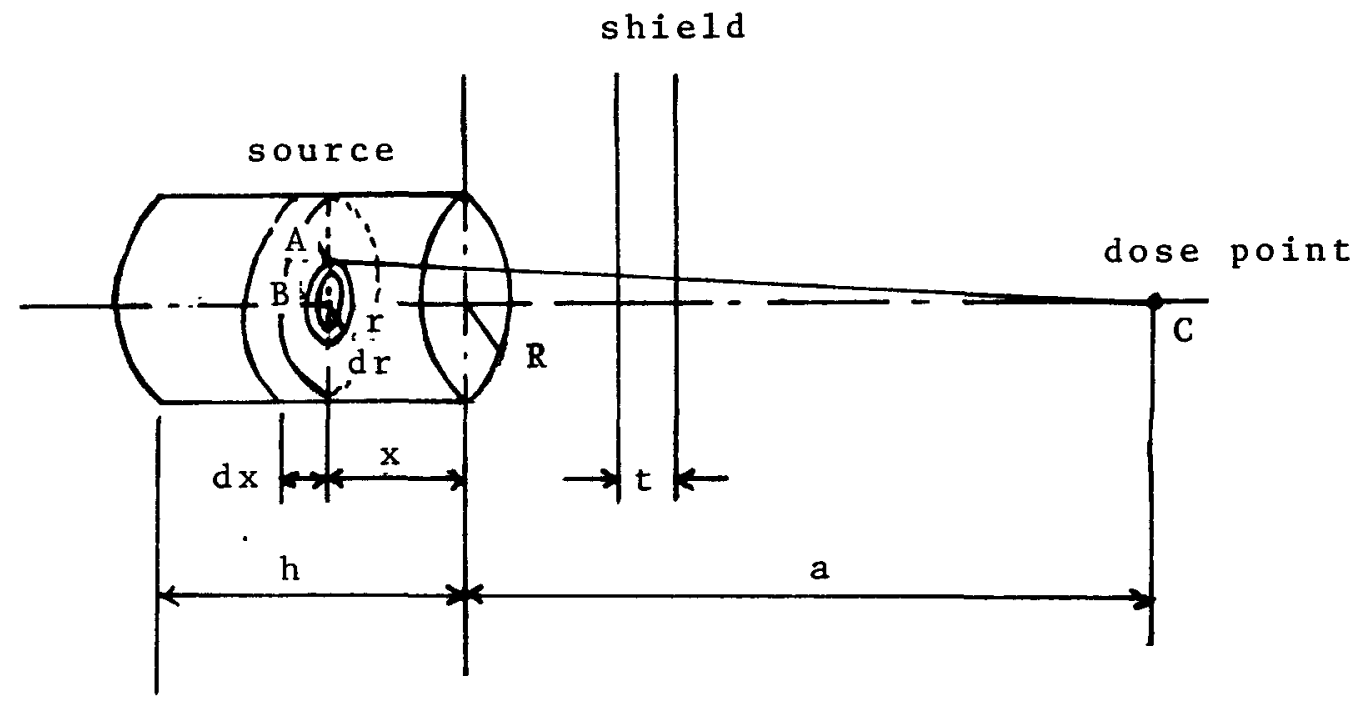

Figure C-1. Spatial Relationships Between Source, Shield and Dose Point

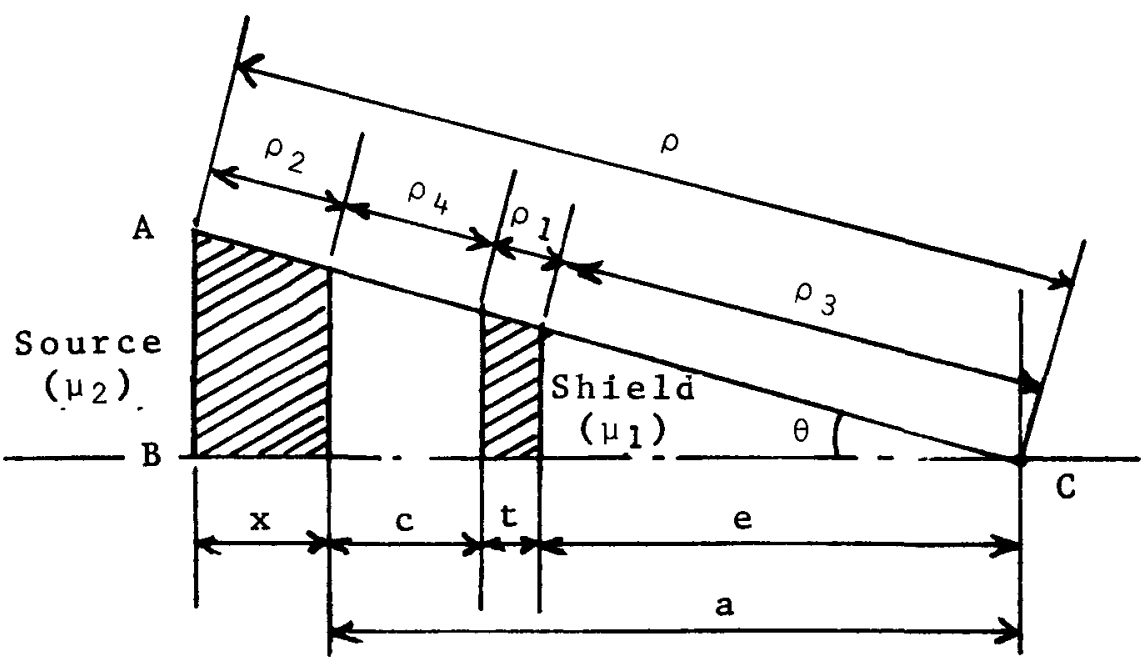

Figure C-2. Attenuation Distances for Self-Absorption and Shielding Materials 
of shield material is t. $\mu_{1}, \mu_{2}$ and $\mu_{3}$ are linear absorption coefficients of shield, source and air, respectively. Figure C-2 shows the triangle $A B C$.

Let $S_{v}=$ volumetric source strength, photons/cm ${ }^{3}-s e c$, the volume element is:

$$
d V=2 \quad r \pi d r d x
$$

the photon strength from the volume element is:

$$
d A=s_{v} 2 \pi r d r d x
$$

and the attenuation factor is equal to:

$$
\mathrm{e}^{-\mu_{1} \rho_{1}-\mu_{2} \rho_{2}-\mu_{3}\left(\rho_{3}+\rho_{4}\right)}
$$

Thus, at dose point $C$, the uncollided gamma flux due to the element volume source $d V$ through various attenuations is:

$$
\mathrm{d} \emptyset=\frac{\mathrm{S}_{\mathrm{v}} 2 \pi \mathrm{r} \mathrm{d} \mathrm{d} \mathrm{x}}{4 \pi \rho^{2}} \quad \mathrm{e}^{-\mu_{1} \rho_{1}-\mu_{2} \rho_{2}-\mu_{3}\left(\rho_{3}+\rho_{4}\right)}
$$

Upon integration, one obtains the total uncollided flux:

$$
\emptyset=\frac{\mathrm{S} v}{2} \int_{0}^{\mathrm{h}} \mathrm{dx} \int_{0}^{\mathrm{R}} \mathrm{dr} \frac{\mathrm{r}}{\rho_{2}} \mathrm{e}^{-\mu_{1}} \rho_{1}-\mu_{2} \rho_{2}-\mu_{3}\left(\rho_{3}+\rho_{4}\right)
$$

$\rho_{1}$, through $\rho_{4}$ can be readily obtained by inspection of Figure $\mathrm{c}-2$.

$$
\begin{aligned}
\cos \theta & =\frac{x+a}{\rho}=\frac{x+a}{\sqrt{(x+a)^{2}+r^{2}}} \\
& =\frac{1}{\sqrt{1+\frac{r^{2}}{(x+a)^{2}}}}=\frac{1}{L}
\end{aligned}
$$

where $L=\sqrt{1+\frac{r^{2}}{(x+a)^{2}}}$

$$
\text { then } \begin{aligned}
\rho_{1} & =\mathrm{t} \mathrm{L} \\
\rho_{2} & =\mathrm{x} \mathrm{L} \\
\rho_{3} & =\mathrm{e} \mathrm{L} \\
\rho_{4} & =\mathrm{cL} L
\end{aligned}
$$


Substitute all the $\rho^{\prime} s$ into equation $(C-3)$. The uncollided flux becomes:

$$
\begin{aligned}
& \emptyset=\frac{{ }_{\mathrm{v}}}{2} \int_{0}^{\mathrm{h}} \mathrm{dx} \int_{0}^{\mathrm{R}} \mathrm{dr} \frac{\mathrm{r}}{\mathrm{r}^{2}+(\mathrm{x}+\mathrm{a})^{2}} \\
& \operatorname{Exp}\left\{-\left[\mu_{1} \mathrm{t}+\mu_{2} \mathrm{x}+\mu_{3}(\mathrm{e}+\mathrm{c})\right] \mathrm{L}\right\} \\
& \text { where } \mathrm{L}=\sqrt{1+\frac{\mathrm{r}^{2}}{(\mathrm{x}+\mathrm{a})^{2}}}
\end{aligned}
$$

To evaluate the above expression, one requires double numerical integration which is more time consuming than the numerical integration with a single independent variable. In the Eollowing section, an expression is given that approximates the cesults that would be achieved if the exact equation (C-4) for ancollided flux were used. It is this approximate solution which is subsequently used to compute the uncollided dose rate, (see Squation $(-1)$.

\subsubsection{APPROXIMATE EQUATION FOR COMPUTING UNCOLLIDED FLUX}

The uncollided flux reaching $C$ from a truncated right:ircular cone source (as shown in Figure $C-3$ ) is given by the Eollowing equation(12).

$$
\begin{aligned}
\emptyset=\frac{s_{v}}{2 \mu_{s}} & {\left[E_{2}\left(b_{1}\right)-E_{2}\left(b_{3}\right)+\frac{E_{2}\left(b_{3} \sec \theta\right)}{\sec \theta}\right.} \\
& \left.-\frac{E_{2}\left(b_{1} \sec \theta\right)}{\sec \theta}\right]
\end{aligned}
$$

where $b_{1}=\sum_{i}^{n} \quad \mu_{i} t_{i}$

$\mathrm{b}_{3}=\mathrm{b}_{1}+u_{\mathrm{s}} \mathrm{h}$

$E_{2}(b)=b \quad \int_{b}^{\infty} \frac{e^{-t}}{t^{2}} d t$

$S_{V}=$ volumetric source strength, photons $/ \mathrm{cm}^{3}-\mathrm{sec}$

$\mu_{s}=1$ inear absorption coefficient of source material, $\mathrm{cm}^{-1}$. 


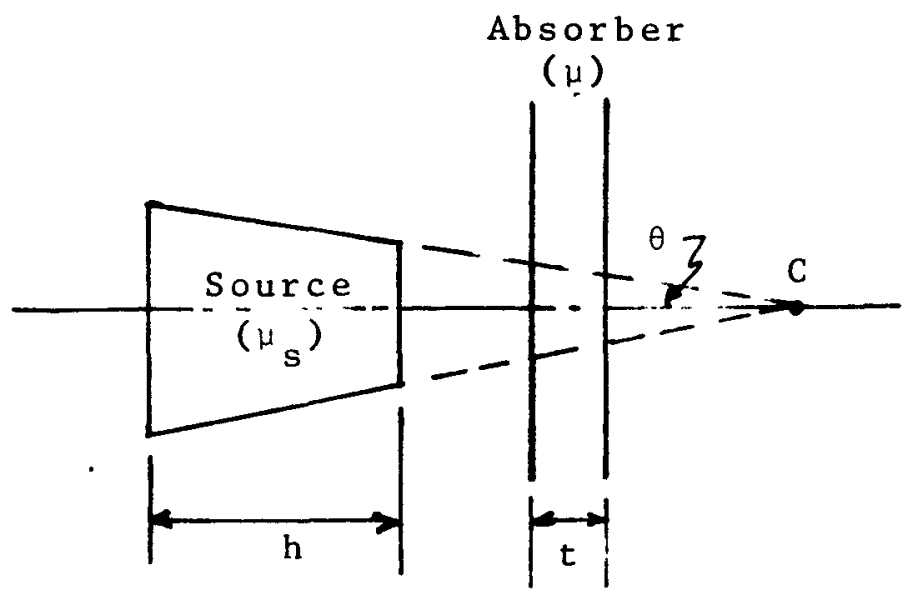

Figure C-3. Geometry For A Truncated Right-Circular Cone Source

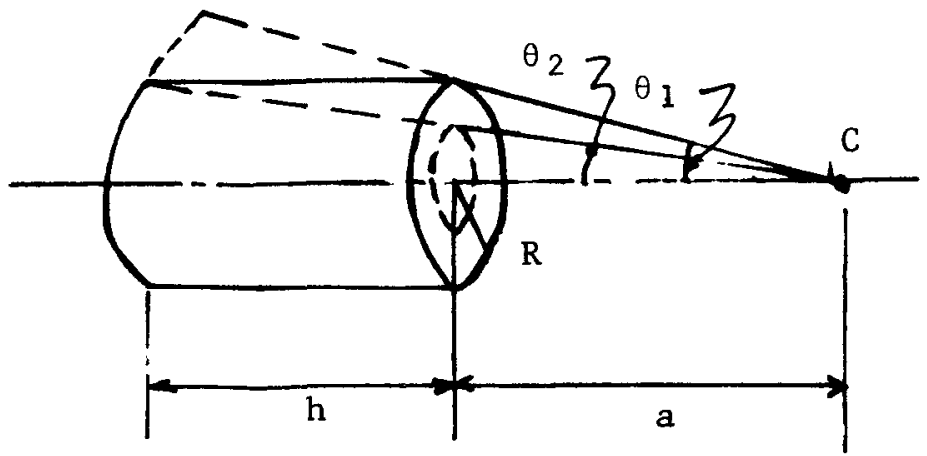

Figure C-4. Simulation of A Cylindrical Source By A Truncated Right-Circular Cone Source 
For a right-circular cylindrical source of radius $R$ and height $h$ (see Figure $C-4$ ), the uncoliided flux at point $c$ on the axis of the cylinder can be evaluated approximately by using equation $(\mathrm{C}-5)$. By replacing the cylinder with a truncated cone, the apex of which is at $C$, an upper limit can be obtained from equation $(C-5)$ with $\theta=\theta_{1}=\tan ^{-1}\left(\frac{R}{a}\right)$. A lower limit can be similarly obtained with $\theta=\theta_{2}=\tan ^{-I^{2}}\left(\frac{R}{a+h}\right)$. It is obvious that the upper 1imit overestimates while the lower limit underestimates the flux The degree of error involved depends on the geometry of the source and the distance between the source and the dose point. If $\theta_{1} \cong \theta_{2}$, one can use this approximation to obtain uncollided gamma flux without significant deviation from the true flux.

C.1.4 JUSTIFICATION FOR USE OF THE APPROXIMATION EQUATION

The source geometry tested favors the use of the approximate equation for determination of the uncollided flux because: (1) the source diameter is greater than the height of the source and (2) the separation distance between source and dose point is much larger than the dimensions of the source. These conditions assure $\theta_{1} \approx \theta_{2}$.

Spectfically, consider the case of the 20.7-watt source (see Appendix B, paragraph B.1, for a detail discussion on source geometry) with separation distance of $19 \mathrm{~cm}$, as shown in Figure $\mathrm{C}-5$. The angles for upper limit $\theta_{1}$, and lower limit $\theta_{2}$, can be evaluated as follows:

$$
\begin{aligned}
\tan \theta_{1} & =\frac{0.94}{19}=0.0495 \\
\tan \theta_{2} & =\frac{0.94}{19+1.016}=0.0470 \\
\text { and } \theta_{1} & =2^{\circ} 50^{\prime} \\
\theta_{2} & =2^{\circ} 41.5
\end{aligned}
$$

Since the only functions of $\theta$ involved in the approximate equation (see eq. $C-5$ ) are in the form of $\sec \theta$ and $E_{2}(b \sec \theta$ ) the deviation of the approximate solution from the true solution is small when $\sec \theta_{1} \cong \sec \theta_{2}$, and $E_{2}\left(b \sec \theta_{1}\right) \cong E_{2}\left(b \sec \theta_{2}\right)$ 
gandeas NuCleAR CORPORATION

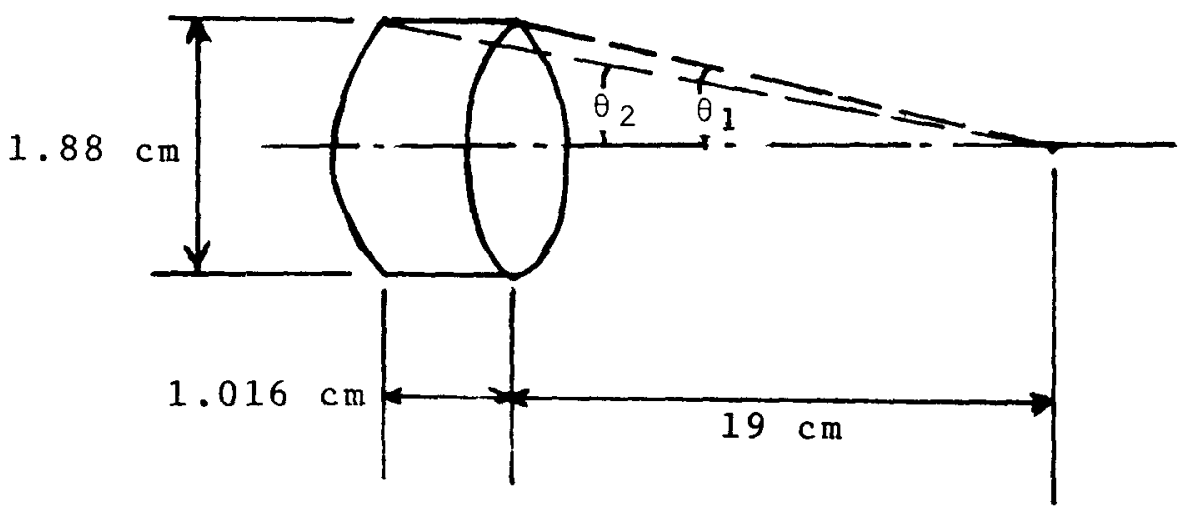

Figure C-5. Spatial Dimensions For The Source and Dose Point Geometry

$$
\text { C-9 }
$$


From mathematical tables:

$$
\begin{aligned}
& \sec \theta_{1}=1.0012 \\
& \sec \theta_{2}=1.0011
\end{aligned}
$$

Therefore, the argument of $E_{2}$ function only changes $0.01 \%$ which indicates that the change in $E_{2}$ function is also small.

The error involved will be smaller still for other sources (i.e., 10 watt and 5 watt) and for the $100 \mathrm{~cm}$ separation distance. Thus, it is concluded that the approximate equation can be used, with either $\theta_{1}$ or $\theta_{2}$ to obtain uncollided flux with negligible deviation from the true flux.. $\theta_{1}$ is selected and is used throughout this report.

\section{2 COMPUTER CODE DEVELOPMENT}

The basic equations for the uncollided dose rate calculation has been developed in the previous paragraph. Equations (C-5) and (c-1) give the gamma flux and the uncollided dose rate, respectively.

FORTRAN was used to develop a computer code for evaluating the set of equations. For each photon energy group (total of 22 groups), dose rates were calculated each for 5 different materials ( $A 1, \mathrm{SS}, \mathrm{Pb}, \mathrm{W}, \mathrm{U})$, at the thicknesses ( $\frac{1}{4}, \frac{1}{2}$ and 1 inch), for three source strengths $(5,10,20$ watts $)$. The dose rates obtained at 20 watts were corrected to dose rates at 20.7 watts (see paragraph C.6).

To calculate the $\mathrm{E}_{2}$ function, a subroutine was obtained (28) to first evaluate $E_{1} ; E_{2}$ was then obtained from the following equation ${ }^{(29)}$ :

$$
E_{2}(b)=\operatorname{EXP}(b)-b E_{1} \text { (b) }
$$

$19 \mathrm{~cm}$ was used as the-source-to-dose point separation distance in the computation. The dose rates at $100 \mathrm{~cm}$ separation distance were not evaluated by the above program due to the extremely small angle $\left(\theta=0^{\circ} 32^{\prime}\right.$, sec $\left.\theta=1.00004\right)$ involved. By considering the terms:

$$
E_{2}(b)-\frac{E_{2}(b \sec \theta)}{\sec \theta}
$$


in equation $(C-5)$ and the nature of the subroutine for the $E_{2}$ function, i.e., terms like $0.010416662 \mathrm{x}$ b Sec $\theta$, and if $\sec \theta$ is very sma11, one observes immediately the difficulties involved to subtract two very close numbers. The truncation error from the finite digits carried in the computer will be significant if $b \sec \theta$ is very small. This is indeed what would happen were the uncollided dose rate for $100 \mathrm{~cm}$ separation distance to be calculated by the program used to perform the calculation at $19 \mathrm{~cm}$ for the specific dose point/source geometry under consideration.

To obtain the uncolidided dose rates at $100 \mathrm{~cm}, \mathrm{a} 1 / \mathrm{r}^{2}$ relationship between the values at $19 \mathrm{~cm}$ and $100 \mathrm{~cm}$ was used.

The main program and the subroutine for calculation of the uncollided dose rate at $19 \mathrm{~cm}$ is presented below.

\section{3 MAIN PROGRAM INPUT DATA \\ C.3.1 VOLUMETRIC SOURCE STRENGTH}

Source dimension (per wafer) =0.1" $\mathrm{x} 0.74 "$ diameter Volume per wafer $=\frac{\pi}{4}(0.74 \times 2.54)^{2} \times 0.254=0.705 \mathrm{~cm}^{3}$

Power per wafer $=5 \mathrm{~W}$

Activity/power $=445 \pm 22 \mathrm{ci} /$ watt (see Appendix B, paragraph B.1) No. of betas/wafer $=(5 \times 445)\left(3.7 \times 10^{10}\right)=8.233 \times 10^{13} \mathrm{~B} / \mathrm{sec}$ Photons per beta $=(\gamma / \beta)$ (see Table c-2)

$\mathrm{s}_{\mathrm{v}}=\left(\frac{\gamma}{\beta}\right) \frac{\# \text { of } \beta}{\text { volume }}=\left(\frac{\gamma}{\beta}\right) \frac{8.233 \times 10^{13}}{0.705}$

$=1.168 \times 10^{14}\left(\frac{\gamma}{\beta}\right)$ photons $/ \mathrm{cm}^{3}-\mathrm{sec}$.

Note that the error involved in source strength is about $\pm 5 \%$.

\section{C.3.2 PHOTON SPECTRUM}

The total photon spectrum, i.e., gamma, x-ray, and bremstrahlung, is presented in Table $\mathrm{C}-2$.

\section{3.3 LINEAR ABSORPTION COEFFICIENTS}

The absorption coefficients (without coherence) for shielding 
$1 /$

OPEN(3, INPUT, /DATA/)

OPEN(4: INPUT:/DTAA/)

DIMENSION AMUS $(3 \notin), G M A(3)$, AMIJA $(3), E(3 *), S V(3 \bullet), C(3 n)$

DIMENSION $A(3 \backsim), B(3 \cap), D(3 \cap n), D R(3 \cap n), E N C(3), A M U(3 *)$

\section{TYPE 1 A}

10 FOKMAT $(/ / / / / \$ T M-17$ DOSE FATE CALCULATIONS $\$ / / /)$

95* FOKMAT $(/ / \$$ SHIEI.DING MATERIAL.S: $1=A L, 2=S S, 3=P B, 4=w, 5=U \$ / /)$ ASEC $=$ SQRT $(1 .+(.94 / 1.9 .38) * * ?)$

READ 3, 11\%,(E(L), GMA (1.), AMUS(1.), AMUA(L.), ENC (L),L=1,22)

11. FORMAT $(1 F, 1 E, 3 F)$

DO ? $L=1,23$

$S V(1)=\operatorname{SMA}(1) * .1.168 \mathrm{E}_{1} 14$

2. CONTINUE.

$C(1)=.A M I J A(1) * E.(1) * .5.767 E_{-}-$?

กก $2.4,1, J=1,5$

REAT 4, $115,($ AMIJ (1.) $, 1 .=1,2.4)$

115 FOFMAT (RF)

117 FOAMAT' 117

22\% TYPE 2?" JUJ

$A H=.1 \geqslant 7$

DO $16 \quad J=1,3$

$A H=\dot{A H}$ ? .

TYFE $12 \%, A H$

12. FOFMAT $(\$$ SOIJRCE THICKNESS $=\$, F 6.4)$

DO 2?. $1.1=1,4$

$31 \quad A L=1.1$.

$\mathrm{T}=.6 .35 * \mathrm{Al}$.

TYPE 125.T

125 FOEMAT $(/ / \$$ SHIELD THICKNESS $=\$, F 6.4 / /)$

DO $8 \quad I=1,22$

$A(I)=A M U(I) * I+E N C(I)$

$A(I+2,2)=A(I)+A M I J S(I) * A H$

$A(I+44)=A(I) * A S E C$

8 CONTINUE

DO $1 ? M=1,88$

AJJG $=A(M)$

CALL EXPI (RES, AUS, IER)

12

$B(M)=E \times P(-A \cup G)-R E S * A I G$

CONTINIJE 
$D F(\omega)=0$

D) $14 \quad K=1,2 ?$

$D(K)=C(K) *(S V(K) /(? . * A \operatorname{MisS}(K))) *(B(K)-B(K+? ?)+(B(K+66)$

$+\quad-B(K+A 4)) / A S E C)$

TYPE $13 r, D(K)$

1.3. FOFMAT $(15(2 \times, F \mid 2.5))$

$D K(K)=D R(K-1)+D(K)$

14 CONTINUE

TYPF $14, \operatorname{DR}(2 ?)$

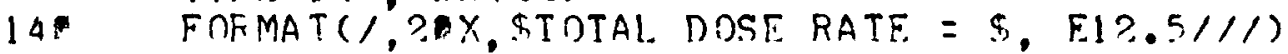

2? CONTINUE.

16 CONTINUF

24 CONTINIJE

END

SUBR OUTI INE EXPI (RES, X, IER)

$I E F=$

IF $(X-4) 10,.1 \%, 2 \%$

If IF $(X+4) 55: 3:$.

3. IF $(X) 4 *, 5 \%, 4$

4. KES $=-A 1.0 G(A B S(X))-c(c(c(c(c(c(c .103176 * 2 E-11 * x-.15798675 E-1 *)$

$+$ $* X+.168 ? 6592 . \mathrm{E}-?) * X-.21 .915699 \mathrm{E}-8) * X+.2763583 * \mathrm{E}-7) * X-.3726221$

$E-6) * X+.3 * 9.96(4 * E-5) * X-.2833759(E-4) * X+.23148392 E-3) * X-$

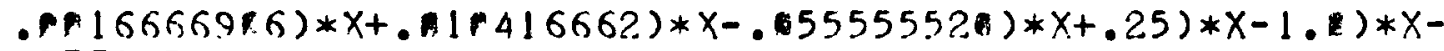
.57721566

F.E.TUFiN

2. $\quad A F G=4 \cdot / X$

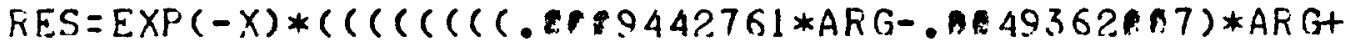

$+$ . 11723272$) * A F G-.017555779) * A F G+.02$ 412.99)*ARG-

$+\quad .22 .95(279) * A R G+.0312 .3561) * A R G-.02498588$ )*ARG+

$+\quad .249999 .997) * A R G_{3}$

RETUKN

5. KES $=1 . E 75$

RETIJK N

55 IEK $=1$

RETURN

END 
TABLE $\quad \mathrm{C}-2$

GAMMA SPECTRUM AND LINEAR ABSORPTION COEFFICIENTS

\begin{tabular}{lll}
$\begin{array}{l}\text { Photon } \\
\text { Energy } \\
\text { (Mev) }\end{array}$ & \multicolumn{2}{c}{$\begin{array}{l}\text { Perotons } \\
(\gamma / \beta)\end{array}$} \\
\cline { 1 - 2 } .084 & $3.459 \times 10^{-2}$ \\
.052 & $5.05 \times 10^{-2}$ \\
.009 & $1.349 \times 10^{-1}$ \\
.05 & $5.574 \times 10^{-2}$ \\
.1 & $2.014 \times 10^{-2}$ \\
.15 & $9.857 \times 10^{-3}$ \\
.2 & $5.43 \times 10^{-3}$ \\
.25 & $3.169 \times 10^{-3}$ \\
.3 & $1.903 \times 10^{-3}$ \\
.35 & $1.155 \times 10^{-3}$ \\
.4 & $6.992 \times 10^{-4}$ \\
.45 & $4.18 \times 10^{-4}$ \\
.5 & $2.441 \times 10^{-4}$ \\
.55 & $1.377 \times 10^{-4}$ \\
.6 & $7.386 \times 10^{-5}$ \\
.65 & 3.7 & $1.683 \times 10^{-5}$ \\
.7 & $6.669 \times 10^{-5}$ \\
.75 & $2.136 \times 10^{-6}$ \\
.95 & $4.778 \times 10^{-7}$ \\
.95 & $1.713 \times 10^{-10}$
\end{tabular}

Linear Absorption Coefficients $\left(\mathrm{cm}^{-1}\right)$

Source

$\mathrm{Tm}_{2} \mathrm{O}_{3}$

56

40

100

42.6

32.2

11.0

5.39

3.25

2.22

1.65

1.31

1.1

.935

.82

.752

.695

.642

.6

.566

.54

.513

.49
Encapsulation

Tissue

.025

6.53

.041

21.7

6.

1950

.0409

21.7

.0252

3.98

.0276

1.97

.0297

1.4

.031

1.13

.0317

1.03

.032

.94

.0325

.87

.0325

.804

.0327

.775

.733

.708

.68

.652

.625

.614

.59

.572

.554 
materials ( $A 1, \mathrm{SS}, \mathrm{Pb}, \mathrm{W}, \mathrm{U}$ ) are obtained form NBS Circular 583(3,5). These coefficients are tabulated in Table $\mathrm{C}-3$.

The coefficients for tissue are obtained from NBS Handbook $85^{(13)}$. For the source material, $\mathrm{Tm}_{2} \mathrm{O}_{3}$, the absorption coefficients are obtained by the following equation:

$$
\text { ( } \mu)_{\operatorname{Tm}_{2} o_{3}}=\frac{2 \mathrm{~A}(\mathrm{Tm}) \frac{\frac{\mu_{0}}{\rho}}{\rho}(\mathrm{Tm})+3 \mathrm{~A}(0)^{\frac{\mu}{\rho}}(0)}{2 \mathrm{~A}(\mathrm{Tm})+3 \mathrm{~A}(0)} \rho\left(\mathrm{Tm}_{2} 0_{3}\right) \quad(\mathrm{C}-7)
$$

The density of $\mathrm{Tm}_{2} \mathrm{O}_{3}$ was assumed to be $8.6 \mathrm{gm} / \mathrm{cm}^{3}$ (8). The values for tissue and $\mathrm{Tm}_{2} \mathrm{O}_{3}$ are given in Table $\mathrm{C}-2$.

Hastelloy $C$ is used for encapsulation materials. There are two layers of encapsulation with 0.05 inch thickness for each layer. The density of Hastelloy $\mathrm{C}$ is $8.94 \mathrm{gm} / \mathrm{cm}^{3}$ (30). The absorption coefficients for Hastelloy $C$ are taken from the coefficients of nickel (4) (see Table C-2) because Hastelloy C is a nickel based a110y.

The attenuation in air is very small compared to that of the encapsulation and therefore, was not included in the computation.

The so called "tunnelling effect", that arises because of a discontinuous change in the coefficient at $K$ edge, has also been analyzed. The dominant energy groups for this shield calculation are somewhere between 0.15 to $0.5 \mathrm{Mev}$ for low $\mathrm{Z}$ materials and between 0.35 to $0.6 \mathrm{Mev}$ for high $\mathrm{Z}$ materials. For example, the $\mathrm{K}$ edge for stainless steel is about $0.007 \mathrm{Kev}$ and the corresponding mass attenuation coefficient is approximately $50^{(31)(32)}$. This value is much greater than the coefficient at $0.030 \mathrm{Mev}$, which is 8 . Therefore, the "tunnelling effect" would not be important in this calculation.

The uncertainty for mass attenuation coefficients is reported as :

$$
\begin{array}{rlrl}
0.1 \mathrm{Mev}<\mathrm{E} & <1 \mathrm{Mev} & \text { about } 3 \text { to } 5 \% \\
\mathrm{E} & <0.1 \mathrm{Mev} \text { about } 10 \%
\end{array}
$$


TABLE $\quad \mathrm{C}-3$

LINEAR ABSORPTION COEFFICIENTS FOR SHIELDING MATERIALS

Photon

Energy

(Mev)

.084

.052

.009

, 05

.1

.15

.2

.25

.3

.35

.4

.45

.5

.55

.6

.65

.7

.75

.8

.85

.9

.95

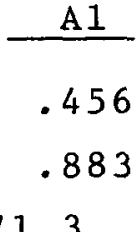

.883

.436

.363

.325

.298

.279

.263

.25

.237

.228

.22

.211

.203

.198

.191

.185

.180

.179

.171
Linear Absorption Coefficients $\left(\mathrm{cm}^{-1}\right)$

\begin{tabular}{rll}
\multicolumn{1}{c}{ SS } & & P B \\
\cline { 1 - 1 } 4.38 & & 13.61 \\
14.46 & & 58.8 \\
140 & & 908
\end{tabular}

58.85

60

20.86

10.16

6.384

4.037

3.016

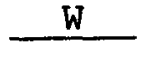

144.6

36.1

134

2113

1120

134

81.2

19.82

1.446

27.79

45.25

1.09

13.66

21.88

.964

8.685

14.21

.837

5.655

8.452

.774

2.359

4.246

6.265

.726

1.928

3.358

4.843

.687

1.644

2. 799

3.927

.654

2.413

3. 291

.632

1.44

2.123

2.899

.602

1.293

1.949

2.543

1.179

1.795

2.3

1.083

1.66

2.113

1.009

1.563

1.926

.525

.948

1.473

1.777

.51

.896

1.4

1.664

.498

1. 332

1.571

.482

1.28

1.487 
Since the photon spectrum for thulium-170 source consists mainly of low energy photons, the uncertainty for mass attenuation coefficients is taken as $5 \%$.

\section{4 UNCOLLIDED DOSE RATES}

The uncollided dose rates for $19 \mathrm{~cm}$ separation distance have been obtained from the computer with the input data presented in the last section. A typical output is given in Table C-4. Note that the sequence of photon energy for each dose rate group is the same as input data (see Table $\mathrm{C}-3$ ). Complete tabulation is not given here because these results are to be modified by a build-up factor as shown in paragraph C.6.

To obtain the uncollided dose rates at $100 \mathrm{~cm}$, a $1 / \mathrm{r}^{2}$ relationship can be used as follows:

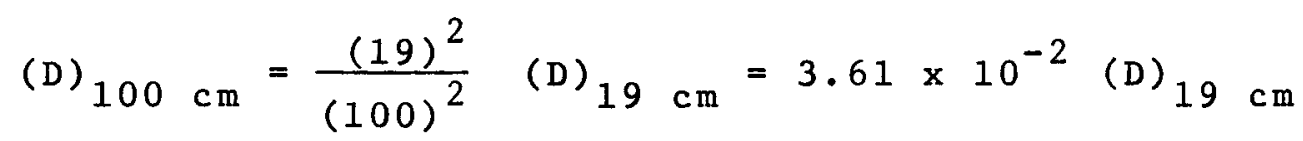

The total dose rate can then be obtained by multiplying the uncollided dose rates by a build-up factor. However, experimental results show that the ratio, (D) $100 \mathrm{~cm} /(D) 19 \mathrm{~cm}$, is equal to $3.61 \mathrm{x}$ $10^{-2}$ only for unshielded case. For shielded dose rates, this ratio is not a constant value but varies depending on shielding materials and thicknesses. To extend the results from $19 \mathrm{~cm}$ to $100 \mathrm{~cm}$ properly, experiments would have to be performed to obtain proper experimental ratios. These experimental ratios would be used to multiply total dose rates at $19 \mathrm{~cm}$ to obtain total dose rates at $100 \mathrm{~cm}$. The calculation procedures are presented in paragraph C.6.

To verify the computer results, half-value thickness studies have been made. Typical examples are shown in Table $\mathrm{C}-5$, and the uncollided dose rates are plotted in Figure C-6. Comparison between theoretical $(0.693 / \mu)$ and calculated half-value-thickness (HVT) indicates good agreement. 
TABLE $\mathrm{C}-4$

TYPICAL UNCOLLIDED DOSE RATES FROM COMPUTER CALCULATIONS

SHIELDING MATERIAL: 3

SOURCE THICKNESS $=.2540$

SHIELD THICKNESS $=.6350$

SHIELD THICKNESS $=1.2700$

$\begin{array}{ll}.16015 E & 0 \\ .21628 E-14 \\ .00000 E & 0 \\ .18178 E-14 \\ .60840 E-13 \\ .14588 E-1 \\ .19413 E & 2 \\ .21742 E & 3 \\ .83098 E & 3 \\ .12390 E & 4 \\ .14027 E & 4 \\ .12899 E & 4 \\ .10377 E & 4 \\ .75014 E & 3 \\ .48885 E & 3 \\ .28779 E & 3 \\ .15048 E & 3 \\ .67366 E & 2 \\ .23971 E & 2 \\ .59372 E & 1 \\ .65529 E & 0 \\ .24838 E- & 2\end{array}$

$.28120 \mathrm{E}-4$

$.12880 E-30$

$.00000 E-30$

$.16903 E-29$

$.25582 \mathrm{E}-7$

$.30518 E-1$

$.37645 E \quad 1$

$.63917 E 2$

$.18232 E 3$

$.31335 E 3$

$.37866 E 3$

$.36511 E 3$

$.30046 E 3$

$.21497 E 3$

.1360623

$.75622 E 2$

$.35483 E 2$

.13125E 2

.33600 E 1

$.38160 E$ D

$.14827 \mathrm{E}-2$

TOTAL DOSE RATE $=.78116 E 4$

TOTAL DOSE RATE = .20866E 4 
TABLE $\quad \mathrm{C}-5$

HALF-VALUE-THICKNESS STUDIES
Uncollided Dose Rates (mrad/hr)

Selected Group

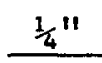

$\frac{1}{2} "$

$1 "$

AI, 5W, $0.2 \mathrm{Mev}$

$1 \times 10^{4}$

$8.17 \times 10^{3}$

$5.4 \times 10^{3}$

$\mathrm{Pb}, 20 \mathrm{~W}, 0.6 \mathrm{Mev}$

$1.5 \times 10^{3}$

$6.6 \times 10^{2} 1.28 \times 10^{2}$

$\mathrm{W}, 10 \mathrm{~W}, 0.4 \mathrm{Mev}$

$8.8 \times 10^{1}$

1.23
Half-Value-Thickness

\begin{tabular}{lll}
\multicolumn{1}{c}{$\mu$} & $\underline{0.693 / \mu}$ & $\underline{\mathrm{HVT}}$ (Fig. C-6) \\
0.325 & 2.13 & 2.15 \\
1.3 & 0.533 & 0.54 \\
3.36 & 0.206 & 0.2
\end{tabular}



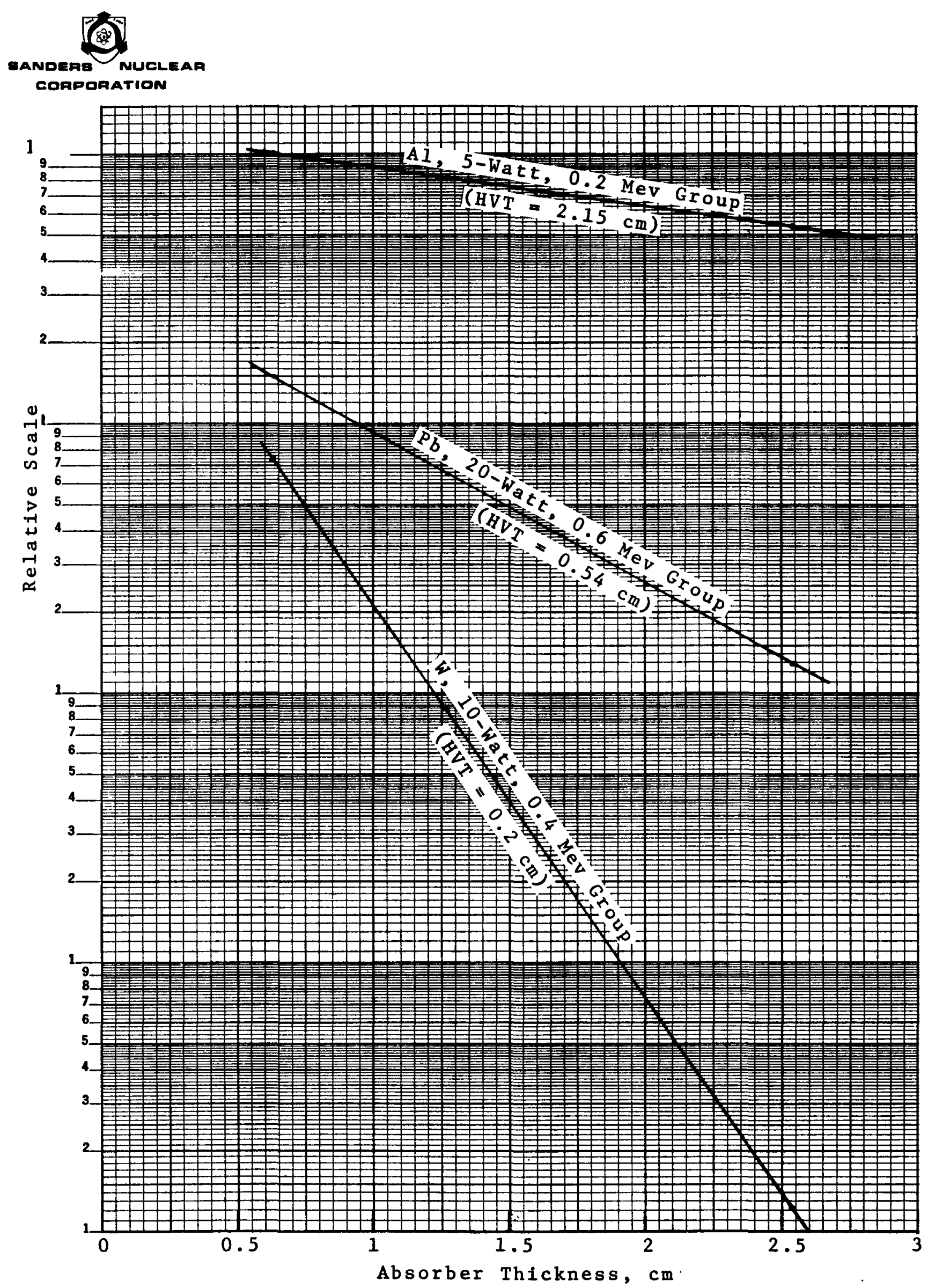

Figure C-6. Determination of Half-Value Thickness 


\section{5 BUILD-UP FACTOR CONSIDERATION}

The dose rates from uncollided photons have been obtained and are presented in the previous sections. The collided photons, in addition, may also reach the dose point after one or more scatterings in the shield medium. Therefore, the total dose rates at the dose point consists of two components:

$$
\text { (D) } \text { total }=\text { (D) uncollided }+ \text { (D) } \text { scattered }
$$

In practice, a buildup factor is defined by the following equation:

$$
B=\frac{(D) \text { tota } 1}{(D) \text { uncol1ided }}
$$

and the total dose rate can be obtained by multiplying the uncollided dose rate by $B$, the build-up factor

$$
\text { (D) } \operatorname{total}_{\text {to }}=B \times \text { (D) uncollided }
$$

The calculation of a build-up factor is a difficult problem because of the complexity of the Compton scattering. An exact solution is almost impossible to obtain. However, various approximation methods have been developed. By using the "moments method" introduced by spencer and Fano $(33,34)$, an extensive series of calculations of dose rate build-up factors of gamma rays in infinite homogeneous media has been carried out by Goldstein and Wilkins (14). $B_{\infty}$ is defined as a build-upfactor in an infinite medium. Table $\mathrm{C}-6$ shows a typical set of $B_{\infty}$ tabulated by Goldstein and Wilkins.

For medium geometry there are boundary conditions that exist. Different techniques, such as Monte Carlo, albedo matrix approach, etc., have to be used. These procedures are more complicated and more time consuming than is worthwhile for most problems and beyond the scope of this report. Therefore, $B_{\infty}$ is used to obtain the total dose rates throughout this report.

It is obvious that the use of $B_{\infty}$ overestimates the total dose rate for a finite geometry because the photons escaping from the 
TABLE $\quad \mathrm{C}-6$

DOSE BUILD-UP FACTOR FOR LEAD

(for point isotropic source in infinite medium)

\begin{tabular}{|l|c|c|c|c|c|c|c|}
\hline \multirow{2}{*}{$\begin{array}{c}E_{\mathrm{o}}, \\
\mathrm{Mev}\end{array}$} & \multicolumn{7}{|c|}{$\mu_{\mathrm{o}} \mathrm{r}$} \\
\cline { 2 - 7 } 0.5 & 1 & 2 & 4 & 7 & 10 & 15 & 20 \\
\hline 1.0 & 1.24 & 1.42 & 1.69 & 2.00 & 2.27 & 2.65 & $(2.73)$ \\
2.0 & 1.37 & 1.69 & 2.26 & 3.02 & 3.74 & 4.81 & 5.86 \\
3.0 & 1.39 & 1.76 & 2.51 & 3.66 & 4.84 & 6.87 & 9.00 \\
4.0 & 1.34 & 1.68 & 2.43 & 3.75 & 5.30 & 8.44 & 12.3 \\
5.1097 & 1.27 & 1.56 & 2.25 & 3.61 & 5.44 & 9.80 & 16.3 \\
6.0 & 1.21 & 1.46 & 2.08 & 3.44 & 5.55 & 11.7 & 23.6 \\
8.0 & 1.18 & 1.40 & 1.97 & 3.34 & 5.69 & 13.8 & 32.7 \\
10.0 & 1.14 & 1.30 & 1.74 & 2.89 & 5.07 & 14.1 & 44.6 \\
\hline
\end{tabular}


boundary can no longer contribute to scattered dose. The magnitude of error involved depends on photon energy, absorbing medium and its geometry.

For example, suppose one replaces the medium by air at some distance from the source. At the boundary, the dose for heavy material ( $Z>50$ ) should be close to that expected for an infinite medium. For light material, however, backscattering is important and therefore the build-up factor should be considerably less for finite medium than that for an infinite medium. This decrease in build-up factor is only observed in the low energy range. Experiments at $N B S^{(15)}$ indicate that for initial energy around $1 \mathrm{Mev}$ and low $\mathrm{Z}$ materials (e.g., A1, SS), the boundary effect reduces the buildup factors by aout $30 \%$. For lower energies the reduction is expected to be much greater. For high $\mathrm{Z}$ materials (e.g., $\mathrm{Pb}, \mathrm{W}, \mathrm{U})$, the reduction is small. For example, for $\mathrm{Pb}$ at 1 Mev, the reduction is about 2 to $3 \%(16)$. If $B \infty$ is used in the calculation, the total dose rates for Al and SS will be overestimated by about $50 \%$. Fortunately, these light materials are unlikely to be chosen as shielding materials. For heavy materials ( $\mathrm{Pb}, \mathrm{W}, \mathrm{U})$, the deviation is usually small.

$B$ for $A 1, S S, P b, W$ and $U$ are obtained from Goldstein and Wilkins $(14)$. A typical set of $B_{\infty}$ for $P b$ is given in Table $C-6$. The values of $B_{\infty}$ for intermediate energy $E_{0}$ are obtained from linear interpolation. Figure $\mathrm{C}-7$ shows a typical set of curves to obtain intermediate values of $B_{\infty}$ for $P b$ (similar curves for $W$ and $U$ absorbers). Figure $\mathrm{C}-8$ shows the same curve for $A 1$ (similar curve for SS). Note that in Figure C-7 the convergence of $B_{\infty}$ at low energies makes extrapolation of $B_{\infty}$ more accurate compared to that in Figure C-8. Therefore, the extrapolation of $B_{\infty}$ in low energy for $A 1$ and $S S$ introduces a much larger uncertainty. This may explain partially why there are large discrepancles between measured and calculated dose rates for $A I$ and $S S$. 


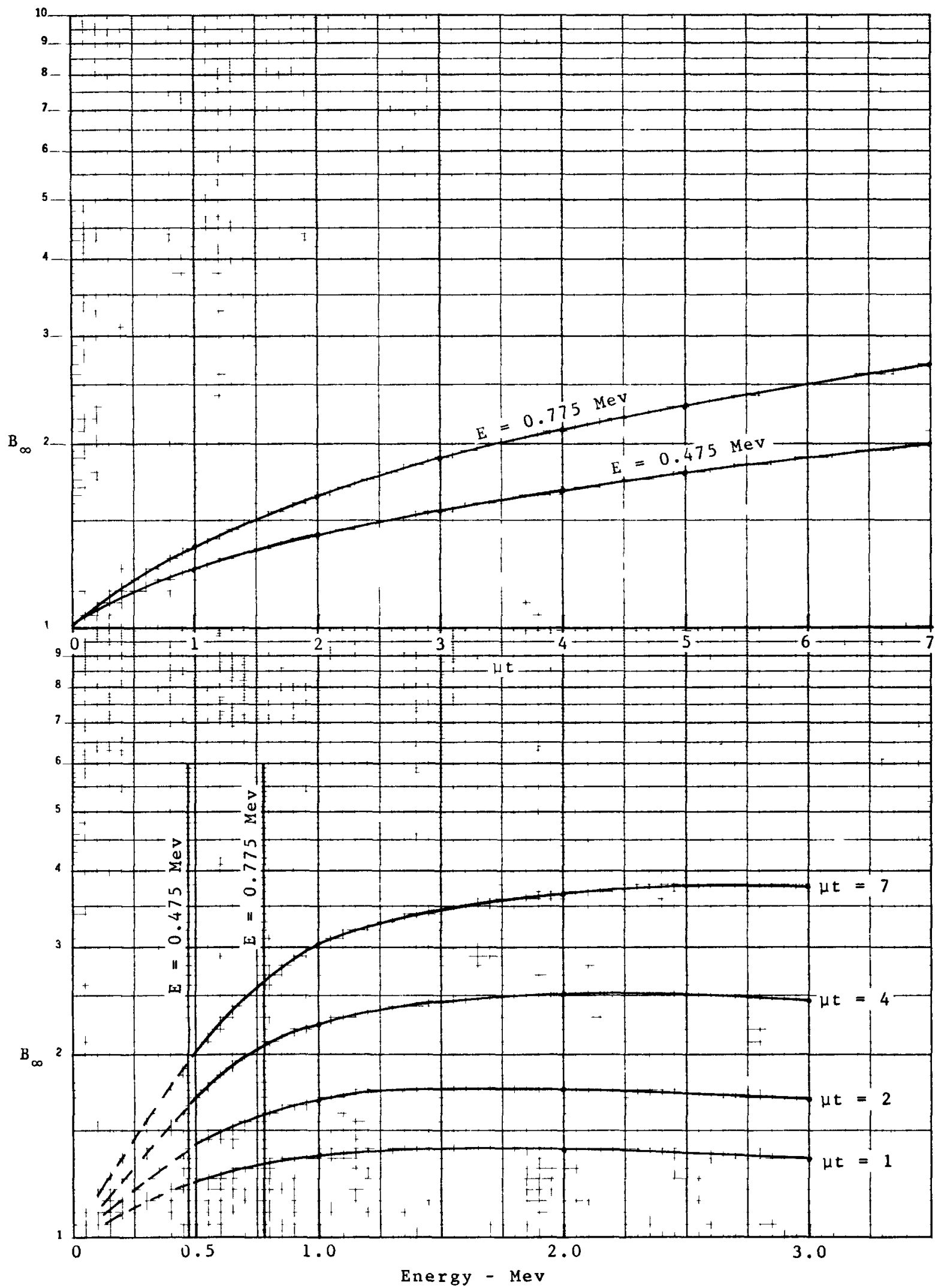

Figure C-7. Dose Build-up Factor - Pb (Point Isotropic Source) 


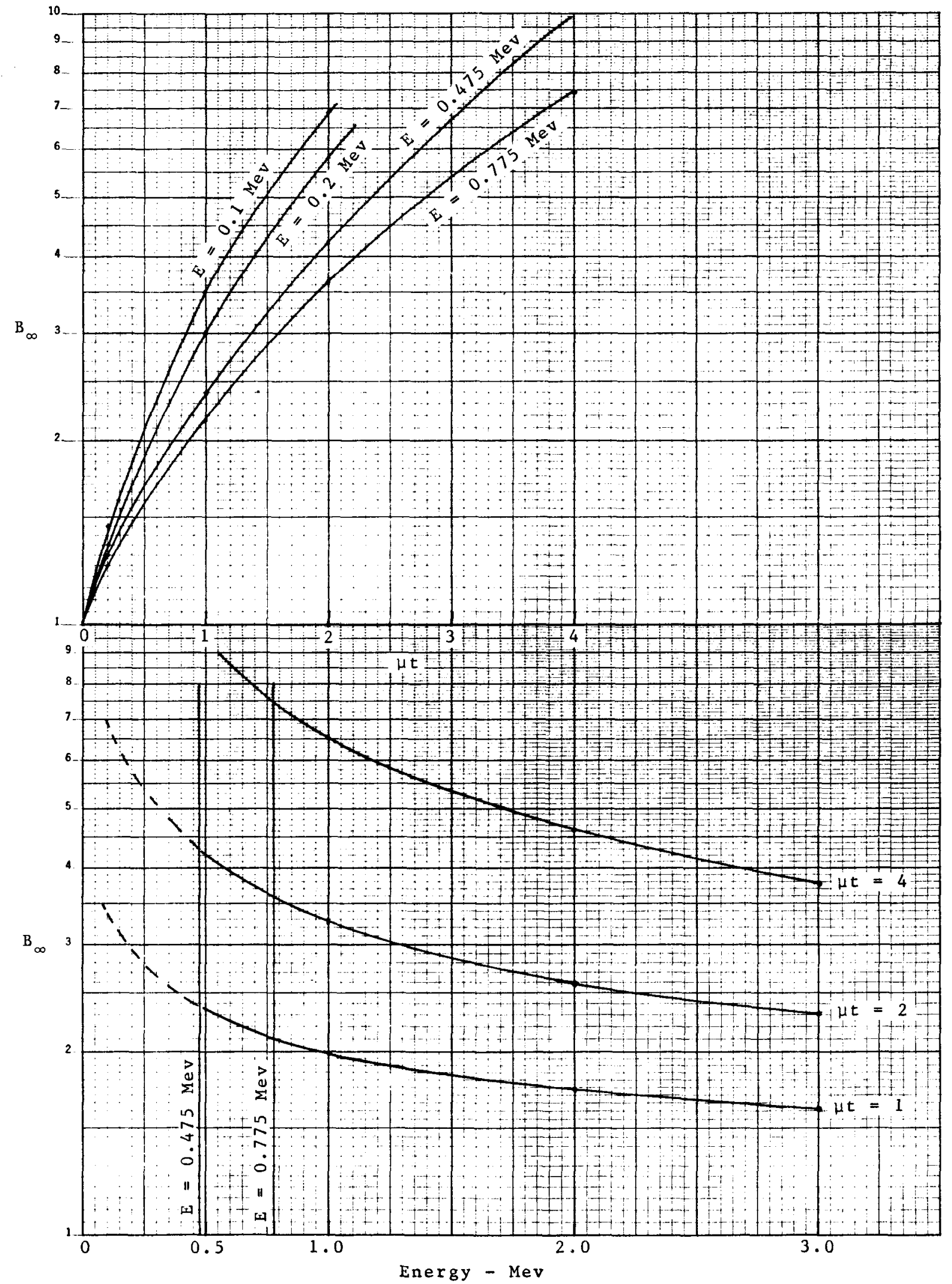

Figure C-8. Dose Build-up Factor - A1 (Point Isotropic Source) 
In calculating uncollided dose rates, 22 energy groups have been used. In obtaining $B_{\infty}$, however, only four energy groups are used: $0.1,0.2,0.475$ and $0.775 \mathrm{Mev}$. This simplifies the work considerably while still retaining accuracy. $\mathrm{Pb}$ has been used to test the validity of this method. The total dose rates obtained from 22 groups of $B_{\infty}$ and four groups of $B$ are in good agreement.

Therefore, $B_{\infty}$ obtained for energies of $0.1,0.2,0.475$ and $0.775 \mathrm{Mev}$ are tabulated in Table C-7. Note that the absence of $B_{\infty}$ in a particular energy group indicates that it is unnecessary to have $B_{\infty}$ because the uncollided dose rate is negligible in this particular group. The uncollided dose rates obtained from computer calculations are also sumed over the four groups (i.e., 0.009 to $0.1,0.15$ to $0.3,0.35$ to 0.6 , and 0.65 to $0.95 \mathrm{Mev})$. The product of $B_{x}$ and the uncollided dose rate is obtained for each group and the sum of the product of al1 four groups gives the total dose rates.

C. 6 TOTAL DOSE RATES

The total dose rates at $19 \mathrm{~cm}$ separation distance are obtained by multiplying $B_{\infty}$ to the uncollided dose rates. Table C-8 shows a typical set of calculations for evaluating total dose rate. Note that the actual source strength of three sources are: 5, 10 and 20.7 watts (see Appendix B.1), while for convenience 5, 10 and 20 watts have been used in calculations. Therefore, the results obtained from calculation for 20 watt source have to be multiplied by $\left(\frac{20.7}{20}\right)$ to give correct dose rates for 20.7 watt source. Table $\mathrm{C}-9$ presents the uncollided and total dose rates at $19 \mathrm{~cm}$.

To extend the uncollided dose rates from $19 \mathrm{~cm}$ to $100 \mathrm{~cm}$, the inverse square $1 \mathrm{aw}, 1 / \mathrm{r}^{2}$ is used. The total dose rates at $100 \mathrm{~cm}$ are obtained by multiplying the dose rates obtained for $19 \mathrm{~cm}$ by $3.6 \times 10^{-2}$. Table $\mathrm{c}-10$ gives the uncollided and total dose rates at $100 \mathrm{~cm}$. 


$$
\begin{gathered}
\text { TABLE } C-7 \\
\text { DOSE BUILD-UP FACTORS } \\
\text { (for point isotropic source in infinite medium) }
\end{gathered}
$$

\begin{tabular}{|c|c|c|c|c|c|}
\hline \multirow[b]{2}{*}{ Material } & \multirow{2}{*}{$\begin{array}{c}\text { Thickness } \\
\text { (inch) } \\
\end{array}$} & \multicolumn{3}{|c|}{ Energy (Mev) } & \multirow[b]{2}{*}{0.775} \\
\hline & & 0.1 & 0.2 & 0.475 & \\
\hline \multirow[t]{3}{*}{$\mathrm{A} 1$} & $\frac{1}{4}$ & 1.7 & 1.4 & 1.21 & 1.14 \\
\hline & $\frac{1}{2}$ & 2.25 & 1.7 & 1.4 & 1.27 \\
\hline & 1 & 3.9 & 2.5 & 1.8 & 1.51 \\
\hline \multirow[t]{3}{*}{ S S } & $\frac{1}{4}$ & 2.85 & 1.7 & 1.44 & 1.32 \\
\hline & $\frac{1}{2}$ & 5.3 & 2.4 & 1.83 & 1.6 \\
\hline & 1 & - & 4.22 & 2.8 & 2.28 \\
\hline \multirow[t]{3}{*}{$\mathrm{Pb}$} & $\frac{1}{4}$ & - & 1.4 & 1.26 & 1.22 \\
\hline & $\frac{1}{2}$ & - & 1.6 & 1.43 & 1.4 \\
\hline & 1 & - & - & 1.7 & 1.73 \\
\hline \multirow[t]{3}{*}{$\mathrm{W}$} & $\frac{1}{4}$ & - & 1.5 & 1.4 & 1.38 \\
\hline & $\frac{1}{2}$ & - & 1.6 & 1.66 & 1.7 \\
\hline & 1 & - & - & 2.11 & 2.28 \\
\hline \multirow[t]{3}{*}{$\mathrm{U}$} & $\frac{1}{4}$ & - & 1.3 & 1.3 & 1.3 \\
\hline & $\frac{1}{2}$ & - & - & 1.48 & 1.53 \\
\hline & 1 & - & - & 1.7 & 1.92 \\
\hline
\end{tabular}


TABLE $\quad C-8$

CALCULATION OF TOTAL DOSE RATE AT $19 \mathrm{~cm}$ FOR 20.7-WATT SOURCE

WITH $\mathrm{Pb}$ SHIELDS OF $\frac{1}{4}, \frac{1}{2}$ and 1 INCH THICKNESSES

Total Dose Rate for 20.7-Watt Source (R/hr)

\begin{tabular}{|c|c|c|c|c|c|c|c|c|c|}
\hline \multirow{2}{*}{$\begin{array}{l}\text { Energy } \\
\text { Group }\end{array}$} & \multicolumn{3}{|c|}{$\frac{1}{4} "$} & \multicolumn{3}{|c|}{$\frac{1}{2} "$} & \multicolumn{3}{|c|}{$1^{\prime \prime}$} \\
\hline & (D) unc & $B$ & (D) tota 1 & (D) unc & B & $(D)_{\text {tot } a 1}$ & $(D)_{\text {unc }}$ & B & (D) tota 1 \\
\hline 0.1 & - & - & - & - & - & - & - & - & - \\
\hline 0.2 & 2.124 & 1.4 & 2.974 & .139 & 1.6 & .222 & - & - & - \\
\hline 0.475 & 16.91 & 1.26 & 21.31 & 4.914 & 1.43 & 7.027 & .544 & 1.7 & .925 \\
\hline 0.775 & 1.698 & 1.22 & 2.072 & .837 & 1.4 & 1.172 & .205 & 1.73 & .354 \\
\hline Tot & $\begin{array}{c}\text { Dose R } \\
20-\mathrm{Wa}\end{array}$ & For & 26.36 & & & 8.421 & & & 1.279 \\
\hline & $\begin{array}{c}\text { Dose R } \\
20.7-\mathrm{Wa}\end{array}$ & For & 27.28 & & & 8.716 & & & 1.324 \\
\hline
\end{tabular}


TABLE $\mathrm{C}-9$

CALCULATED DOSE RATES AT $19 \mathrm{CM}$ (RAD/HR)

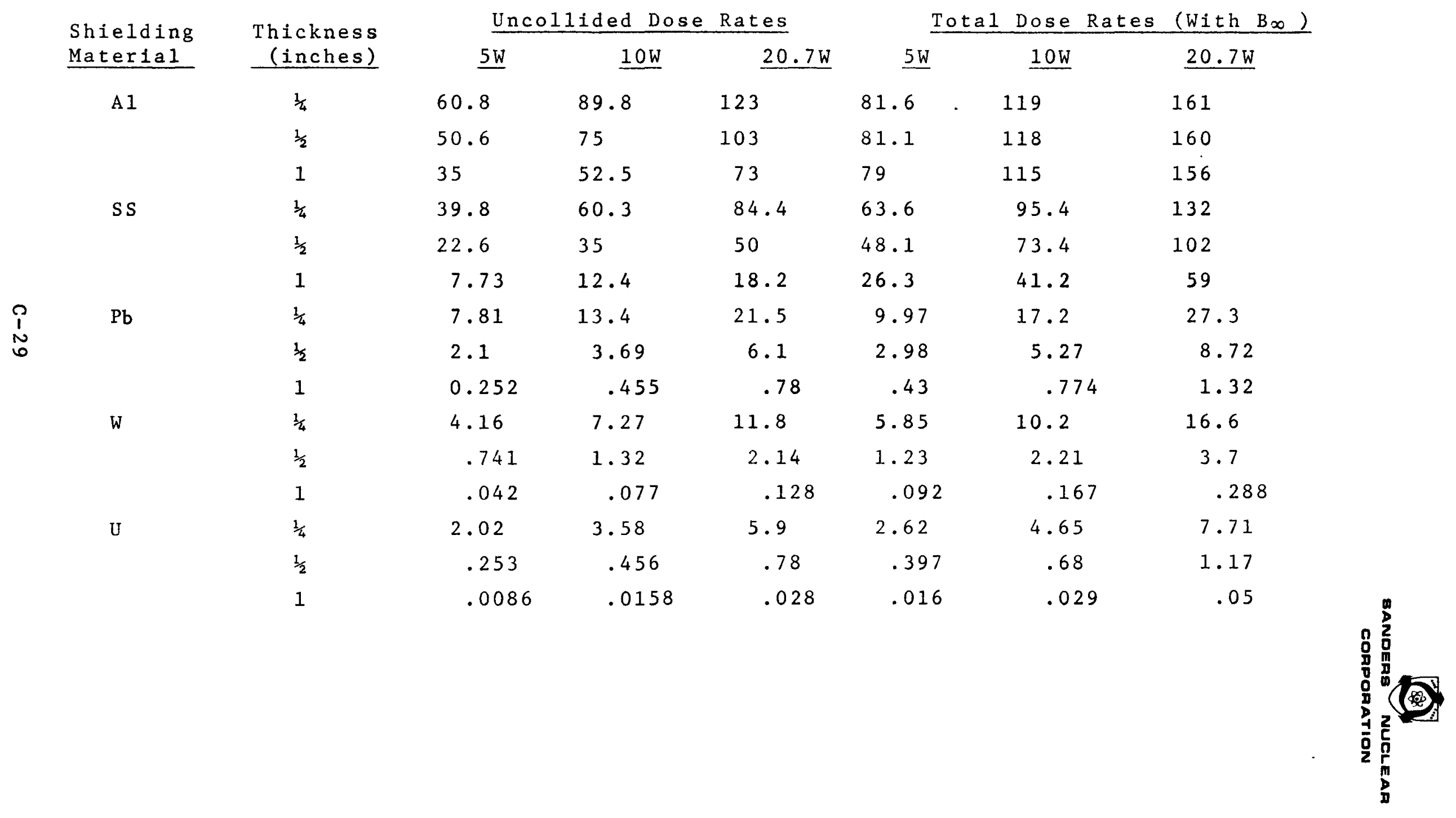


TABLE C-10

CALCULATED DOSE RATES AT $100 \mathrm{CM}$ (RAD/HR)

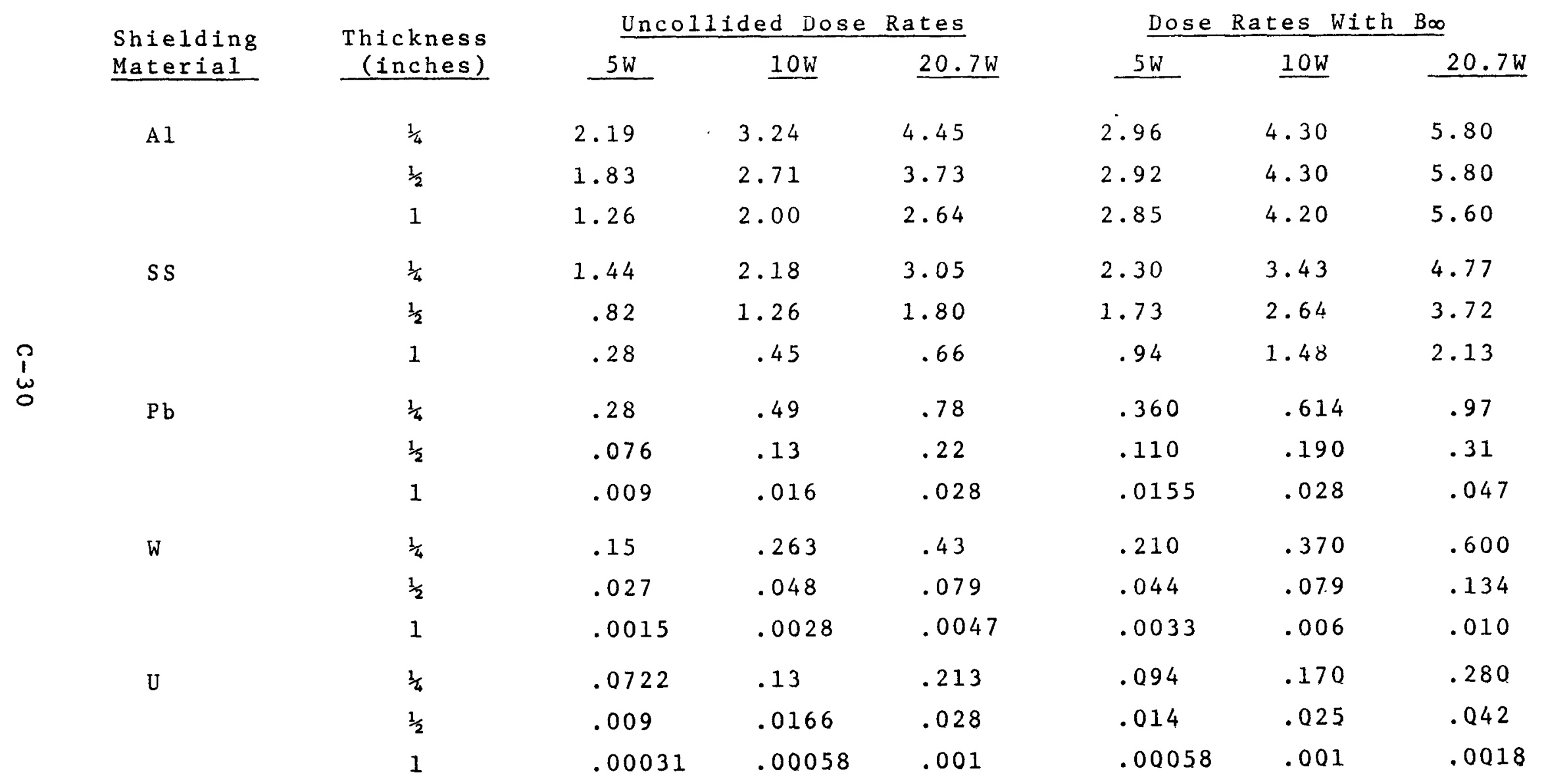


The estimated overall uncertainties for $\mathrm{Pb}, W$ and $U$ are expected to be approximately $20 \%$. However, for A1, and SS, the overall uncertainties are estimated to be much greater, perhaps $50 \%$ or more.

Radiation scattered from the experimental fixture and from the hot cell walls are considered below.

\section{7 RADIATION SCATTERING FROM THE EXPERIMENTAL ENVIRONMENT}

Investigations were conducted into the possible modes and effects of radiation scatter in the experimental geometry. Consideration of experimental setup (see Figure B-6) reveals that in operation, the thulium-170 sources were well shielded in their experimental cask, and that the only exit path for the emitted radiation was the beam tunnel which was designed to the same diameter as the source wafers themselves. Thus, the solid beam of radiation emerging from this tunnel was well defined, and the absorber specimens were designed to completely intercept this beam in their experimental positions. Since the scatter of these radiations in air is insignificant, the possible sources of such scattering become: (1) single and multiple scatter by the shielding material to dose point; (2) double scatter by the absorber and a part of the experimental fixture; (3) single backscatter off the rear wall of the hot cell to the dose point; and (4) double scatter by the absorber and a hot cell structural member.

\section{C.7.1 SINGLE AND MULTIPLE SCATTER BY SHIELDING MATERIAL}

Single and multiple scatter by the shielding material to the dose point constitutes the build-up factor and is discussed in paragraph (.5)

\section{C.7.2 DOUBLE SCATTER BY THE ABSORBER}

Examination of Figure $B-6$ and the diagrammatic sketch shown in Figure C-9 reveals that only the radiations scattered by the absorbers approximately straight ahead and in the downward direction 
had any probability of encountering a part of the experimental fixture (notably the aluminum base channel) and thus had any real probability of second scatter to the dose point. Therefore, to prevent this from occurring, a lead scatter shield was designed and installed to intercept and attenuate al1 such scattered radiations (see Figure B-6).

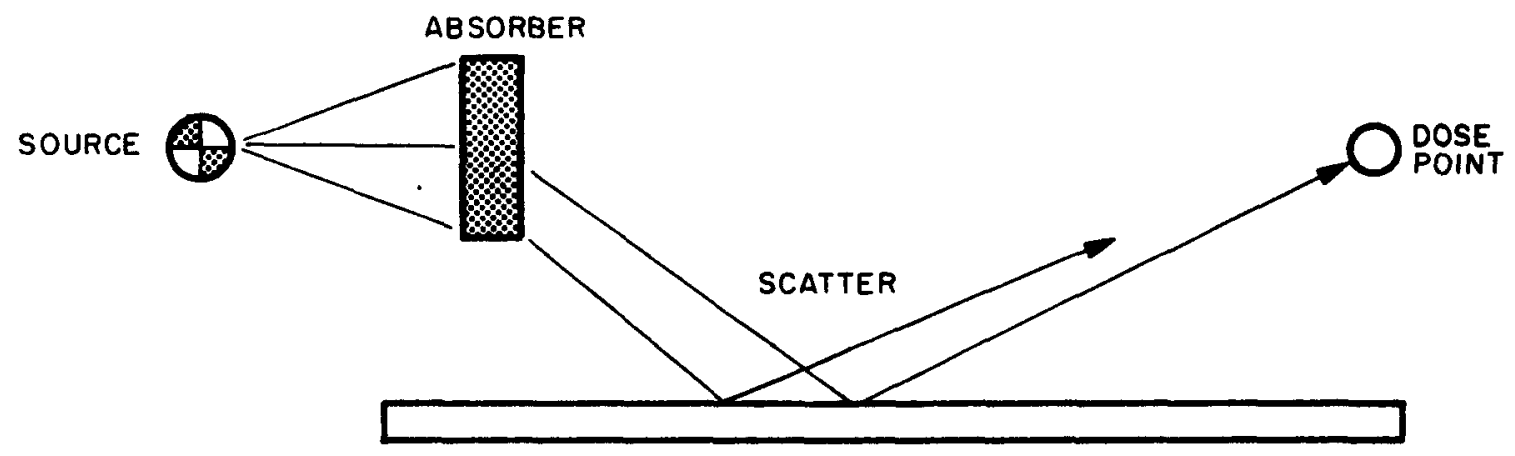

Figure C-9. Radiation Scattering from Experimental Set-up

\section{C.7.3 SINGLE BACKSCATTER}

The calculation to determine the intensity of radiation backscattered off the rear wall of the hot cell to the dose point was performed with the aid of Figure c-10. The intensity of the radiation scattered within the unit volume of scattering medium through an angle ( $\theta)$ is ${ }^{(12)}$ :

$$
\mathrm{d} I=I_{0} \times\left(7.94 \times 10^{-26}\right) \eta \mathrm{F}_{1}\left(\mathrm{E}_{0}, \theta\right)\left(\frac{\mathrm{e}^{-\mu_{\mathrm{r}_{2}}}}{4 \pi \mathrm{r}_{1}}\right)\left(\frac{\mathrm{e}^{-\mu_{\mathrm{r}}}}{\mathrm{r}_{4}^{2}}\right) \mathrm{dV}
$$

by integrating over volume, then

$$
\frac{I}{I_{0}}=\frac{7.94 \times 10^{-26} \eta}{4 \pi} \int_{V o 1} F_{1}\left(E_{0}, \theta\right) \frac{e^{-\mu\left(r_{2}+r_{3}\right)}}{r_{1}{ }^{2} r_{4}^{2}} d V
$$


where:

$I=$ intensity of the scattered beam, Mev/cm ${ }^{2}-\mathrm{sec}$

$I_{0}=$ intensity of the initial beam, Mev/ $\mathrm{cm}^{2}-\mathrm{sec}$

$\eta=$ number of electrons per $\mathrm{cm}^{3}$ of scattering material

$r=$ path length of scattered radiation, $\mathrm{cm}$

$\mathrm{dV}=$ volume element of scattering volume, $\mathrm{cm}^{3}$

$\mu=$ linear attenuation coefficient of scattering material, $\mathrm{cm}^{-1}$

$F_{1}\left(E_{0}, \theta\right)=$ scatter probability for particle energy $E$ (Mev) and scattering angle $\theta$. It defines as:

$F_{1}\left(E_{0}, \theta\right)=\frac{p^{3}}{2}\left(\frac{1}{p}+p-\sin ^{2} \theta\right)$

and

$p=\frac{E}{E_{0}}=\frac{1}{1+\frac{E_{0}}{m_{0} c^{2}}(1-\cos \theta)}$

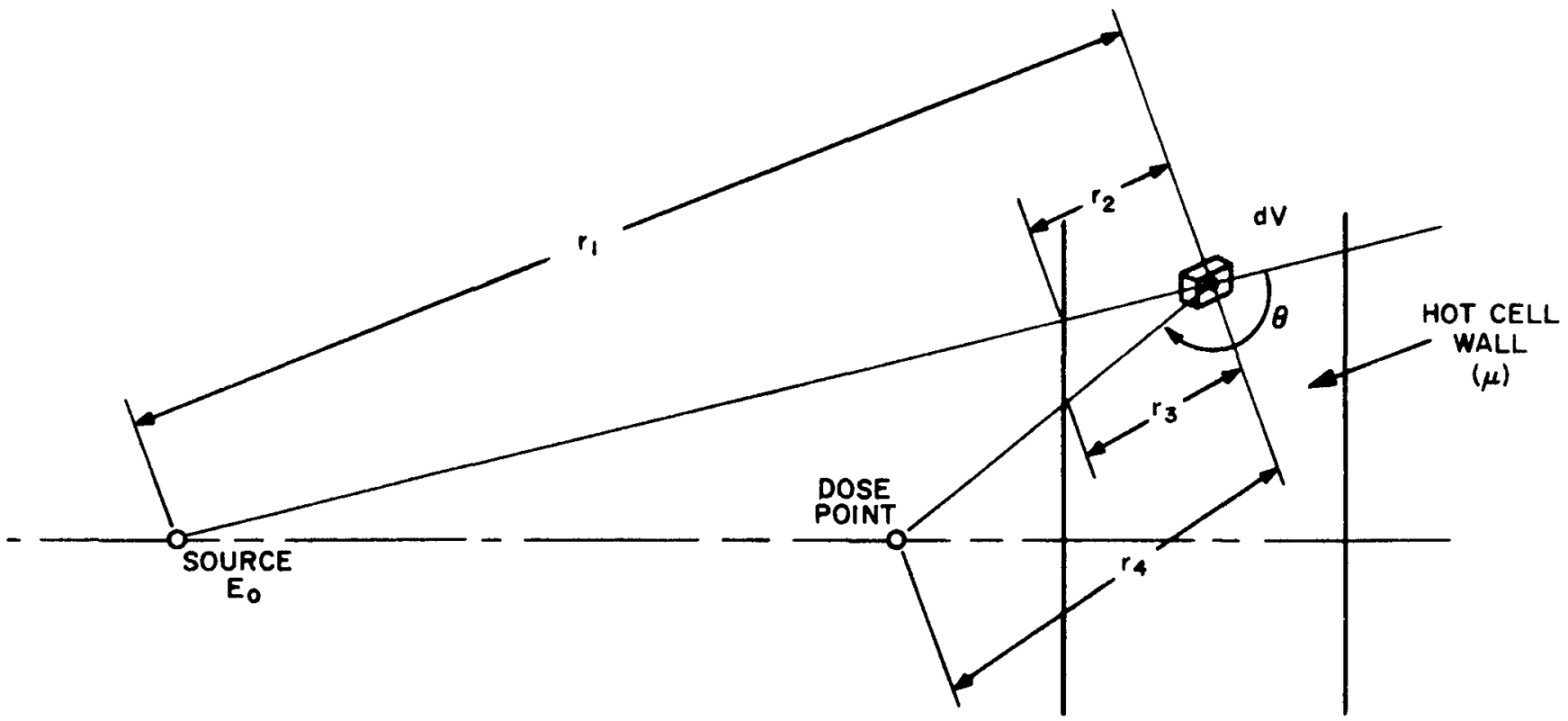

Figure C-10. Radiation Scattering from Hot Ce11 Wall 
From the geometry of the experiment, as shown in Figure C-11, the approximate scattering intensity was calculated as follows :

$$
\text { Assume } \begin{aligned}
E_{0} & =0.5 \mathrm{Mev} \\
\eta & =2.2 \times 10^{24} \mathrm{e}-1 \mathrm{~cm}^{3} \text { (for steel) } \\
r_{1} & =3.4 \times 10^{2} \mathrm{~cm} \\
r_{4} & =2.5 \times 10^{2} \mathrm{~cm}
\end{aligned}
$$

From Figure $C-11$, Sin $\theta=\sin (180-\phi)=\sin \phi=\sin 4.50^{\circ}$

and

$$
\begin{aligned}
\cos \theta & =\cos \left(180^{\circ}-\emptyset\right) \\
& =-\cos \emptyset \\
& =-\cos 4.5^{\circ}
\end{aligned}
$$

Then, $p=\frac{1}{1+(1+\cos 4.5)}=\frac{1}{1+2}=\frac{1}{3}=0.33$

$$
F_{1}=\frac{1}{2}\left(p^{2}+p^{4}-p^{3} \sin ^{2} \theta\right)=6 \times 10^{-2}
$$

Assuming all scattering to take place at this surface, then

$$
e^{-\mu\left(r_{2}+r_{3}\right)}=1
$$

For the maximum scattering case, a circular disc volume with radius $=75.1 \mathrm{~cm}$ and $1 \mathrm{~cm}$ thick was assumed.

$$
\text { Then } \Delta V=1.7 \times 10^{4} \mathrm{~cm}^{3}
$$

Substitute all the quantities into equation (c-12).

$$
\frac{I}{I_{0}}=\frac{7.94 \times 10^{-26}}{4 \pi} \eta F_{1}\left(E_{0}, \theta\right) \frac{1}{\left(r_{1}^{2}\right)\left(r_{4}^{2}\right)} \Delta v=10^{-9}
$$

Therefore, the scattering contribution from the rear wall of the hot cell is so small that it can be neglected. 


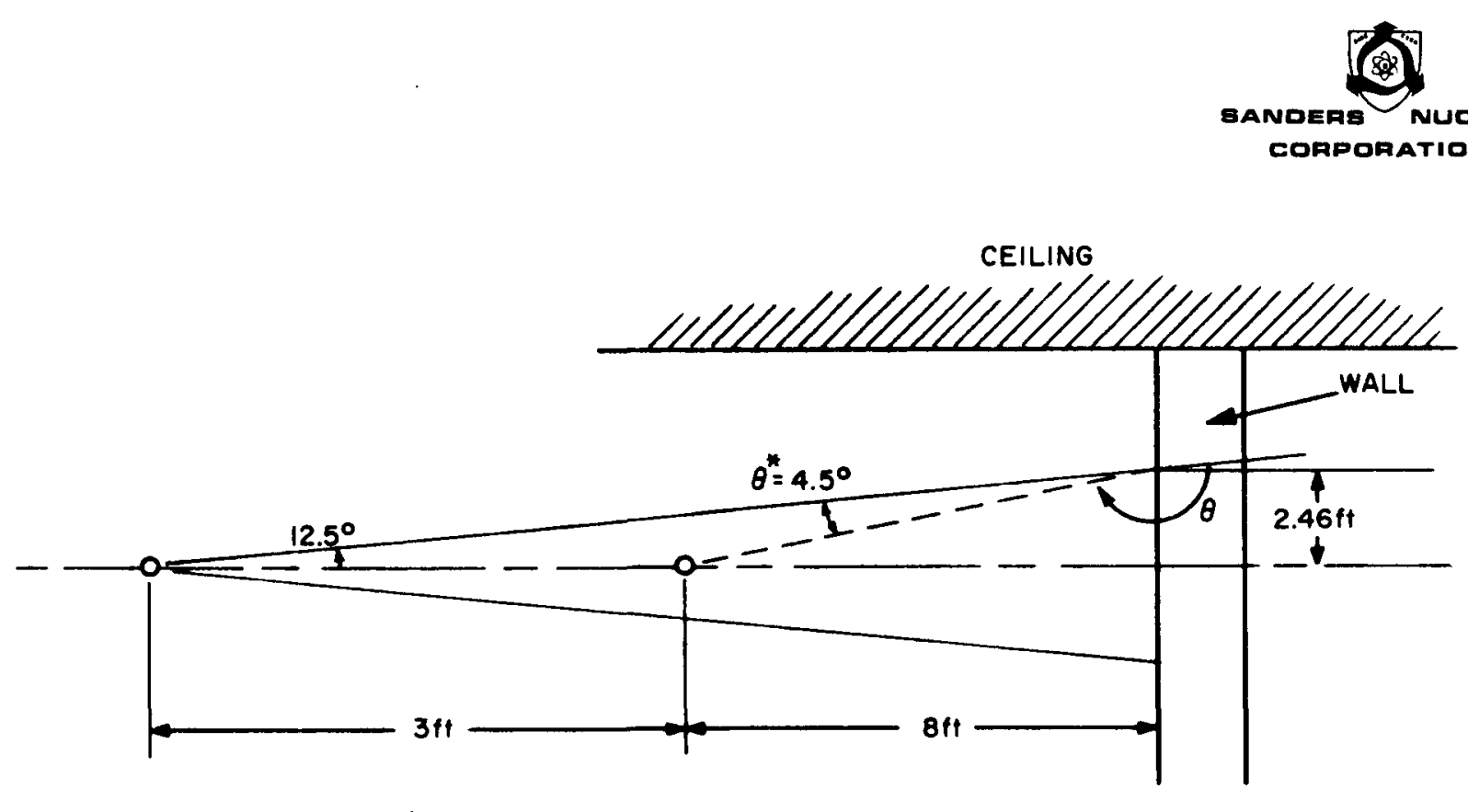

Figure C-11. Spatial Dimensions Between Source and Hot Cell Wall

\section{C.7.4 DOUBLE SCATTER}

The size of the solid angle of radiation beyond the absorber was such that no radiation could be directly incident upon any of the side walls, the ceiling or the hot cell floor. Thus, only double scatter by the absorber and one of these structural materials could possibly result in scattered radiation incident at the dose point as 11lustrated in Figure C-12.

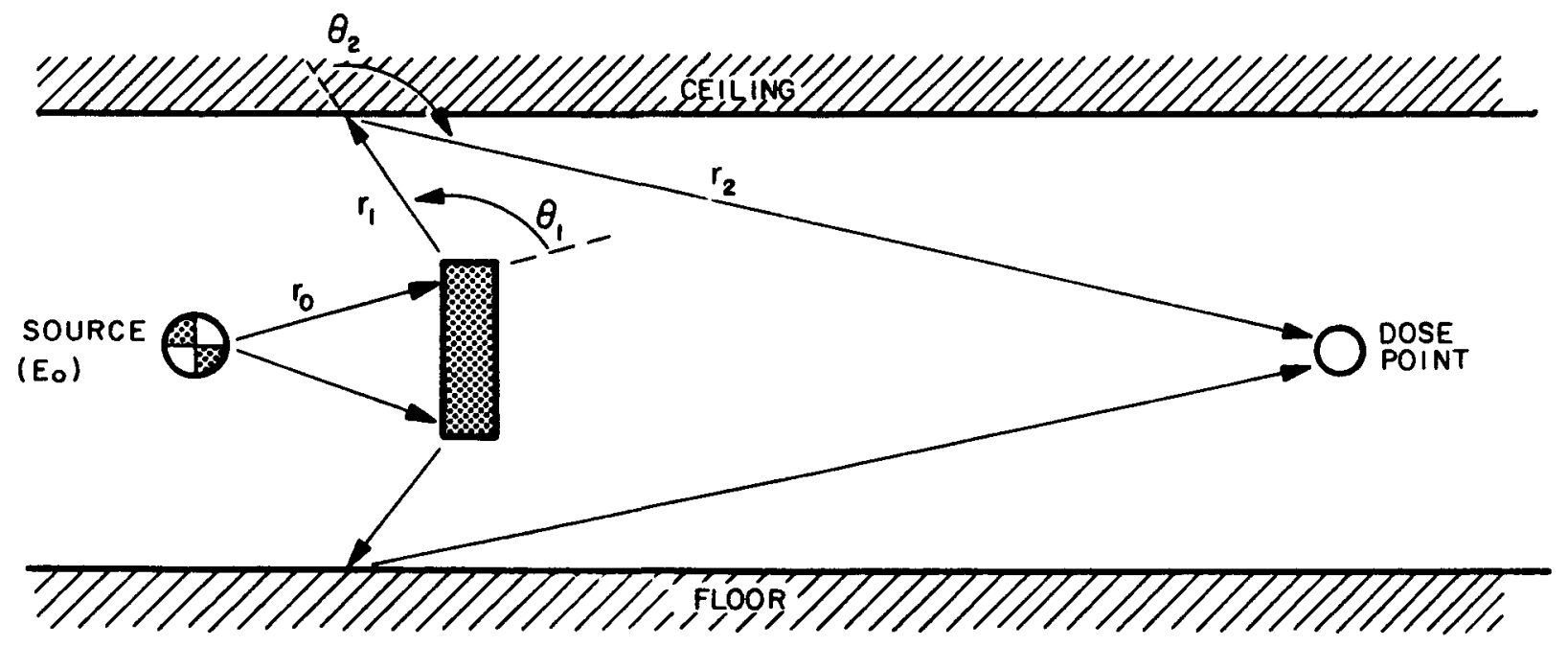

Figure C-12. Double scattering from Source and Hot Cell 
To calculate the intensity of radiation scattered out of the original flux to the dose point ( $\left.I / I_{0}\right)$, reference is made to the scattering equation (12).

$$
\begin{gathered}
\frac{I}{I_{0}}=7.94 \times 10^{-26} \eta_{1} F_{1}\left(E_{0}, \theta_{1}\right) \frac{1}{4 \pi r_{0}^{2} r_{1}{ }^{2}} \Delta v_{1} \\
\quad 7.94 \times 10^{-26} \eta_{2} F_{2}\left(E_{1}, \theta_{2}\right) \frac{1}{r_{2}^{2}} \Delta v_{2}
\end{gathered}
$$

where the quantities are previously defined.

It is assumed that all radiation scatter occurs at the surfaces of the scattered materials. The following are the pertinent dimensions of the assumed scattering system:

$$
\begin{aligned}
\eta_{1} & =\eta_{2}=2.2 \times 10^{24} \text { electrons } / \mathrm{cm}^{3} \text { (for stee1) } \\
r_{0} & =15 \mathrm{~cm} \\
r_{1} & =90 \mathrm{~cm} \\
r_{2} & =120 \mathrm{~cm} \\
\Delta v_{1} & =24.6 \mathrm{~cm}^{3} \\
\Delta v_{2} & =1.7 \mathrm{x} 10^{4} \mathrm{~cm}^{3} \\
E_{0} & =0.5 \mathrm{Mev}
\end{aligned}
$$

Upon insertion of these into equations $(C-13),(C-14)$ and $(C-15)$, the intensity of radiation doubly scattered to the dose point becomes:

$$
\frac{I}{I_{0}}=1.65 \times 10^{-10}
$$

which is negligible except for very high fluxes incident over long irradiation intervals. It should be noted that the highest strength sources with the thinnest absorbers also had the briefest irradiation intervals. Therefore, this scattering mechanism was not thought to constitute a significant source of error. In light of these results, it was concluded that with the exception of buildup factor, no significant contributions to the radiation dose rates would arise due to scattering. 